\title{
Ferramentas computacionais para \\ a síntese de imagens de difusão por ressonância magnética
}

\author{
Renato Callado Borges
}

\author{
DISSERTAÇÃO
}

$\mathrm{AO}$

Instituto De MatemáticA e EstatísticA

DA

Universidade DE SÃo PAUlo

PARA

OBTENÇÃO DO TÍTULO

DE

Mestre em CiÊnCIAS

Programa: Ciências da Computação

Orientador: Prof. Dr. Marcel Parolin Jackowski

São Paulo, Novembro de 2013 


\section{Ferramentas computacionais para a síntese de imagens de difusão por ressonância magnética}

Esta versão da dissertação contém as correções e alterações sugeridas pela Comissão Julgadora durante a defesa da versão original do trabalho, realizada em 04/11/2012. Uma cópia da versão original está disponível no

Instituto de Matemática e Estatística da Universidade de São Paulo.

Comissão Julgadora:

- Prof. Dr. Marcel Parolin Jackowski (orientadora) - IME-USP

- Prof. Dr. Roberto Hirata Junior - IME-USP

- Prof. Dr. Marco Antonio Gutierrez - FM-USP 


\section{Agradecimentos}

Quero agradecer ao professor Marcel, por ter misturado cobrança e incentivo na medida certa, à professora Maria Concepcion Garcia Otaduy da FMUSP, ao professor Choukri Mekkaoui e à profa. Shu Ning da Harvard Medical School por terem viabilizado o uso de equipamentos de ressonância magnética, ao Fabrício Pereira por me permitir usar algumas de suas imagens de ressonância, aos funcionários do IME, por me auxiliarem com todas as questões burocráticas e por manterem a infraestrutura que utilizei, aos colegas do grupo ANIME, por sempre terem tempo para me ajudar com as dúvidas, aos professores Marcelo Munhoz e Alexandre Suaide, meus empregadores, por me deixarem brincar com o cluster Sampa fora do horário de trabalho, e aos meus amigos e familiares, por terem suportado minhas "idéias malucas" e minhas ausências frequentes.

Agradeço em especial à minha esposa Luciana, por inventar e confeccionar alguns fantomas, e por diversas vezes assumir tarefas extras para me ajudar. Mas principalmente pela dedicação e paciência comigo, e por tantas coisas ter me ensinado ao longo do caminho. 


\section{Resumo}

BORGES, Renato Callado. Ferramentas computacionais para a síntese de imagens de difusão por ressonância magnética Dissertação (Mestrado) - Instituto de Matemática e Estatística, Universidade de São Paulo, São Paulo, 2013.

Trabalhos anteriores sobre a síntese de imagens de difusão por ressonância magnética se limitaram a estudos sobre estruturas microscópicas, menores que as dimensões típicas de um voxel (e.g., [BF08] [BF13] [LFS $\left.{ }^{+} 10\right]$ e [BA94]). Isto decorre em parte devido às metodologias utilizadas, que têm como ponto em comum serem simulações de tipo Monte Carlo, nas quais os elementos mínimos da simulação são as partículas de água. Portanto o custo computacional destas simulações é proporcional ao número de partículas a simular, e isto limita os volumes que podem ser simulados a tamanhos microscópicos. Propomos uma metodologia alternativa, que utiliza a imagem $T_{2}$ de uma amostra para sintetizar imagens de difusão por ressonância magnética. Os elementos mínimos desta nova metodologia são os pontos da imagem $T_{2}$, e portanto seu custo computacional é proporcional à resolução da imagem $T_{2}$ utilizada, o que permite a síntese a partir de amostras de qualquer tamanho físico. Estas sínteses são realizadas por meio da integração numérica da equação do artigo seminal de Stejskal e Tanner [ST65] que relaciona a atenuação do sinal de ressonância magnética devida à difusão com os parâmetros da sequência de pulsos PGSE. Usamos os parâmetros típicos dessa sequência $\left(b, \gamma, \tau^{\prime}, g_{0}, g, \delta\right.$ e $\left.\Delta\right)$, que podem ser configurados explicitamente em máquinas de ressonância magnética, para calcular valores do coeficiente de difusão aparente $D$ em direções arbitrárias. Desenvolvemos software, disponibilizado [Bor] por licença GPL [Fou07], para realizar estas simulações, e para especificar uma "máscara de direções", útil para modelar a difusão de uma amostra. Estas ferramentas permitem o estudo sistemático das variações dos parâmetros na síntese de imagens de difusão por ressonância magnética. Apresentamos um estudo de um fantoma de capilares imersos em água, exemplificando como utilizar as ferramentas para investigar a influência destes parâmetros na difusão da água da amostra.

Palavras-chave: Difusão, DWI, DW-MRI, Fantoma, MRI, Ressonância Magnética, RM, Simulação, Síntese. 


\section{Abstract}

BORGES, Renato Callado. Computational tools for the synthesis of diffusion-weighted magnetic resonance imaging 2013. Thesis (Masters) - Instituto de Matemática e Estatística, Universidade de São Paulo, São Paulo, 2013.

Previous work on the synthesis of diffusion-weighted magnetic resonance imaging are limited to microscopic structures, smaller than the typical dimensions of a single voxel (e.g., [BF08] [BF13] $\left[\mathrm{LFS}^{+} 10\right]$ and [BA94]). This is consequence, in part, of the methodologies used, that have in common the adoption of Monte Carlo simulation strategies, in which the minimal elements of simulation are the water particles. Therefore the computational cost of these simulations is proportional to the number of particles to simulate, and this limits the volume to be simulated to microscopic sizes. We propose a novel methodology, that uses the $T_{2}$ image from a sample to synthesize diffusion-weighted magnetic resonance images. The mininal elements of this novel methodology are the points of the $T_{2}$ image, and therefore its computational cost is proportional to the resolution of the $T_{2}$ image to be used, which allows the synthesis from samples of any physical size. These syntheses are made through numerical integration of the equation from the seminal article by Stejskal and Tanner [ST65] that relates the attenuation of the magnetic resonance signal due to diffusion to the parameters of the PGSE pulse sequence. We use the typical parameters of this sequence $\left(b, \gamma, \tau^{\prime}, g_{0}, g, \delta\right.$ and $\left.\Delta\right)$, that can be explicitly configured in magnetic resonance machines, to calculate apparent diffusion coefficients $D$ in arbitrary directions. We developed software, available [Bor] through GPL license [Fou07], to run these simulations, and to specify a "mask of directions" useful to model diffusion. These tools allow the systematic study of parameter variation in the synthesis of diffusion-weighted magnetic resonance images. We present a case study of a phantom made of capillary tubes immersed in water, to exemplify the use of these tools and how to investigate the influence of parameter variation on diffusion in the sample.

Keywords: Diffusion, DWI, DW-MRI, Phantom, MRI, Magnetic Resonance, MR, Simulation, Synthesis. 


\section{Sumário}

$\begin{array}{ll}\text { Lista de Abreviaturas } & \text { ix }\end{array}$

Lista de Símbolos $\quad$ xi

Lista de Figuras $\quad$ xiii

1 Introdução $\quad \mathbf{1}$

1.1 Motivação . . . . . . . . . . . . . . . . . . . . . . . . . . 3

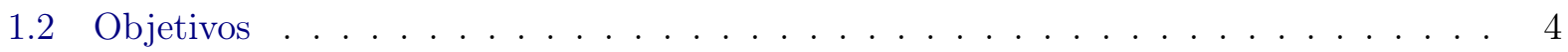

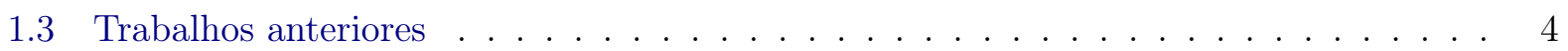

$\begin{array}{lll}2 & \text { Teoria } & 7\end{array}$

2.1 Difusão de massa . . . . . . . . . . . . . . . . . . . . . . . . . . 7

2.2 Ressonância Magnética . . . . . . . . . . . . . . . . . . . . . . . . . . 8

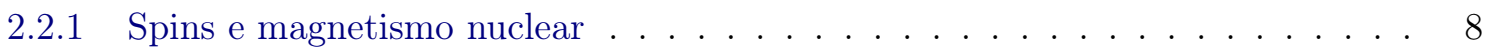

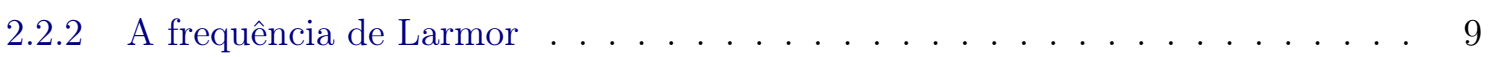

2.2 .3 Ressonância Magnética . . . . . . . . . . . . . . . . . . . . . . . . . . . . . 9

$2.2 .4 \quad$ A taxa de relaxamento $T_{2} \ldots \ldots \ldots \ldots \ldots \ldots \ldots$

2.2.5 Resolução espacial de imagens de RM . . . . . . . . . . . . . . . . . . . 12

$2.2 .6 \quad$ A sequência de pulso Spin Echo . . . . . . . . . . . . . . . . . . . . . 12

2.3 Imagens de Difusão por RM . . . . . . . . . . . . . . . . . . . . . . 13

2.3.1 A sequência de pulsos de Stejskal e Tanner . . . . . . . . . . . . . . . . . 13

2.3.2 A equação de Tanner e Stejskal . . . . . . . . . . . . . . . . . . . . . . . 14

2.3.3 Relação entre difusividade e sinal nas imagens de difusão por RM . . . . . . . 15

3 Metodologia $\quad 17$

3.1 Síntese de imagens de difusão . . . . . . . . . . . . . . . . . . . . 17

3.1 .1 Criação de máscaras . . . . . . . . . . . . . . . . . . 17

3.1.2 Relação entre máscaras e modelos de difusão . . . . . . . . . . . . . . . . . . 19

3.1 .3 Estrutura da especificação de máscaras . . . . . . . . . . . . . . . . . . 20

3.1.4 Geração da máscara a partir de sua especificação . . . . . . . . . . . . . . . . . 21

3.1 .5 Visualização das projeções da máscara . . . . . . . . . . . . . . . . . 21

3.1 .6 Simulação computacional . . . . . . . . . . . . . . . . . . 23

3.1 .7 Verificação do b-value . . . . . . . . . . . . . . . . . . 25 
4 Resultados

4.1 Fantoma de tubos capilares . . . . . . . . . . . . . . . . . 27

4.1 .1 Especificação da máscara relativa ao fantoma . . . . . . . . . . . . . . . . . . . . 29

4.1.2 Comparação entre a imagem adquirida e sintetizada . . . . . . . . . . . . 30

4.2 Consumo de recursos pela simulação . . . . . . . . . . . . . . . . . . . 31

5 Conclusões $\quad 35$

5.1 Considerações Finais . . . . . . . . . . . . . . . . . . . . . 35

5.2 Sugestões para Pesquisas Futuras . . . . . . . . . . . . . . . . . . 36

6 Apêndice A $\quad 39$

6.1 As equações de Bloch . . . . . . . . . . . . . . . . . . . . . . . . 39

6.2 As equações de Torrey-Bloch . . . . . . . . . . . . . . . . . . . 39

7 Apêndice B $\quad 4 \mathbf{1}$

7.1 Seleção dos parâmetros da sequência de pulso simulada . . . . . . . . . . . . . . . . . 41

8 Apêndice C $\quad 43$

8.1 Integração numérica . . . . . . . . . . . . . . . . . . 43

8.2 Os algoritmos da simulação . . . . . . . . . . . . . . . . . . . . 43

9 Apêndice D $\quad 45$

9.1 Fluxo de trabalho . . . . . . . . . . . . . . . . . . . . . 45

9.1 .1 Conversão de arquivos . . . . . . . . . . . . . . . . . . . 45

9.1 .2 Mapas de difusão . . . . . . . . . . . . . . . . . . . . . . . . . 46

10 Apêndice E $\quad 47$

10.1 Resultados preliminares . . . . . . . . . . . . . . . . . . . . 47

10.1.1 Fantomas de primeira geração . . . . . . . . . . . . . . . . . . . . . 48

10.1.2 Fantomas de segunda geração . . . . . . . . . . . . . . . . . . . . . . . 48

10.1.3 Fantoma de nylon . . . . . . . . . . . . . . . . . . . . . 50

10.1.4 Fantoma de salsão . . . . . . . . . . . . . . . . . . . . . . . . 50

10.1.5 Fantoma de salsão com sal . . . . . . . . . . . . . . . . . . . . . . 51

10.1.6 Processamento das imagens adquiridas . . . . . . . . . . . . . . . . 54

10.1.7 Convergência da simulação com a imagem real . . . . . . . . . . . . . . . . 54

10.1.8 Estudo de variação do parâmetro "ADC do vapor d'água" . . . . . . . . . . . 55

$\begin{array}{ll}\text { Referências Bibliográficas } & 57\end{array}$ 


\section{Lista de Abreviaturas}

\begin{tabular}{|c|c|}
\hline $\mathrm{ADC}$ & $\begin{array}{l}\text { Coeficiente Aparente de Difusão } \\
\text { (Apparent Diffusion Coefficient) }\end{array}$ \\
\hline DOT & $\begin{array}{l}\text { Transformada pela Orientação de Difusão } \\
\text { (Diffusion Orientation Transform) }\end{array}$ \\
\hline DTI & $\begin{array}{l}\text { Imagem por Tensor de Difusão } \\
\text { (Diffusion Tensor Imaging) }\end{array}$ \\
\hline $\begin{array}{l}\text { DWI } \\
\text { (ou DW-MRI) }\end{array}$ & $\begin{array}{l}\text { Imagem de Difusão por Ressonância Magnética } \\
\text { (Diffusion Weighted Magnetic Resonance Imaging) }\end{array}$ \\
\hline EM & Esclerose Múltipla \\
\hline FA & $\begin{array}{l}\text { Anisotropia Fracionada } \\
\text { (Fractional Anisotropy) }\end{array}$ \\
\hline FID & $\begin{array}{l}\text { Decaimento de Indução Livre } \\
\text { (Free Induction Decay) }\end{array}$ \\
\hline FOV & $\begin{array}{l}\text { Campo de Visão } \\
\text { (Field of View) }\end{array}$ \\
\hline HTC & $\begin{array}{l}\text { Computação de Alta Produtividade } \\
\text { (High Throughput Computing) }\end{array}$ \\
\hline $\mathrm{iFT}$ & $\begin{array}{l}\text { Transformada inversa de Fourier } \\
\text { (inverse Fourier Transform) }\end{array}$ \\
\hline $\mathrm{MC}$ & Monte Carlo \\
\hline MD & $\begin{array}{l}\text { Difusividade Média } \\
\text { (Mean Diffusivity) }\end{array}$ \\
\hline MD & $\begin{array}{l}\text { Dinâmica Molecular } \\
\text { (Molecular Dynamics) }\end{array}$ \\
\hline MRI & $\begin{array}{l}\text { Imagem por Ressonância Magnética } \\
\text { (Magnetic Resonance Imaging) }\end{array}$ \\
\hline NMR & $\begin{array}{l}\text { Ressonância Magnética Nuclear } \\
\text { (Nuclear Magnetic Resonance) }\end{array}$ \\
\hline OOP & $\begin{array}{l}\text { Programação Orientada a Objetos } \\
\text { (Object Oriented Programming) }\end{array}$ \\
\hline PGSE & $\begin{array}{l}\text { Eco de Spins por Pulsos de Gradiente } \\
\text { (Pulsed Gradient Spin Echo) }\end{array}$ \\
\hline $\mathrm{SNC}$ & Sistema Nervoso Central \\
\hline SNP & Sistema Nervoso Periférico \\
\hline
\end{tabular}


SNR
Razão entre Sinal e Ruído

(Signal to Noise Ratio)

Tempo até o Eco

(Time to Echo)

Linguagem de Marcação Extensível

(eXtensible Markup Language) 


\section{Lista de Símbolos}

$\delta \quad$ Duração do pulso do gradiente na sequência PGSE

$\Delta \quad$ Intervalo entre o ramp-up (início) do primeiro e do segundo pulsos de gradiente da sequência PGSE

$\gamma \quad$ Constante giromagnética da substância

$\tau^{\prime} \quad$ Tempo até a leitura do sinal na sequência PGSE

$\tau \quad \frac{\tau^{\prime}}{2}$

$b$, b-value Fator b, que indica magnitude da influência da difusão na intensidade do sinal

D $\quad$ Coeficiente Aparente de Difusão (ADC)

$g \quad$ Intensidade do campo magnético devido ao pulso do gradiente na sequência PGSE (depende da posição da partícula)

$g_{0} \quad$ Intensidade do campo magnético principal

$T_{1} \quad$ Tempo de relaxamento spin-lattice

$T_{2} \quad$ Tempo de relaxamento spin-spin 


\section{Lista de Figuras}

1.1 Imagem RM de um joelho humano, em orientação sagital. É possível diferenciar tecidos moles, como o muscular (cinza escuro) e cartilaginoso (cinza claro, exceto os ossos da perna e joelho). É possível também distinguir estruturas menores, como vasos sanguíneos, nessa imagem. Fonte: [Wikb]. . . . . . . . . . . . . . . . 1

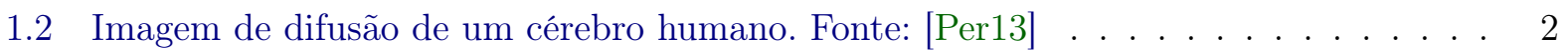

1.3 Interface gráfica do simulador PJNMR. Fonte: [LBS03]. Nesta figura, o simulador PJNMR mostra o estado de um único próton após um pulso de $90^{\circ}$ e precessão por $0.33 \mathrm{~ms} \ldots \ldots \ldots \ldots \ldots \ldots \ldots \ldots$

1.4 Imagens sintetizadas por meio do SIMRI, para exemplificar que este simulador pode gerar artefatos realísticos. As duas imagens foram obtidas com a mesma sequência Spin Echo. A) A excitação dos prótons da água e da gordura estão em resonância. B) Os prótons da água são excitados em resonância enquanto que os prótons da gordura estão fora de resonância. Fonte: $\left[\mathrm{BCCB}^{+}\right] \ldots \ldots$. . . . . . . . . . . . . . . .

2.1 Ilustração de um spin em dois instantes, aonde as flechas pretas indicam a direção do campo magnético externo, as flechas azuis indicam a direção do momento magnético associado ao spin, e o círculo verde hachurado indica o "caminho" que a ponta da flecha irá percorrer ao precessar em torno do campo magnético. . . . . . . . . . . . . 9

2.2 Ilustração de uma pequeníssima região contendo spins, na ausência de campo magnético externo. Todas as partículas representadas são idênticas; a variação no tamanho indica sua posição com relação ao plano do papel. . . . . . . . . . . . . . . . . . . . .

2.3 Ilustração esquemática de duas partículas com spin, uma precessando paralelamente e outra antiparalelamente à direção do campo externo. As flechas azuis indicam a direção do momento magnético associado ao spin, as flechas pretas indicam a direção do campo magnético externo, e as curvas tracejadas verdes indicam o caminho da precessão para a "ponta" das flechas verdes. O fóton (laranja) é absorvido e a partícula muda do estado antiparalelo para o estado paralelo. . . . . . . . . . . . . . . . . . 10

2.4 Conjunto de spins precessando em torno da direção de um campo externo intenso e homogêneo. A flecha azul indica a direção do campo. Note que os spins formam pequenos ângulos com relação à direção do campo. Mas para uma população de spins, as contribuições perpendiculares ao campo tendem a se cancelar mutuamente. Portanto, a magnetização de um spin packet seria de mesma direção que o campo. $\quad 10$

2.5 O vetor de magnetização $M$. Em A) $M=M_{z}$. Após um pulso de $90^{\circ}$, em B) $M=M_{x y}$. 11 
2.6 "Partitura" simplificada da sequência de pulsos de Stejskal-Tanner. Adaptação de uma figura de Basser e Ozarslan [BO].

3.1 Esquema simplificado de uma aquisição de imagem de difusão por RM. Nas imagens em que $b=0$, não há informações sobre a difusão de água na amostra - estas informações são adquiridas somente quando há aplicação de gradientes de difusão (ou seja, quando $b>0$ ). Uma vez obtidos dados suficientes, os tensores de difusão podem ser calculados, e a visualização das informações contidas nesses tensores nos permitem quantificar a difusão da água na amostra e sua direcionalidade.

3.2 Esquema simplificado de uma aquisição e síntese de imagem de difusão por RM. As linhas tracejadas azuis indicam o fluxo de controle para a sintetização de imagens pelo simulador. Na sintetização de imagens de difusão por RM, substituímos o trecho mais demorado da sequência PGSE pela integração numérica de uma estrutura composta por uma máscara de direções, especificada pelo usuário, e pelas intensidades dadas pela imagem em que $b=0$.

3.3 Especificação de uma máscara contendo um prisma retangular com água em difusão isotrópica. . . . . . . . . . . . . . . . . . . . . . . . . .

3.4 Esboço do exemplo a ser sintetizado: três prismas retangulares de diferentes tamanhos, cada um contendo os prismas que forem menores.

3.5 Coleção organizada em colunas de imagens das projeções ortogonais de máscara com especificação de um único objeto com $\mathrm{ADC}=1$ e difusão isotrópica. A) Projeção da máscara no eixo X. B) Projeção da máscara no eixo Y. C) Projeção da máscara no eixo Z. . . . . . . . . . . . . . . . . . . . . . . . . . . . . .

3.6 Coleção organizada em colunas de imagens das projeções ortogonais de máscara com especificação de um objeto com $\mathrm{ADC}=1$ e difusão isotrópica, e um objeto com $\mathrm{ADC}=5$ e difusão isotrópica, contido no anterior. A) Projeção da máscara no eixo X. B) Projeção da máscara no eixo Y. C) Projeção da máscara no eixo Z. . . . . . . . .

3.7 Coleção organizada em colunas de imagens das projeções ortogonais de máscara com especificação de um objeto com $\mathrm{ADC}=1$ e difusão isotrópica, um objeto com $\mathrm{ADC}=5$ e difusão isotrópica, contido no anterior, e um objeto com $\mathrm{ADC}=10$, de difusão anisotrópica, contido no anterior e com direção $(x=0.1, y=0.1, z=0.9)$. A) Projeção da máscara no eixo X. B) Projeção da máscara no eixo Y. C) Projeção da máscara no eixo Z. . . . . . . . . . . . . . . . . . . . . . . . . . . . . .

4.1 Fotos do fantoma de tubos capilares. Pode-se ver na foto à direita que ele é composto por pequenos tubos capilares. Um invólucro transparente mantém os capilares em seu lugar, como pode ser visto na foto à esquerda. Os tubos capilares foram torcidos para que coubessem no invólucro. . . . . . . . . . . . . . . . . . . . . . . . . .

4.2 Fotos do fantoma de tubos capilares. Na foto da esquerda, o recipiente transparente contendo os capilares está fechado, e contendo água. Na foto da direita, o recipiente está colocado dentro de um invólucro com tampa, e também foi colocada água no espaço entre os dois recipientes. . . . . . . . . . . . . . . . . . . . . . 
4.3 Imagens de difusão obtidas por meio de um equipamento de RM, e processada pelos softwares MedSquare [JMea] e BioImage [JMea]. A imagem esquerda mostra as magnitudes dos coeficientes de difusão. A linha amarela indica o raio aproximado da região que contém os tubos capilares. A linha vermelha indica a espessura aproximada do recipiente. A linha verde indica a espessura aproximada da região que contém água entre o recipiente e o invólucro. A imagem da direita foi colorida de acordo com a direção da difusão. É possível notar que as regiões contendo água têm predomínio da cor azul, que neste caso, indica predominância da difusão na direção que atravessa o papel

4.4 Imagem de difusão do fantoma de tubos capilares. As barras tridimensionais representam os vetores principais de difusão, filtrados para o intervalo aonde FA está entre

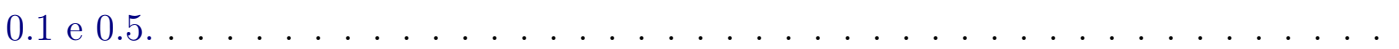

4.5 Imagens de cada um dos 8 cortes axiais das imagens original e sintética, lado a lado, em duas colunas. As imagens originais estão identificadas com a letra A, e as imagens sintéticas com a letra B. As imagens têm colorização de seu fundo de acordo com a direcionalidade (azul para direção axial, verde para direção sagital e vermelho para direção coronal). Os segmentos de reta indicam a direção dos autovetores da direção principal de difusão em cada ponto, e são coloridos usando cores frias para FA próximo de 0 e cores quentes para FA próximo de 1. Qualitativamente, as diferenças entre as duas séries de imagens se resumem a uma tonalidade mais esverdeada para a região isotrópica da imagem sintética, enquanto a imagem original tem tonalidade mais alaranjada, e a região com água é mais intensamente azul na imagem síntetica do que na original.

4.6 Imagens das Regiões de Interesse (ROI ou Region Of Interest) das imagens original (esquerda) e sintética (direita). É possível notar claramente que a imagem sintética tem a região com água modelada de maneira excessivamente "homogênea", se comparada à imagem original: as barras tridimensionais sugerem que no fantoma a difusão da água ocorre privilegiadamente num intervalo de direções aproximadamente axiais, enquanto que na imagem sintética, a difusão se dá quase que exclusivamente ao longo de uma única direção. . . . . . . . . . . . . . . . . . . . . . . . . 32

4.7 Gráfico do consumo de tempo por número de passos, para 70 núcleos em paralelo. . . 33

6.1 Trajeto percorrido pela ponta de um vetor em nutação em torno dos eixos $\mathrm{X}$ e $\mathrm{Z}$.

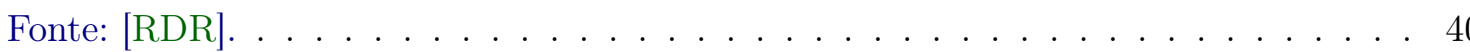

8.1 Esboço de gráfico de uma soma Riemmaniana similar à do algoritmo utilizado nesta dissertação. i é o intervalo de discretização (intervalo total / número de passos), e o valor da integral é aproximado como sendo o valor da soma da série de $\mathrm{f}(\mathrm{x})$ multiplicado pelo intervalo de discretização. Quanto menor o intervalo, mais o valor da soma da série se aproxima do valor da integral, e mais custoso computacionalmente o algoritmo. Figura adaptada do livro de McAloon e Trombe [MT72] . . . . . . . . . . 44

8.2 Diagrama ilustrativo do fluxo de trabalho da simulação. . . . . . . . . . . . . . . . 44 
10.1 No artigo de Roberts, esta é a figura número 6. Corresponde ao FID obtido pelo autor para o algoritmo que ele propõe. . . . . . . . . . . . . . . . . . 47

10.2 Nossa tentativa de reproduzir os resultados da figura 6 do artigo de Roberts. . . . . . 47

10.3 FID para os parâmetros $\mathrm{T} 1=\mathrm{T} 2=3000 \mathrm{~ms}$, usando o algoritmo adaptado de Roberts. As unidades dos eixos são as mesmas da figura 10.2 . . . . . . . . . . . . 48

10.4 Suporte dos fantomas de primeira geração. . . . . . . . . . . . . . . . . . . . . 49

10.5 Imagens de difusão do fantoma de nylon. Produzidas com os software MedSquare [JMea] e Bioimage $\left[\mathrm{PJR}^{+}\right] . \ldots \ldots \ldots \ldots$. . . . . . . . . . . . . . . . 49

10.6 Imagem do fantoma de nylon. $\mathrm{b}=0$. Produzido com o software MedSquare [JMea]. . 50

10.7 Gráfico da variação do parâmetro "ADC do vapor d'água". A curva contínua indica uma interpolação polinomial de grau 2, e sugere que há um máximo local para a simulação, com estas condições, para ADC do vapor próximo de $23 \mathrm{~s} / \mathrm{mm}^{2}$. . . . . . 50

10.8 Especificação da máscara para a simulação $50 \ldots$. . . . . . . . . . . . . . . . . 51

10.9 Fantoma de nylon, aberto. . . . . . . . . . . . . . . . . . 52

10.10Fantoma de salsão, aberto. . . . . . . . . . . . . . . . . . . 52

10.11Medição do diâmetro externo do talo de salsão. . . . . . . . . . . . . . . . . . . 52

10.12Medição da espessura máxima do talo de salsão. . . . . . . . . . . . . . . . . . . . 53

10.13Fantoma de salsão com sal, aberto. . . . . . . . . . . . . . . . . . 53

10.14Gráfico da variação do parâmetro "ADC da água líquida". . . . . . . . . . . . . . . 55 


\section{Capítulo 1}

\section{Introdução}

As técnicas de imagens por Ressonância Magnética $(\mathrm{RM})^{1}$ são valiosas para a realização de diagnósticos médicos pois permitem visualizar e qualificar tecidos moles do corpo (e.g., ver figura 1.1) e porque sua produção se dá por técnicas não-ionizantes ${ }^{2}$. As técnicas de imagens por ressonância magnética são não-invasivas e, até onde se sabe, inócuas ${ }^{3}$ [PL06].

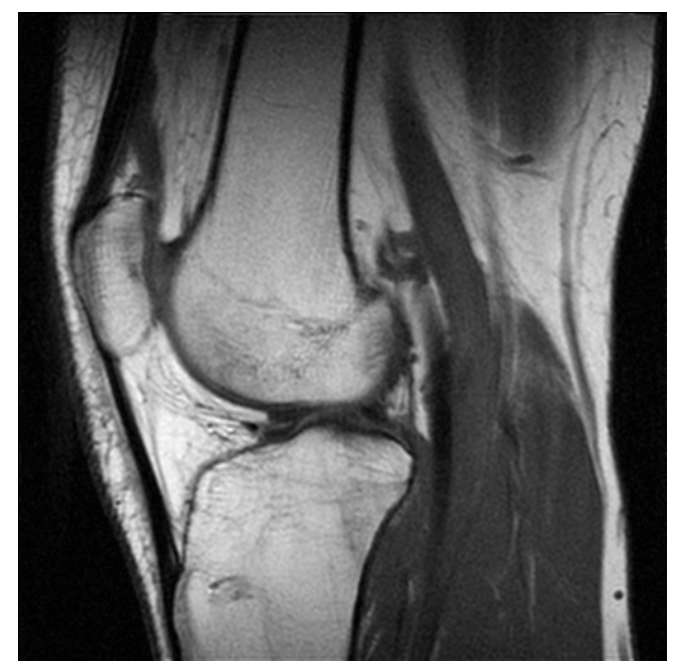

Figura 1.1: Imagem RM de um joelho humano, em orientação sagital. É possivel diferenciar tecidos moles, como o muscular (cinza escuro) e cartilaginoso (cinza claro, exceto os ossos da perna e joelho). É possivel também distinguir estruturas menores, como vasos sanguíneos, nessa imagem. Fonte: [Wikb].

As imagens RM ponderadas pela difusão da água (DWI, ou Diffusion Weighted Imaging), também chamadas imagens de difusão são técnicas de RM nas quais a imagem produzida apresenta, em cada ponto da imagem, um sinal que, em comparação com o sinal do mesmo ponto de uma imagem produzida sem ser "ponderada pela difusão da água", tem atenuação da intensidade proporcional à difusão de moléculas de água ${ }^{4}$ em uma direção específica (e.g., ver figura 1.2).

Em outras palavras, cada ponto de uma imagem de difusão por RM tem magnitude inversamente proporcional à quantidade de água que se difundiu naquele ponto da amostra.

Por exemplo, consideremos uma amostra que consiste em um material fibroso, no qual a água se difunde mais facilmente ao longo do que através da fibra, ou seja, uma amostra composta por

\footnotetext{
${ }^{1}$ Um termo equivalente é MRI, do inglês Magnetic Resonance Imaging, ou Imagens por Ressonância Magnética.

${ }^{2}$ Em contraste com outras técnicas, por exemplo o raio-X, que utiliza radiação ionizante, que é um agente cancerígeno. Uma radiação é dita ionizante quando parte de sua energia causa a perda de elétrons de átomos da amostra.

${ }^{3}$ Supondo que o paciente siga todas as orientações de segurança - em especial, que não tenha objetos metálicos consigo - os equipamentos de RM de uso clínico são considerados seguros.

${ }^{4}$ Concretamente, as sequências de pulso estudadas para a elaboração desta dissertação utilizam a frequência do núcleo de hidrogênio pertencente a uma molécula de água. Por conveniência, iremos ignorar esta tecnicalidade, e escrever "molécula de água" ou apenas "água", quando verdadeiramente deveríamos escrever "próton que pertence a uma molécula de água".
} 

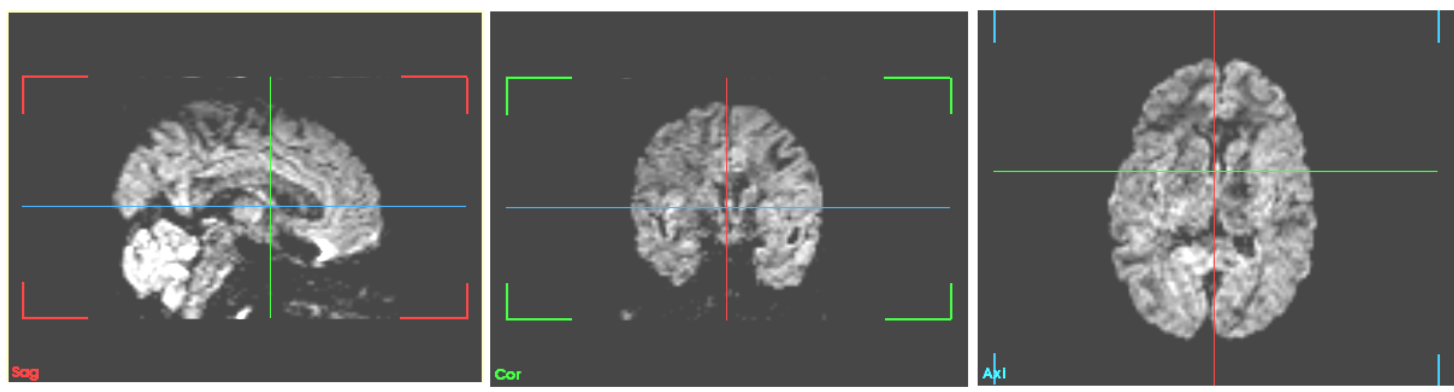

Figura 1.2: Imagem de difusão de um cérebro humano. Fonte: [Per13]

pequenos "tubos" semipermeáveis, imersos em água. Vamos supor que seja possível visualizar cada fibra individual, em imagens de RM estruturais ${ }^{5}$. Consideremos ainda que nessa amostra suas fibras estão dispostas numa única direção (ou seja, uma distribuição anisotrópica). Uma imagem de difusão dessa amostra, feita com a máquina de ressonância calibrada para medir a intensidade ponderada pela difusão da água na direção das fibras, consiste numa imagem equivalente à imagem RM estrutural da amostra, mas na qual cada ponto tem sua intensidade diminuída proporcionalmente à quantidade de moléculas de água que se difundiram na direção em que a máquina foi calibrada. Portanto, no nosso exemplo, os pontos da imagem que correspondem à parte interna das fibras serão mais escuros na imagem de difusão do que numa imagem equivalente, sem "ponderação por difusão. Como a difusão da água na região externa às fibras é aproximadamente isotrópica, haverá pouca diferença, nessa região, entre a imagem de difusão e a estrutural. Se subtrairmos a imagem de difusão da imagem estrutural, teremos uma imagem aproximada das regiões internas às fibras.

Outro exemplo: consideremos a mesma amostra, mas da qual não se sabe de antemão a direção em que as fibras estão dispostas. Nesse caso, é possível produzir um conjunto de imagens de difusão dessa amostra, cada uma ponderada pela difusão numa direção diferente. Como a amostra tem difusão anisotrópica, ou seja, difusão que ocorre preferencialmente numa certa direção, as imagens terão sinal com maior ou menor diferenças de intensidade, de acordo com o quanto a direção em que a máquina foi calibrada coincide com a direção real das fibras. Nesse caso, as imagens que tiverem, no interior das fibras, menor diferença de intensidade entre a imagem de difusão e a estrutural, foram obtidas com direções de difusão aproximadamente perpendiculares à direção real de difusão. As imagens que tiverem maior diferença de intensidade foram obtidas com direções de difusão aproximadamente paralelas à direção das fibras. Dessa forma, pode-se determinar a direção aproximada em que a difusividade é máxima, e portanto determinar a direção dessas fibras.

Quanto maior o número de direções diferentes nas quais forem produzidas imagens, menor será a incerteza associada à medida da direção de difusividade máxima. Uma extensão natural deste mecanismo seria acompanhar o trajeto provável de uma fibra por meio de imagens de difusão por RM. Um conjunto de técnicas sofisticadas para este tipo de aplicação é a técnica de Imagens por Tensor de Difusão (DTI, ou Diffusion Tensor Imaging), que é essencial para a reconstrução computacional das trajetórias das fibras neuronais no cérebro in vivo - sendo esta reconstrução chamada de tractografia neuronal por RM.

O uso clínico e científico das imagens de difusão por RM é especialmente rico em estudos sobre cérebros vivos. O interesse no estudo cerebral, em especial de sua substância branca, utilizando imagens de difusão é devido ao menos em parte pela anisotropia da difusão da água ao longo das fibras neuronais presentes num cérebro. Estas fibras consistem em feixes neuronais, contendo neurônios imersos em tecido conjuntivo. Cada neurônio tem seu axônio envolto por uma estrutura denominada bainha de mielina, cuja composição química em geral apresenta uma grande proporção de lipídios. A difusão da água é muito menor através das paredes do axônio, e através da bainha de mielina, do que a autodifusão da água ao longo do citoplasma do axônio[Bea] ${ }^{6}$. Por isso, a água

\footnotetext{
${ }^{5}$ Denominamos como estruturais as imagens $T_{2}$ e as imagens com $b=0$ comuns no início de volumes de imagens de difusão. Esses termos serão explicados em detalhes no capítulo Teoria (p. 7).

${ }^{6} \mathrm{~A}$ difusão da água no citoplasma não é exatamente igual à autodifusão da água, mas devido à prevalência da
} 
se difunde com relativa facilidade ao longo das fibras neuronais, e com relativa dificuldade através delas.

Devido à diferença entre a difusividade da água ao longo do eixo principal do axônio e nas direções radiais, é possível determinar através de imagens de difusão a direção "preferencial" da difusão ao longo das fibras neuronais, e tomando estas informações como base, podemos usar algoritmos de tractografia neuronal para identificar as trajetórias prováveis de fibras neuronais do cérebro ${ }^{7}$.

Por caracterizar as fibras neuronais por meio da difusão, a difusão por RM é útil como ferramenta de diagnóstico para desordens associadas à mudança da difusividade da água no cérebro, algo que ocorre frequentemente em casos de Esclerose Múltipla [JBB09] [CIF99] e outras doenças neurodegenerativas, por exemplo. Outras aplicações das imagens de difusão incluem: diagnóstico e acompanhamento de traumas, epilepsia e transtornos psiquiátricos e neurológicos.

\subsection{Motivação}

A relação entre anisotropia e intensidade do sinal de RM não é ainda plenamente entendida [Laz04] [JBB09]. Os modelos analíticos publicados correspondem a amostras microscópicas, homogêneas e de geometria simples (por exemplo, [BF13] [BF08] [LFS ${ }^{+}$10] [BA94] [SJ95] [BCGT05] [HJNS03] [KLD96]). Apesar desta insuficiência teórica, as correlações entre mudanças na difusividade da água na substância branca e condições patológicas são observações frequentes [Laz04], e uma explicação causal é necessária.

Para investigadores, o uso de simulações pode ajudar a resolver esse problema, ao permitir estudos exploratórios virtuais e quantitativos. Nosso intuito foi desenvolver um simulador de imagens de difusão por RM, tal que permita ao investigador prever como será a imagem de difusão resultante de uma certa amostra.

O procedimento "padrão" de uso da ferramenta consiste em variar um parâmetro, seja um dos parâmetros que modelam a sequência de pulsos, por exemplo o Tempo até o Eco (TE ou Time to Echo) ou um dos parâmetros que modelam a amostra, como o valor do Coeficiente de Difusão Aparente (ADC, ou Aparent Diffusion Coefficient) de uma região da amostra. Dessa forma, podemos obter as imagens de difusão correspondentes, o que permite estabelecer uma correlação entre o parâmetro variado da amostra e o resultado quantitativo da imagem de difusão sintetizada. Esta correlação, ao contrário da correlação feita com tecidos cadavéricos ou de biópsia, não sofre com deformações decorrentes da morte do tecido e de sua fixação e corte.

Dos demais obstáculos para estudos sistemáticos das relações entre difusividade da água e o sinal registrado em imagens de difusão na substância branca do cérebro, existem o alto custo associado a obter imagens de ressonância sensíveis a difusão, essencialmente devido ao longo tempo necessário para adquirir várias imagens de difusão da mesma amostra em diferentes direções, a impossibilidade ética de se realizar estudos invasivos com seres humanos, e os custos associados aos estudos com modelos animais. Estas dificuldades também sugerem a necessidade de se usar modelos computacionais para a investigação deste tema.

O uso do equipamento de RM, para um dado experimento, tem sua duração determinada pela sequência de pulsos a ser utilizada, e, no caso de sequências utilizadas em exames de seres humanos em ambientes hospitalares, essa duração pode variar de poucos minutos a poucas horas. É de interesse geral que o tempo de cada experimento seja minimizado, para que um maior número de experimentos sejam realizados por uma mesma máquina. $\mathrm{O}$ uso de um simulador pode evitar a aquisição de imagens espúrias, e também pode ajudar no treinamento de pessoal[LBS03].

Os simuladores de difusão por RM disponíveis atualmente se limitam a modelar a difusão por ressonância magnética de volumes menores que um voxel, ou intervalos mais curtos que a aquisição

água como componente do citoplasma, por conveniência tomamos a liberdade de chamar a esta difusão de moléculas de água no citoplasma, uma autodifusão da água.

${ }^{7}$ Existem limitações à tractografia, oriundas da limitação de resolução dos equipamentos de ressonância magnética, o que geralmente impede identificar cada fibra individual, e existem limitações dos algoritmos de tractografia, que por exemplo não têm resultados amplamente aceitos para regiões de cruzamento de fibras. Por isso, a determinação dos circuitos neuronais é incompleta, e incerta. 
do sinal de um único eco [HJNS03] [BCGT05] [Bea] [BF08] [BF13] [DMS01] [KLD96], ou no máximo a aquisição do sinal de um único voxel de amostra sintética [LFS $\left.{ }^{+} 10\right]$. Estes simuladores servem para validar modelos matemáticos da difusão por ressonância, porém sua pequena extensão impede que sejam aplicados à síntese de imagens de amostras macroscópicas. O método que desenvolvemos para síntese de imagens de difusão por RM não é limitado pelo tamanho da amostra, e por isso podemos usá-lo para gerar imagens sintéticas de amostras macroscópicas.

\subsection{Objetivos}

Nosso objetivo foi produzir um sintetizador de imagens de difusão por ressonância magnética, que seja útil para o estudo das correlações entre anisotropia da difusão e condições patológicas da substância branca. A mesma ferramenta também terá utilidade didática, de treinamento, ou operacional.

Descrevemos aqui uma técnica de simulação que permite sintetizar imagens de difusão a partir de imagens de ressonância estruturais, e avaliamos sua fidelidade pela comparação com imagens de difusão por ressonância das mesmas amostras que foram simuladas.

Desenvolvemos um software capaz de, a partir de imagens de RM estruturais, que comumente podem ser adquiridas em pouco mais do que um minuto, e de uma máscara de direções desenhada pelo operador (a ser descrita em detalhes no capítulo Metodologia, p. 17), gerar imagens de difusão por RM que são equivalentes às imagens de difusão adquiridas para as mesmas amostras.

Os trabalhos anteriores que desenvolveram sínteses de imagens de difusão por RM têm em comum o fato de sintetizarem o sinal de ressonância de cada voxel a partir de um modelo geométrico da amostra naquele voxel. Em seguida, por meio de técnicas de simulação de Monte Carlo [TdO01], são amostradas um pequeno número de moléculas de água (entre milhares e milhões de moléculas) para que sua trajetória seja calculada. $\mathrm{O}$ valor resultante para a amostra é suposto como igual ao valor da população inteira de partículas do voxel.

Este sistema é adequado para os resultados obtidos, de pequena extensão espacial (menor que 1 voxel), mas é impraticável usá-lo para sintetizar imagens macroscópicas devido ao custo computacional elevado. Portanto nosso principal objetivo foi elaborar um sistema novo, que permita sintetizar imagens de difusão por RM de amostras macroscópicas. Obtivemos isso, essencialmente, usando imagens estruturais da própria amostra no lugar dos modelos geométricos propostos pelos autores. Para cada voxel da imagem estrutural, realizamos uma série de cálculos, e obtemos o valor da atenuação do sinal original numa direção. Atribuímos o sinal de difusão a partir dessa atenuação e do sinal original desse voxel. Por ser uma estratégia voxel-a-voxel, nosso método tem custo computacional proporcional à resolução da imagem original, e é indiferente à extensão espacial da amostra.

Para exemplificar o uso da ferramenta, apresentamos um estudo sobre um fantoma de tubos capilares. A ferramenta foi publicada sob licença GPL, e pode ser obtida gratuitamente [Bor].

\subsection{Trabalhos anteriores}

Da literatura investigada, alguns livros foram utilizados de maneira mais extensa, e por isso merecem ser indicados com destaque: o livro de Johansen-Berg e Behrens [JBB09], foi nossa fonte primordial na teoria da aquisição de imagens de RM, e nas aplicações médicas das modalidades simuladas. O livro de Slichter [Sli10], foi consultado quanto à física da ressonância magnética. O paper seminal de Stejskal e Tanner [ST65] foi usado como o modelo matemático a ser numericamente computado para a síntese de imagens. O livro de Cussler [Cus97] foi consultado sobre a teoria da difusão.

Durante a investigação bibliográfica, não foram encontrados exemplos de sintetizadores de imagens de difusão por RM capazes de lidar com amostras macroscópicas, nos jornais científicos pesquisados. Encontramos exemplos de simulações de RM de outros tipos, como o simulador SIMRI $\left[\mathrm{BCCB}^{+}\right]$de Benoit-Cattin, que não oferecem a possibilidade de sintetizar imagens de difusão por 
ressonância, mas que sintetizam imagens de amostras macroscópicas. Acreditamos portanto que a aplicação de síntese de imagens de difusão por RM macroscópicas é inédita.

Roberts [Rob91] realizou a integração numérica das equações de Bloch para obter gráficos sintéticos de experimentos de onda contínua e FID (Decaimento de Indução Livre, ou Free Induction Decay). É a partir da discretização do FID do eco que é construída a maioria das imagens de RM, e portanto este trabalho exemplifica a maneira mais fundamental de computar uma simulação de RM.

Beaulieu e Allen [BA94] tiveram por objetivo identificar a estrutura neuronal responsável pela anisotropia da difusão da água em tecidos neuronais. Para tanto, eles realizaram estudos histológicos e simulações Monte Carlo[TdO01]. Em suas simulações, obtiveram como resultados a distribuição das partículas após um intervalo de tempo simulado, para a difusão livre de barreiras, e na presença de um conjunto hexagonal de barreiras, e compararam numericamente os resultados.

Kuchel et al [KLD96] desenvolveram um modelo matemático para a difusão de spins em uma esfera. A simulação computacional se resume, essencialmente, na aplicação do método de Monte Carlo [TdO01] para gerar soluções numéricas das soluções analíticas encontradas pelos autores.

Duh et al [DMS01] investigaram os limites do modelo matemático de difusão que supõe distribuição gaussiana dos deslocamentos das partículas. Para isso, criaram modelo alternativo que corresponde mais precisamente aos resultados de regiões do tipo "poro", aonde as partículas colidem com as paredes do recipiente muitas vezes durante o intervalo de aquisição da informação sobre a difusão. Simulações numéricas foram realizadas, e usadas para validar o modelo analítico.

Hagslatt et al, [HJNS03] tiveram por interesse principal elaborar uma solução analítica generalizada para descrever o decaimento do eco quando a amostra possui poros com geometria não trivial. Usando uma extensão para MatLab [Mat13] chamada FEMLAB, eles usaram o método de elementos finitos para desenhar reticulados triangulares na região de interesse.

Letourneau et al [LBS03] construíram uma ferramenta didática que permite simular e visualizar a representação vetorial do efeito de diferentes parâmetros de sequências de pulso em um conjunto de até 3 spins. Uma captura de tela desse simulador pode ser vista na figura 1.3. O objetivo desta ferramenta é visualizar a dinâmica dos spins de acordo com os parâmetros de uma sequência de pulsos especificada pelo usuário. Em outras palavras, os autores esperam facilitar o treinamento de operadores de equipamentos de RM por meio de uma ferramenta gráfica de simulação de sequências de pulso.

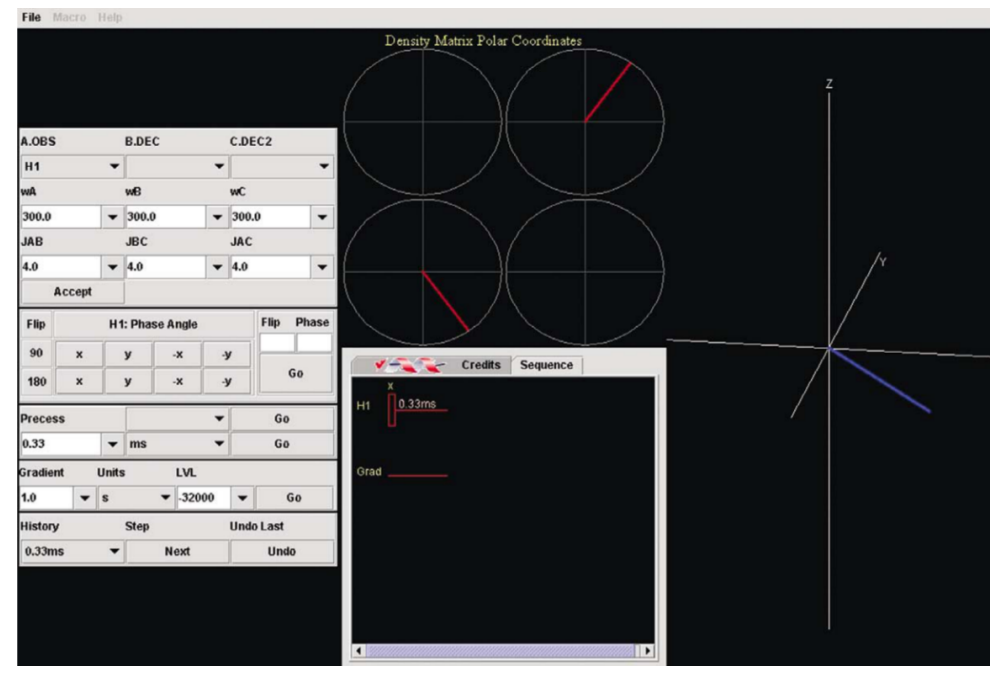

Figura 1.3: Interface gráfica do simulador PJNMR. Fonte: [LBS03]. Nesta figura, o simulador PJNMR mostra o estado de um único próton após um pulso de $90^{\circ}$ e precessão por $0.33 \mathrm{~ms}$.

Benoit-Cattin et al $\left[\mathrm{BCCB}^{+}\right]$desenvolveram o simulador SIMRI, e algumas de suas possibilidades são exemplificadas pelos autores. O SIMRI é um sintetizador de imagens de RM (ver por exemplo a figura 1.4), e permite ser configurado de modo a obter imagens com diferentes configu- 
rações de sequência de pulso, e usa arquivos arbitrários para a simulação da amostra. Entretanto, não é capaz de realizar simulações de imagens de difusão por ressonância magnética.
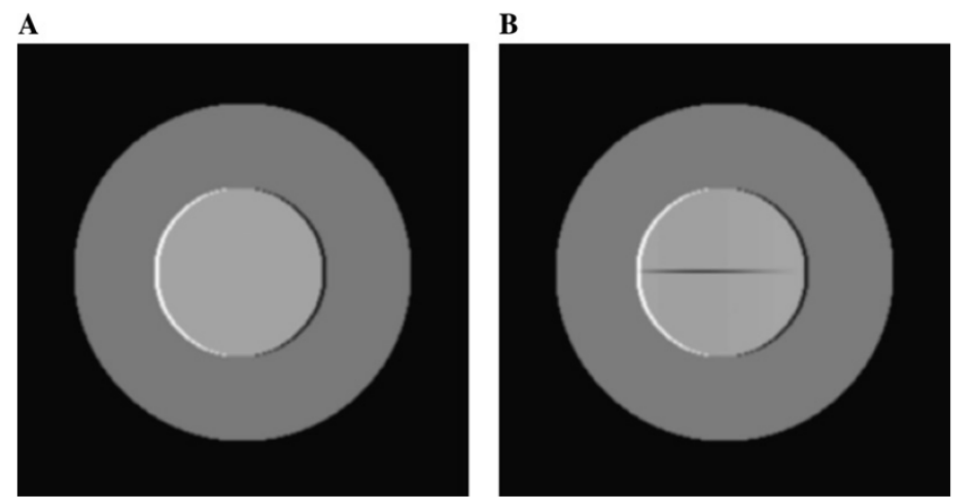

Figura 1.4: Imagens sintetizadas por meio do SIMRI, para exemplificar que este simulador pode gerar artefatos realísticos. As duas imagens foram obtidas com a mesma sequência Spin Echo. A) A excitação dos prótons da água e da gordura estão em resonância. B) Os prótons da água são excitados em resonância enquanto que os prótons da gordura estão fora de resonância. Fonte: $\left[B C C B^{+}\right]$.

Balls e Frank [BF08], usando o software MCell, construíram um modelo de cruzamento de fibras, aonde é possível variar a permebialidade das paredes da fibra, e também incluíram modelos de células, usando elipsóides com permeabilidade variável. Os resultados apresentados são o efeito da variação desses parâmetros sobre a anisotropia resultante, quantificada pela Anisotropia Fracionada (FA, ou Fractional Anisotropy) ${ }^{8}$. Também foi variado o "empacotamento" das fibras, ou seja, o quão próximas as fibras estiveram umas das outras, e analisado o efeito dessa variação sobre a FA.

Landman et al [LFS $\left.{ }^{+} 10\right]$ tiveram como foco desvendar a relação entre microestruturas nervosas e sua participação no sinal de difusão por ressonância magnética. Eles realizaram o estudo por meio de simulações de tipo Monte Carlo [TdO01] escritas em MatLab [Mat13]. Dos resultados obtidos, destacam-se os modelos de axônio normal, interrompido, e com diâmetros "apertado" e "expandido". Para cada modelo, foi calculada a distribuição de distância paralela e perpendicular (com relação ao eixo do modelo) até o centro para 100,000 partículas. A partir dos dados levantados, foram feitas análises estatísticas.

Baxter e Frank [BF13] empreenderam uma continuação do trabalho de Balls e Frank [BF08], que consiste na aplicação do sistema de simulação desenvolvido anteriormente para uma geometria em que as restrições à difusão são dadas por um reticulado de cilindros dispostos de maneira parametrizável. Os autores elaboraram um modelo matemático correspondente, e avaliaram a coincidência dos resultados para os dois modelos.

\footnotetext{
${ }^{8} \mathrm{O}$ FA consiste na razão entre o autovalor máximo e o autovalor mínimo do tensor de difusão. Não iremos usar a representação tensorial da difusividade, por motivo de brevidade. Remetemos o leitor interessado à bibliografia, em especial ao livro de Johansen-Berg [JBB09].
} 


\section{Capítulo 2}

\section{Teoria}

Uma simulação requer a elaboração de um modelo matemático do sistema a ser simulado. No caso de um modelo da difusão por RM, é preciso que o modelo respeite a física que descreve os fenômenos da ressonância magnética e da difusão de massa simultaneamente. Usamos um modelo já existente, de Stejskal e Tanner [ST65]. Para justificar o uso desse modelo, é necessário explorar temas de física teórica que são especialidades em si mesmos. Não poderia ser nosso objetivo dominar todos estes assuntos, mas apenas apresentar o suficiente para construir e analisar o modelo proposto. Estes assuntos, porém, são tratados com muito maior profundidade e clareza nas fontes indicadas na bibliografia, à qual nos reportamos continuamente.

\subsection{Difusão de massa}

Difusão é um conceito relacionado a fenômenos de transporte de massa ou energia num sistema. Em imagens de difusão por RM, o fenômeno crucial para a geração da imagem é o transporte de massa.

Neste caso, a difusão consiste no transporte de massa ao longo do espaço, que pode estar vazio ou conter outros corpos com massa. Por exemplo, um litro de vapor de água no vácuo se difunde livremente. Um litro de vapor de água na atmosfera terrestre se difunde através dessa atmosfera. A difusão de massa é causada por movimentos moleculares que levam uma solução a uma mistura homogênea [Cus97].

A difusão de massa é um fenômeno que pode ser observado diretamente, por exemplo, podemos ver a difusão de uma gota de leite em um copo de água. Esse fenômeno ocorre mesmo quando o sistema aparenta estar em repouso, e o resultado final é uma mistura que aparenta ser homogênea.

Se tivermos um tubo muito mais comprido do que largo, como por exemplo um tubo de ensaio, repleto de água, e colocarmos uma gota de leite na superfície desse volume de água, observaremos que a difusão ocorre gradativamente, e que a mistura se torna homogênea na direção radial (na largura do tubo) muito antes de se tornar homogênea na direção axial (ao longo do comprimento do tubo). Dessa maneira, ao descrever a difusão de uma substância, estaremos descrevendo parte da geometria do objeto que contém essa substância.

Robert Brown, um botânico investigador dos mecanismos de fertilização de plantas, observou o movimento incessante do pólen suspenso em água, em 1827 [BO]. Por seu pioneirismo, esse fenômeno foi denominado movimento browniano. Esse movimento aleatório das partículas está presente em toda a matéria, exceto quando uma substância tem temperatura próxima do zero absoluto.

Adolf Fick, um estudioso de anatomia, propôs uma equação com base fenomenológica para descrever a difusão de massa, semelhante às equações de calor de Fourier e de corrente elétrica de Ohm [BM62] [Cus97]:

$$
J=-D \frac{d n}{d x}
$$


Aonde $J$ é o fluxo de difusão, $D$ é o coeficiente de difusão ${ }^{1}$, e $\frac{d n}{d x}$ é o gradiente de concentração da substância ${ }^{2}$.

Einstein derivou uma relação entre a distância típica percorrida por uma partícula em movimento browniano $[\mathrm{BO}]$ e o tempo decorrido durante esse movimento:

$$
<x^{2}>=2 D \Delta
$$

Aonde $<x^{2}>$ é a média dos quadrados das distâncias percorridas num intervalo de tempo $\Delta$, e $D$ é o coeficiente de difusão de massa.

A partir destes fundamentos, é possível construir modelos mais complexos, que se aproximem realisticamente de fenômenos observáveis. Indicamos os livros de Cussler [Cus97] e Bennet e Myers [BM62] para uma discussão mais completa do assunto.

\subsection{Ressonância Magnética}

Essencialmente, a aquisição de imagens de RM consiste num processo com três etapas: sensibilização da amostra, leitura do sinal, e processamento dos dados para resultar numa imagem.

Tanto a sensibilização da amostra quanto a leitura do sinal são fenômenos eminentemente físicos. O fenômeno físico que é utilizado para fazer com que a amostra gere um sinal é chamado ressonância magnética nuclear.

\subsubsection{Spins e magnetismo nuclear}

O spin é uma propriedade fundamental da matéria ${ }^{3}$. O spin é associado ao momento magnético das partículas, e por isso é comumente descrito como sendo o vetor de direção do momento magnético da partícula.

Esse vetor realiza um movimento denominado precessão em torno do eixo da direção do campo externo, similar a um pião que precessa em torno do eixo do campo gravitacional externo (vide figura 2.1).

De uma certa amostra, se diz que possui uma "população" de spins, que corresponde às partículas que compõem a amostra e que possuem spin. Devido ao número de partículas em amostras macroscópicas, é necessário considerar os spins agrupados em grande número, e por isso a literatura usa o termo "população". Também é comum a expressão "pacote de spins" (spin packet) para se referir a um vetor que é a soma dos vetores que representam cada spin individual de um certo volume.

$\mathrm{Na}$ ausência de um campo magnético externo, os spins de uma amostra estão livres para orientarem-se apenas devido à interação de uns com os outros. Nesse caso, a população de spins é heterogênera e não há uma direção preferencial para a orientação dos spins. A figura 2.2 ilustra essa situação.

${ }^{1} \mathrm{O}$ coeficiente de difusão é comparável ao recíproco da resistividade elétrica [Cus97]:

$$
\begin{aligned}
& \text { (fluxo de elétrons) } \quad=\quad\left(\frac{1}{\text { resistividade }}\right)\left(\frac{\text { diferença de potencial }}{\text { comprimento }}\right) \\
& \text { (fluxo de solvente) } \quad=\quad D \quad\left(\frac{\text { diferença na concentração do solvente }}{\text { comprimento }}\right)
\end{aligned}
$$

\footnotetext{
${ }^{2}$ Neste caso, em uma única dimensão. Vamos nos resumir ao caso unidimensional por motivo de brevidade.

${ }^{3} \mathrm{O}$ spin de uma partícula é representado como um número múltiplo de $1 / 2$, positivo ou negativo. O valor do spin de um átomo é a soma dos spins das partículas que o constituem. [Sli10]. Uma vez que não iremos lidar com partículas de spin inteiro, iremos ignorar a distinção daqui em diante, e falar apenas de spin, mas subentenda-se que se trata de spin não-inteiro.
} 

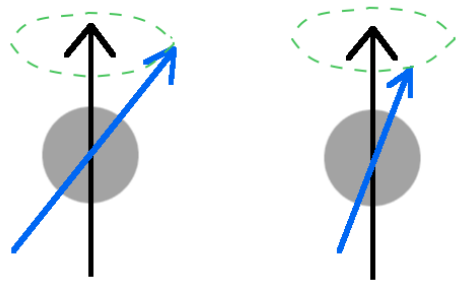

Figura 2.1: Ilustração de um spin em dois instantes, aonde as flechas pretas indicam a direção do campo magnético externo, as flechas azuis indicam a direção do momento magnético associado ao spin, e o círculo verde hachurado indica o "caminho" que a ponta da flecha irá percorrer ao precessar em torno do campo magnético.

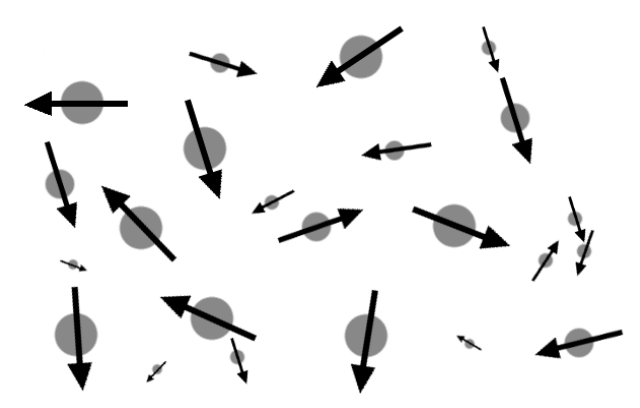

Figura 2.2: Ilustração de uma pequeníssima região contendo spins, na ausência de campo magnético externo. Todas as partículas representadas são idênticas; a variação no tamanho indica sua posição com relação ao plano do papel.

\subsubsection{A frequência de Larmor}

Quando há campo magnético externo, o estado paralelo possui uma energia associada maior que o estado antiparalelo ${ }^{4}$. A diferença de energia entre esses dois estados é proporcional à magnitude do campo magnético. Quanto maior o campo, maior a diferença. O efeito do aumento da diferença energética devido ao aumento do campo magnético é denominado efeito Zeeman [Sli10].

Esse movimento de precessão de um spin em um campo magnético externo tem, para cada tipo de partícula, um intervalo característico para realizar uma "volta" em torno do eixo de precessão, e portanto cada tipo de partícula tem associado a si uma frequência característica de precessão: essa frequência é chamada de frequência de Larmor devido a seu descobridor, Joseph Larmor [Wika].

A relação encontrada por Larmor entre a frequência da precessão e o campo magnético externo é [BO]:

$$
\omega=-\gamma B
$$

Aonde $\omega$ é a frequência angular da precessão, $\gamma=\frac{-q}{2 m}$ é uma constante (aonde $q$ é a carga da partícula considerada, e $m$ é sua massa) chamada constante giromagnética, e $B$ é a magnitude do campo magnético externo[Wika] [JBB09] [PL06] [Sli10].

\subsubsection{Ressonância Magnética}

As partículas com spin podem absorver e emitir fótons que tenham energia igual à diferença energética entre os estados paralelo e antiparalelo de sua precessão. Quando a partícula está no

\footnotetext{
${ }^{4}$ Podemos imaginar dois ímãs, com seus pólos lado a lado. O estado paralelo desse sistema é quando os dois pólos norte estão juntos, e o estado antiparalelo é quando os pólos opostos estão juntos.
} 
estado mais energético, o paralelo, ela pode emitir um fóton ${ }^{5}$ e dessa forma mudar sua orientação para antiparalela. Analogamente, as partículas no estado menos energético, o antiparalelo, podem absorver um fóton e mudar sua orientação para o estado paralelo [Lev08] (cf. figura 2.3).

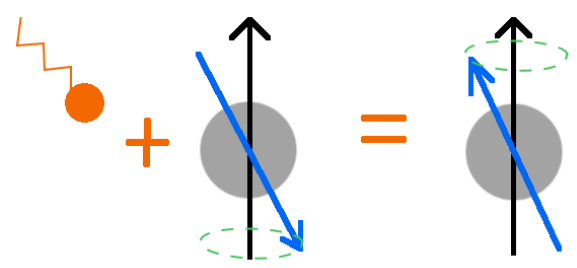

Figura 2.3: Ilustração esquemática de duas partículas com spin, uma precessando paralelamente e outra antiparalelamente à direção do campo externo. As flechas azuis indicam a direção do momento magnético associado ao spin, as flechas pretas indicam a direção do campo magnético externo, e as curvas tracejadas verdes indicam o caminho da precessão para a "ponta" das flechas verdes. O fóton (laranja) é absorvido e a partícula muda do estado antiparalelo para o estado paralelo.

Estes fenômenos de absorção e emissão de energia podem ocorrer espontaneamente em qualquer partícula de uma amostra. Quando consideramos a absorção e emissão de fótons por meio da RM para uma população de spins com um número grande de partículas (tal como em toda amostra macroscópica), o processo pode ser descrito por meio da física estatística, que nos indica que para certas condições externas constantes (temperatura, pressão, volume e campo magnético) os dois grupos da população atingem um equilíbrio dinâmico, no qual a diferença entre o número de spins paralelos e antiparalelos ao longo do tempo é aproximadamente constante.

Num sistema em equilíbrio, na ausência de campo magnético externo, as orientações dos spins estarão distribuídas de maneira isotrópica, isto é, sem privilegiar nenhuma direção específica. A figura 2.2 ilustra este caso.

Se um campo magnético intenso é aplicado nessa amostra, os spins irão reorientar-se de modo a precessar em torno desse campo, conforme ilustrado na figura 2.4.

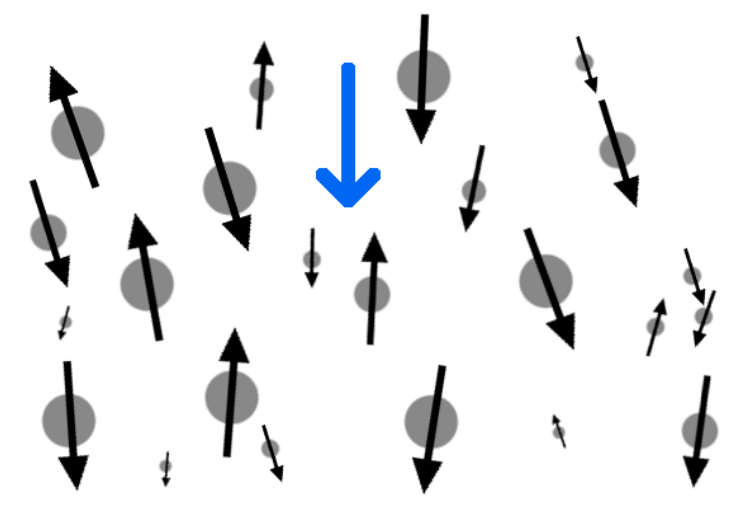

Figura 2.4: Conjunto de spins precessando em torno da direção de um campo externo intenso e homogêneo. A flecha azul indica a direção do campo. Note que os spins formam pequenos ângulos com relação à direção do campo. Mas para uma população de spins, as contribuições perpendiculares ao campo tendem a se cancelar mutuamente. Portanto, a magnetização de um spin packet seria de mesma direção que o campo.

Durante a aquisição de imagens de RM, aplica-se nas amostras ao menos um pulso de radiação eletromagnética, que poderia ser descrito microscopicamente como um "banho" de fótons na amostra. Uma vez que esse pulso é gerado sob nosso controle, podemos escolher a energia dos fótons que

\footnotetext{
${ }^{5}$ Os fótons que podem ser absorvidos ou emitidos têm uma energia que é proporcional ao campo magnético externo. Isto foi investigado por Pieter Zeeman, e por isso tem o nome de efeito Zeeman[Lev08].
} 
irão banhar a amostra. Iremos escolher um valor idêntico para todos os fótons (i.e., iremos aplicar uma onda monocromática $)^{6}$, e com a energia correta para gerar mudanças de orientação nos spins dos hidrogênios das moléculas de água.

O "banho" de fótons dura um intervalo de tempo definido pelo operador da máquina de RM. Após este banho começar, a diferença numérica entre a população de spins paralela e antiparalela diminui $^{7}$, pois a energia dos fótons é absorvida gerando mudanças de orientação nos spins, de modo a aumentar a população paralela. Quando o pulso termina, a amostra retorna gradativamente a seu estado de equilíbrio, e este processo implica na perda de energia da amostra, que ocorre ao menos em parte por meio do aumento na diferença entre a população de spins com orientação paralela e antiparalela.

Atribuiremos um vetor $M$ correspondente à direção e magnitude da soma dos momentos magnéticos de uma amostra; esse vetor é chamado de vetor de magnetização da amostra. Supomos que esse vetor está paralelo à direção do campo principal, quando a amostra está em repouso. A aplicação de Rádio Frequência (RF, ou Radio Frequency) na amostra resulta em uma rotação do vetor $M$ no espaço tridimensional, em torno de um eixo ortogonal ao eixo da direção do campo magnético (cf. a figura 2.5).
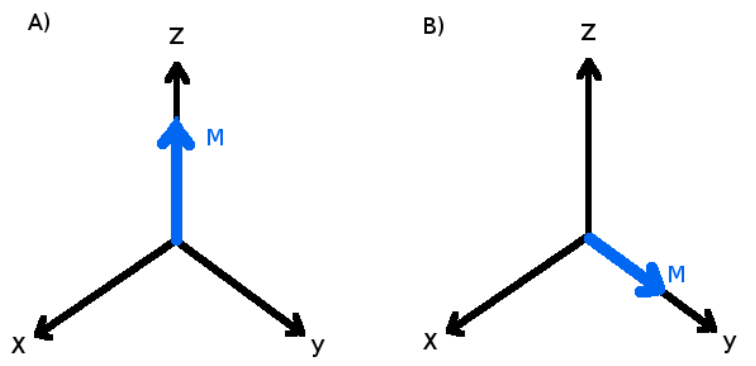

Figura 2.5: $O$ vetor de magnetização $M$. Em A) $M=M_{z}$. Após um pulso de $90^{\circ}$, em B) $M=M_{x y}$.

\subsubsection{A taxa de relaxamento $T_{2}$}

Representamos o campo magnético externo ${ }^{8}$ com o vetor $B_{0}$.

$\mathrm{O}$ vetor $M$ pode ser decomposto em dois componentes: um componente paralelo a $B_{0}$ e um componente ortogonal a $B_{0}$. É usual identificar a direção de $B_{0}$ com o eixo $Z$, e portanto o componente ortogonal de $M$ pertence ao plano $X Y^{9}$. Esses componentes são denominados longitudinal e transversal, respectivamente (cf. figura 2.5).

A cada um destes componentes correspondem fenômenos de relaxamento da magnetização da amostra, ou seja, fenômenos que transformam parte da energia magnética em calor. Cada um destes fenômenos corresponde a uma "taxa de relaxamento".

A taxa de relaxamento transversal ( $T_{2}$, também chamada taxa de relaxamento spin-spin) corresponde à dispersão dos spins individuais, do estado inicial em que todos têm a mesma fase, para

\footnotetext{
${ }^{6}$ Esta descrição corresponde mais adequadamente ao experimento CW (Onda Contínua, ou Continuous Wave), que não é comumente utilizado para obter imagens de RM por ser muito mais demorado do que o método de aplicar um pulso de um intervalo de frequências e depois identificar cada contribuição individual por meio de Transformadas inversas de Fourier (iFT ou inverse Fourier Transform). Entretanto, o método CW é de mais simples explicação.

${ }^{7}$ Em equilíbrio, a população de spins com orientação antiparalela é sempre maior que a população de spins com orientação paralela, pois este segundo estado é mais energético que o primeiro, e a matéria em equilíbrio tende ao estado de menor energia.

${ }^{8}$ Supomos que o campo magnético externo é constante e homogêneo.

${ }^{9}$ É comum utilizar um eixo $Z$ que rotaciona com a mesma velocidade angular que a frequência de Larmor, pois nesse caso os componentes transversais de $M$ permanecem estacionários, a menos de mudanças de fase. Adotaremos esse esquema, e remetemos o leitor à bibliografia para uma explicação detalhada [Sli10] [Lev08].
} 
o estado de equilíbrio no qual as fases se distribuem homogeneamente ${ }^{10}$. Um modelo matemático que descreve esse relaxamento é [PL06] [FR81] [Lev08] [JBB09]:

$$
M_{x y}(t)=M_{0} e^{-t / T_{2}}
$$

Aonde $M_{0}$ é a magnitude do vetor de magnetização no estado de equilíbrio, e $t$ é o tempo decorrido desde o banho de fótons na amostra até a medição do sinal ${ }^{11}$.

Uma imagem de RM é dita "ponderada por $T_{2}$ " quando cada ponto dessa imagem tem intensidade proporcional ao relaxamento $T_{2}{ }^{12}$. Essencialmente, isto é feito por meio de uma configuração da máquina de $\mathrm{RM}^{13}$ em que o sinal é adquirido num instante após o fim da aplicação da RF. Se a amostra conter partículas com diferentes suscetibilidades ao relaxamento spin-spin, isso resultará em diferenças de intensidade nos pontos da "imagem $T_{2}$ " final.

\subsubsection{Resolução espacial de imagens de RM}

A resolução de uma imagem tridimensional de RM é usualmente quantificada pelo volume do espaço que cada voxel da imagem representa. Quanto menor o volume representado por cada voxel, mais precisa é a representação.

Uma vez que as imagens de RM são produzidas por máquinas, sua resolução é limitada pelas capacidades do aparelho, e pela configuração específica empregada para adquirir a imagem. O limite de resolução da RM está vinculado à relação entre a magnitude do sinal de ressonância gerado pela amostra e a magnitude do ruído eletromagnético local. A magnitude do sinal de ressonância gerado pela amostra, por sua vez, é relacionado ao tempo de aquisição da imagem de cada ponto, à intensidade dos campos e gradientes magnéticos, e da intensidade das antenas usadas para emitir e detectar RF.

\subsubsection{A sequência de pulso Spin Echo}

A sequência de pulso de Eco de Spins (SE, ou Spin Echo) é caracterizada pelo uso de dois pulsos de RF adicionais (com relação a uma sequência sem eco). A função do primeiro desses pulsos é fazer com que o vetor de magnetização $M$ se desloque 90 graus com relação à direção do campo $B_{0}$. Após um intervalo de tempo, os efeitos de relaxamento spin-spin irão ocorrer (relaxamento $T_{2}$ ), e os spins deixarão de estar em fase, devido a pequenas diferenças entre os campos efetivos locais. Após um tempo denominado $\tau$, é aplicado o segundo pulso, que tem por finalidade rotacionar os vetores dos spins 180 graus no plano $x y$.

Desta forma, os spins que entre o primeiro e o segundo pulso modificaram sua fase, irão agora modificá-la novamente, mas com sentido oposto. Supondo que eles estejam sujeitos a campos magnéticos locais constantes (apesar de diferentes entre si), cada spin irá "retornar" à sua fase original em um intervalo de tempo $\tau$. Portanto, os spins após um intervalo $2 \tau$ irão estar todos com a mesma fase, e por isso o sinal gerado nesse instante é chamado um "eco" do sinal original.

Enquanto a Razão entre Sinal e Ruído (SNR, ou Signal to Noise Ratio) for suficientemente alta, é possível aplicar outros pulsos de 180 graus, e dessa forma obter diversos "ecos" sequencialmente.

Este mecanismo básico é utilizado para compor diversos tipos de sequências de pulso, parametrizados por diferentes intervalos de tempo para os pulsos, leitura e seleção de fases e frequências. As sequências de pulsos das imagens de difusão por RM utilizam Spin Echo.

\footnotetext{
${ }^{10} \mathrm{~A}$ fase dos spins corresponde ao componente ortogonal de $M$. Logo após a aplicação de RF, todos os spins têm aproximadamente a mesma direção. Porém, a direção do componente ortogonal de cada spin irá modificar-se devido a pequenas variações no campo magnético local de cada partícula.

${ }^{11}$ Como podemos medir $M_{0}$ e $M_{x y}$, podemos calcular $T_{2}$.

${ }^{12}$ Também é usual denominar este tipo de imagens "estruturais".

${ }^{13}$ Uma dada "classe" de configurações de uma máquina de RM é chamada sequência de pulsos.
} 


\subsection{Imagens de Difusão por RM}

O primeiro modelo matemático que descreve a ressonância magnética contemplando fenômenos de difusão de massa foi desenvolvido por Bloch [Blo46], e posteriormente adaptado por Torrey [Tor], cuja versão foi reformulada por Abragam [Abr61]. Este último modelo serviu de base para o desenvolvimento teórico de Tanner e Stejskal [ST65]. No Apêndice A apresentamos uma breve descrição das equações de Bloch e de Torrey.

Por simplicidade, vamos considerar apenas imagens que consistem em um único ponto, e supor que imagens compostas por muitos pontos sejam apenas repetições de um procedimento equivalente. Isso pode ocorrer, mas foram desenvolvidas muitas técnicas para otimizar esses processos, que estão fora do escopo desta dissertação. Para uma compreensão de como se dá a aquisição de uma imagem de vários pontos, remetemos o leitor à bibliografia.

A difusão por RM pode medir deslocamentos de moléculas de água no intervalo de aproximadamente 5 a 10 micrômetros, por intervalos de tempo de dezenas de milissegundos [Bea].

Geometricamente, a aquisição da difusão por RM é sensível à direção de mensuração. Especificamente, cada sequência de pulsos individual pode medir com precisão significativa a difusão da água em apenas uma direção. A medição numa direção específica corresponde ao ADC da substância naquela direção.

Ao medirmos o ADC em várias direções ${ }^{14}$ podemos calcular a direção de difusividade máxima, e a diferença entre o máximo e o mínimo da magnitude da difusão. Essa diferença é usualmente medida por meio do cálculo da Anisotropia Fracionada.

Realizando em rápida sucessão aquisições similares em ao menos seis direções, é possível construir um mapa das direções de máxima difusividade da água em cada ponto da imagem. Ao fazer isso para todo um volume de uma amostra, pode-se obter um mapa tridimensional que indica as trajetórias prováveis da água dentro do volume.

\subsubsection{A sequência de pulsos de Stejskal e Tanner}

Os pesquisadores Tanner e Stejskal publicaram dois trabalhos seminais sobre a difusão por RM: em 1965 publicaram um modelo matemático e sua análise [ST65], e em 1968 descreveram os resultados de alguns experimentos e sua concordância com a teoria [TS68 $]^{15}$.

Além do desenvolvimento da teoria suportando a noção de que é possível detectar a difusão da água por meio da magnetização de uma amostra, Stejskal e Tanner desenvolveram uma sequência de pulsos para RM que permite medir a difusão (especificamente, que permite medir a atenuação do sinal, em comparação a um sinal sem atenuação por difusão) ${ }^{16}$.

A sequência de Tanner e Stejskal também é conhecida como Ecos de Spin por Pulso de Gradiente $^{17}$ (PGSE, ou Pulsed Gradient Spin Echo). A "partitura" desta sequência está ilustrada na figura 2.6.

O mecanismo essencial de funcionamento desta sequência consiste na aplicação dos dois pulsos de gradiente, o primeiro entre as duas aplicações de RF de "rotação em torno do eixo ortogonal" (flip), e o segundo pulso aplicado após o segundo flip. O primeiro pulso irá modificar o campo magnético da amostra por um intervalo de tempo $\delta$, e uma vez que esse campo é variável no espaço (ou seja, é um gradiente), os spins terão suas fases modificadas, de acordo com sua posição e com a taxa de variação do gradiente.

Entre o primeiro e o segundo pulsos de gradiente, é aplicada a RF de flip de $180^{\circ}$. Dessa forma, a fase acumulada devido à aplicação do primeiro pulso é invertida. Uma vez que o segundo pulso é idêntico ao primeiro, seu efeito será, para partículas estacionárias, o de anular os efeitos do primeiro

\footnotetext{
${ }^{14}$ Usualmente, algumas dezenas de direções.

${ }^{15}$ Note que estes autores sublinham a importância de pesquisas similares de outros autores, na introdução de seus dois artigos. Eles também revezaram a ordem de seus nomes nos papers.

${ }^{16}$ Decidimos apresentar estes dois resultados na sua ordem histórica inversa, por considerar que o entendimento qualitativo da sequência de pulsos é mais intuitivo, e serve como esquema para a análise da equação que descreve essa sequência.

${ }^{17}$ Tradução livre, nossa. O termo geralmente encontrado na literatura é PGSE.
} 

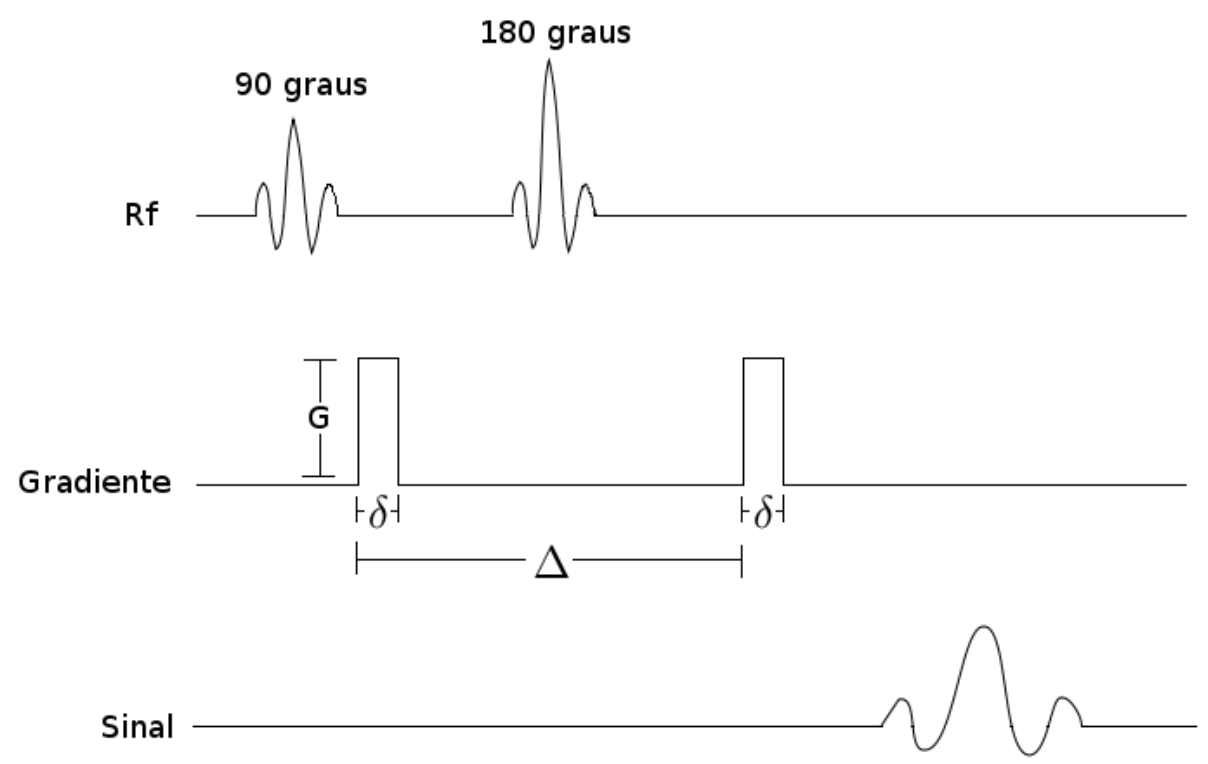

Figura 2.6: "Partitura" simplificada da sequência de pulsos de Stejskal-Tanner. Adaptação de uma figura de Basser e Ozarslan [BO].

pulso (pois suas fases foram invertidas pela aplicação da RF de flip de $180^{\circ}$ ). Por outro lado, as partículas que tiverem transladado ao longo da direção do gradiente, terão uma discrepância no acúmulo da fase devida ao primeiro e ao segundo pulsos de RF terem sido aplicados em campos efetivos ligeiramente diferentes.

Essa discrepância correponde a uma atenuação do sinal, quando o equipamento está sintonizado para receber sinal da região da qual essas partículas partiram. Em outras palavras, o sinal obtido em resposta a esta sequência terá atenuação proporcional à quantidade de spins que tenham transladado.

\subsubsection{A equação de Tanner e Stejskal}

A partir da versão de Abragam [Abr61], que reescreveu as equações de Torrey, Stejskal e Tanner desenvolveram uma teoria e metodologia para medir a difusão de massa por meio de experimentos utilizando equipamentos de RM em seu paper de 1965 [ST65]. Estes autores derivaram a seguinte equação, que descreve a atenuação de um sinal de RM quando há difusão de massa:

$$
\ln \left[\frac{A\left(\tau^{\prime}\right)}{A(0)}\right]=-\gamma^{2} D\left[\int_{0}^{\tau^{\prime}} F^{2} d t-4 f \int_{\tau}^{\tau^{\prime}} F d t+4 f^{2}\left(\tau^{\prime}-\tau\right)\right]
$$

Aonde $A(t)$ corresponde à amplitude do sinal de ressonância no instante $t$, D é o coeficiente de difusão aparente, $\tau^{\prime}$ é o intervalo entre a sensibilização da amostra e o eco, $\tau=\frac{\tau^{\prime}}{2}$, e as funções $f$ e $F$ são dadas por:

$f=F(\tau)$

$F(t)=\int_{0}^{t} G\left(t^{\prime}\right) d t^{\prime}$

Sendo que a função $G$ é dada por:

$$
\begin{array}{llrll}
g_{0} & \text { se } & 0<t<t_{1} \\
g_{0}+g & \text { se } & t_{1}<t<t<t_{1}+\delta>\tau \\
g_{0} & \text { se } & t_{1}+\delta<t<t_{1}+\Delta>\tau \\
g_{0}+g & \text { se } & t_{1}+\Delta<t<t_{1}+\Delta+\delta<2 \tau \\
g_{0} & \text { se } & t_{1}+\Delta+\delta<t
\end{array}
$$

Aonde $\delta$ e $\Delta$ correspondem aos intervalos de tempo de duração do pulso do gradiente, e do intervalo entre os dois lóbulos dos pulsos de gradiente, respectivamente (cf. figura 2.6). $g_{0}$ é a 
intensidade do campo magnético principal, e $g$ é a intensidade do campo magnético auxiliar (o campo do gradiente).

Podemos interpretar esta equação da seguinte forma: uma vez que $A(0)$ é a amplitude na ausência de gradiente de difusão, e $A\left(\tau^{\prime}\right)$ é a amplitude durante o máximo de eco, a fração $\frac{A\left(\tau^{\prime}\right)}{A(0)}$ representa o efeito da difusão sobre a amplitude do eco de uma sequência Spin Echo. Este valor é numericamente igual ao produto da suscetibilidade da amostra ao campo magnético (constante giromagnética) pela difusão que ocorre na direção do campo auxiliar, pela integral do tempo em que a amostra está efetivamente sob o campo auxiliar.

Portanto, se estivermos de posse dos parâmetros $\gamma, g_{0}, \tau, \tau^{\prime}, \delta, \Delta, A\left(\tau^{\prime}\right)$ e $A(0)$, podemos calcular o valor de $D$, ou seja, do ADC, por meio desta equação.

\subsubsection{Relação entre difusividade e sinal nas imagens de difusão por RM}

No caso específico das imagens de difusão por RM, a escala de mensuração da difusão de massa é usualmente codificada pelo chamado fator b (ou b-value) [JBB09]:

$$
b=\gamma^{2} G^{2} \delta^{2}\left(\Delta-\frac{\delta}{3}\right)
$$

Aonde $G$ é a magnitude do gradiente magnético aplicado durante a sequência de pulsos de difusão, $\delta$ é a duração dos pulsos do gradiente magnético, e $\Delta$ é o intervalo entre o início de cada um dos dois pulsos aplicados.

Valores típicos do b-value para imagens cerebrais são da ordem de $b \approx 1000 \mathrm{~s} / \mathrm{mm}^{2}$ [BAJA12].

Ainda que o b-value seja proporcional a quanto a imagem final será ponderada pela difusão, sequências utilizando b-values pequenos (i.e., menores que $100 \mathrm{~s} / \mathrm{mm}^{2}$ ), são métodos importantes para o diagnóstico de Acidente Vascular Cerebral (AVC) isquêmico agudo, monitoramento de terapia anticâncer, detecção de persistência ou recorrência de tumores e avaliação de inflamações e infecções [TK12]. Mas quando o b-value é menor que $300 \mathrm{~s} / \mathrm{mm}^{2}$, o sinal medido terá um componente devido ao fluxo da água, além da difusão. 


\section{Capítulo 3}

\section{Metodologia}

As contribuições originais desta pesquisa consistem essencialmente nas ferramentas necessárias para concretizar a tarefa de síntese de imagens de difusão por ressonância. As aplicações realizadas da ferramenta (descritas no capítulo Resultados, p. 27 e no Apêndice D, p. 45) servem como provas de conceito da técnica desenvolvida.

O uso da ferramenta é restrito ao subconjunto de técnicas de imagens por RM em que as imagens de difusão são obtidas com sequências de pulso que sejam análogas à sequência PGSE. Por outro lado, não há restrição com relação às dimensões espaciais da amostra utilizada. As instruções de uso das ferramentas são apresentadas no Apêndice D (p. 45).

Devido ao seu custo computacional, executamos o sintetizador paralelamente num cluster. $\mathrm{O}$ número de processamentos paralelos é obtido dividindo o trabalho pelo número de slices da imagem original.

\subsection{Síntese de imagens de difusão}

Ilustramos abaixo (ver figura 3.1) um esquema simplificado dos passos para adquirir uma imagem de difusão por RM usando uma máquina de RM. O uso de um aparelho de RM é um assunto abrangente, sobre o qual iremos apenas mencionar que a especificação dos parâmetros que são usados na simulação $\left(\delta, \Delta, \tau, \tau^{\prime}, \gamma, g, g_{0}\right.$ e $\left.b\right)$ podem ser também especificados pelo operador do equipamento de RM. Também notamos que geralmente o operador procura encontrar um ponto de equilíbrio entre minimizar o tempo de aquisição e maximizar a qualidade da imagem. Portanto o esquema da figura 3.1 é simplificado, e se refere exclusivamente à sequência PGSE.

Para sintetizar uma imagem de difusão equivalente à gerada pela máquina de RM, partimos de uma imagem de RM de tipo $T_{2}$, e por meio de software, calculamos qual será a imagem de difusão por RM para um certo conjunto de parâmetros realísticos. Finalmente, confrontamos a imagem sintética com a imagem de difusão obtida usando parâmetros equivalentes num equipamento de RM.

Podemos visualizar o método para síntese de imagens de difusão por RM como sendo um "desvio" do fluxo de trabalho da aquisição de uma imagem de RM, que se diferencia do esquema regular a partir da imagem $T_{2}$ e retorna para os cálculos dos tensores de difusão (cf. figura 3.2).

Iremos agora descrever as duas etapas da técnica de síntese de imagens de difusão por RM.

\subsubsection{Criação de máscaras}

É através do mecanismo de máscara que o usuário do software especifica seu modelo de difusão para sua amostra.

Chamamos de máscara o arquivo gerado pelo programa denominado "mask_generator", e essa máscara consiste num arquivo em que, para cada voxel da amostra, há um conjunto de dados, a saber: a magnitude do sinal $T_{2}$, a magnitude do ADC, a razão entre a difusão principal e transversal, e os componentes ortogonais da direção principal de difusão. A figura 3.3 ilustra um exemplo o mais 


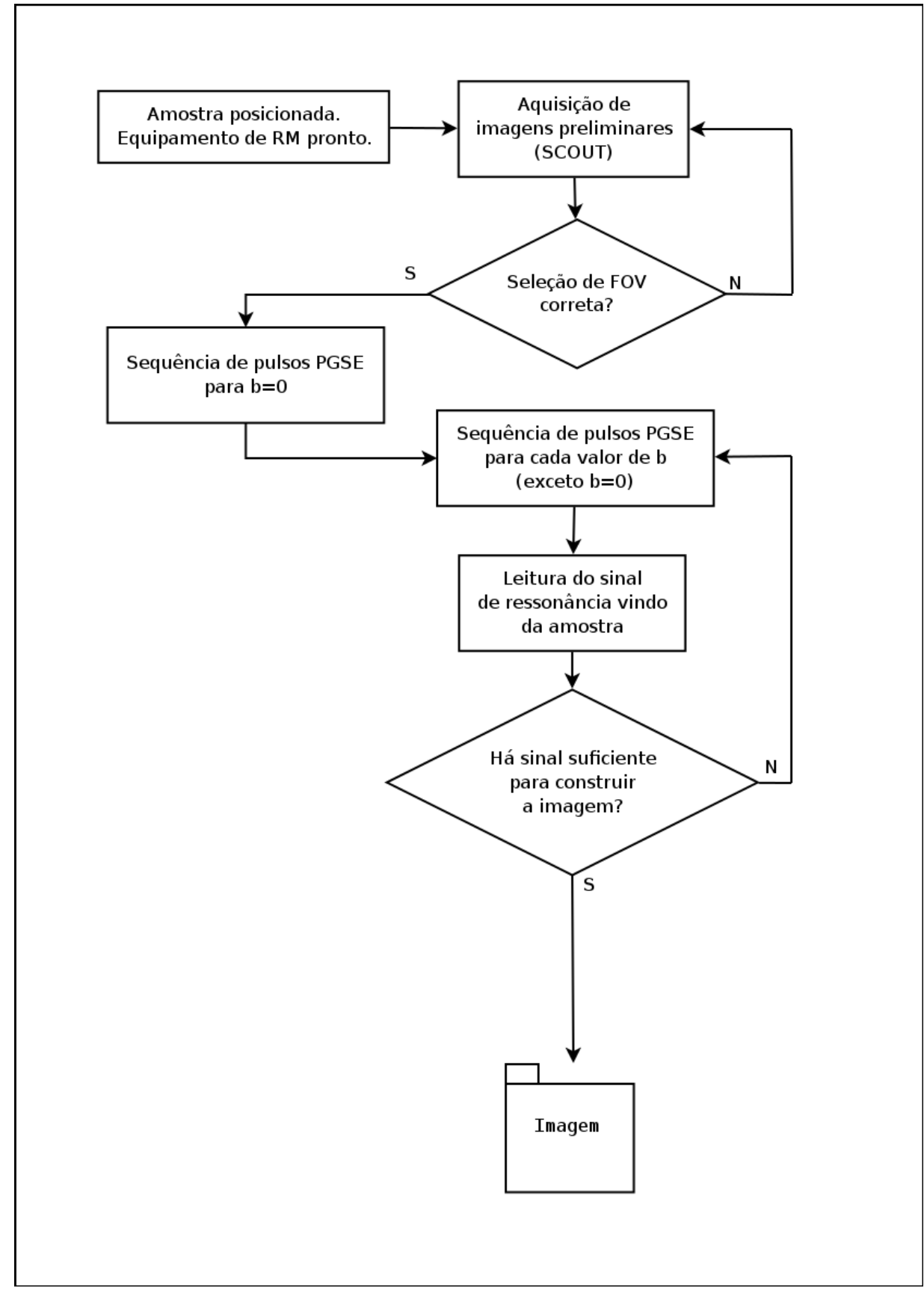

Figura 3.1: Esquema simplificado de uma aquisição de imagem de difusão por RM. Nas imagens em que $b=0$, não há informações sobre a difusão de água na amostra - estas informações são adquiridas somente quando há aplicação de gradientes de difusão (ou seja, quando b > 0). Uma vez obtidos dados suficientes, os tensores de difusão podem ser calculados, e a visualização das informações contidas nesses tensores nos permitem quantificar a difusão da água na amostra e sua direcionalidade.

simples possível de um arquivo de especificação de máscara, que corresponde a um prisma retangular com difusão isotrópica em seu interior.

A máscara é gerada por meio do "mask_generator" a partir de uma especificação de alto nível. Usamos a tecnologia de Linguagem de Marcação eXtensível (XML, ou eXtensible Markup Language) [W3C] para isto.

A importância de especificar a máscara por meio de um documento XML é dissociar essa especificação do código-fonte da simulação; para modificar parâmetros, ou desenhar uma máscara geometricamente diferente, basta editar o arquivo de configuração da máscara, sem exigir que o usuário edite os arquivos que contêm os algoritmos, ou que tenha de recompilar os arquivos 


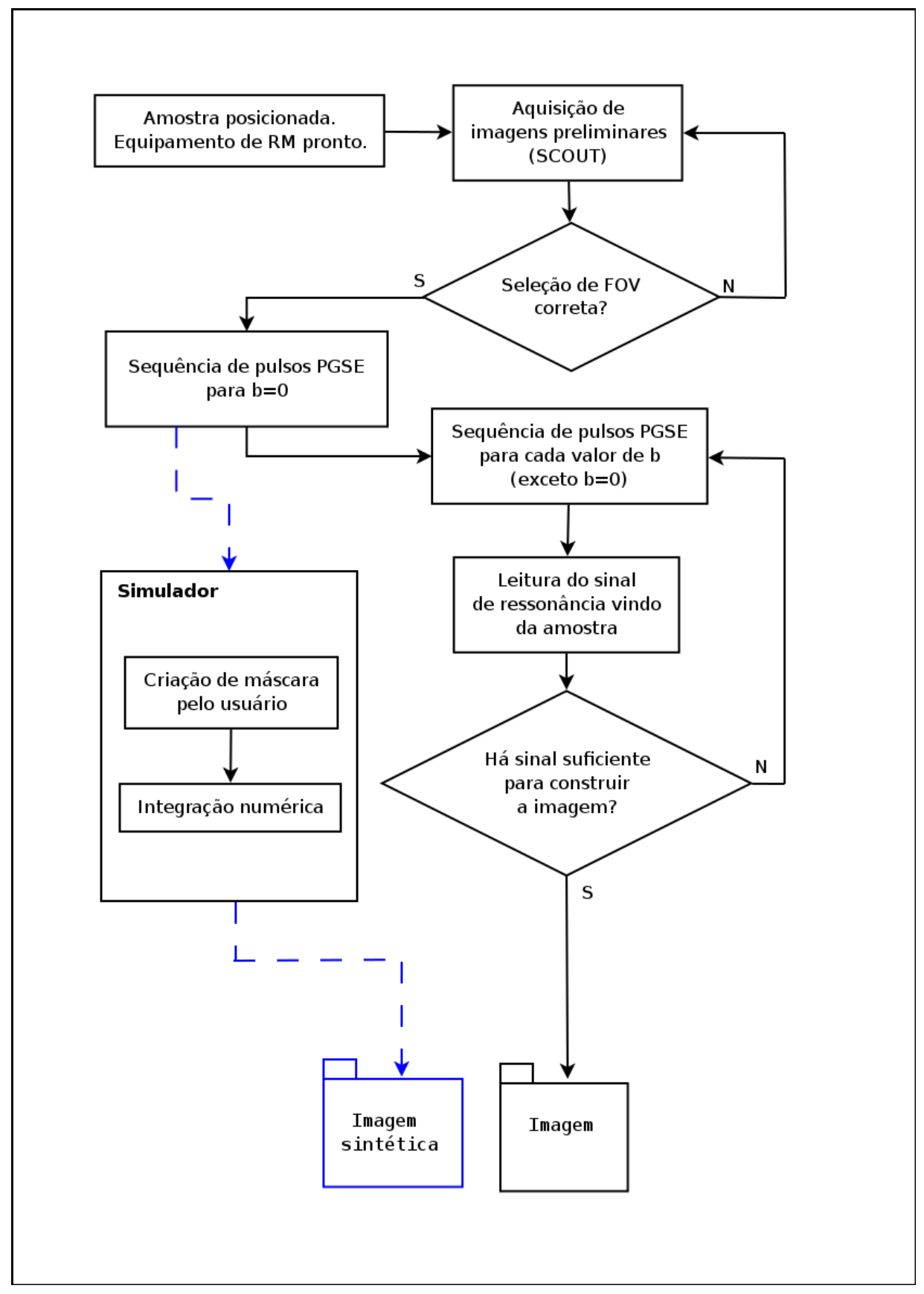

Figura 3.2: Esquema simplificado de uma aquisição e sintese de imagem de difusão por RM. As linhas tracejadas azuis indicam o fluxo de controle para a sintetização de imagens pelo simulador. Na sintetização de imagens de difusão por RM, substituímos o trecho mais demorado da sequência PGSE pela integração numérica de uma estrutura composta por uma máscara de direções, especificada pelo usuário, e pelas intensidades dadas pela imagem em que $b=0$.

executáveis.

\subsubsection{Relação entre máscaras e modelos de difusão}

Conceitualmente, é crucial entendermos a diferença entre uma máscara e um modelo de difusão.

Um modelo de difusão consiste numa descrição da difusão da água numa amostra. Esse modelo pode ser extremamente abstrato (por exemplo, "a amostra tem difusão isotrópica em todo o seu volume") ou pode ser extremamente concreta (por exemplo, uma descrição da direção e magnitude da difusão em cada voxel da amostra). Nossas ferramentas auxiliam o operador a sintetizar imagens a partir de modelos que o operador deverá elaborar por si mesmo, a partir de seu conhecimento a 


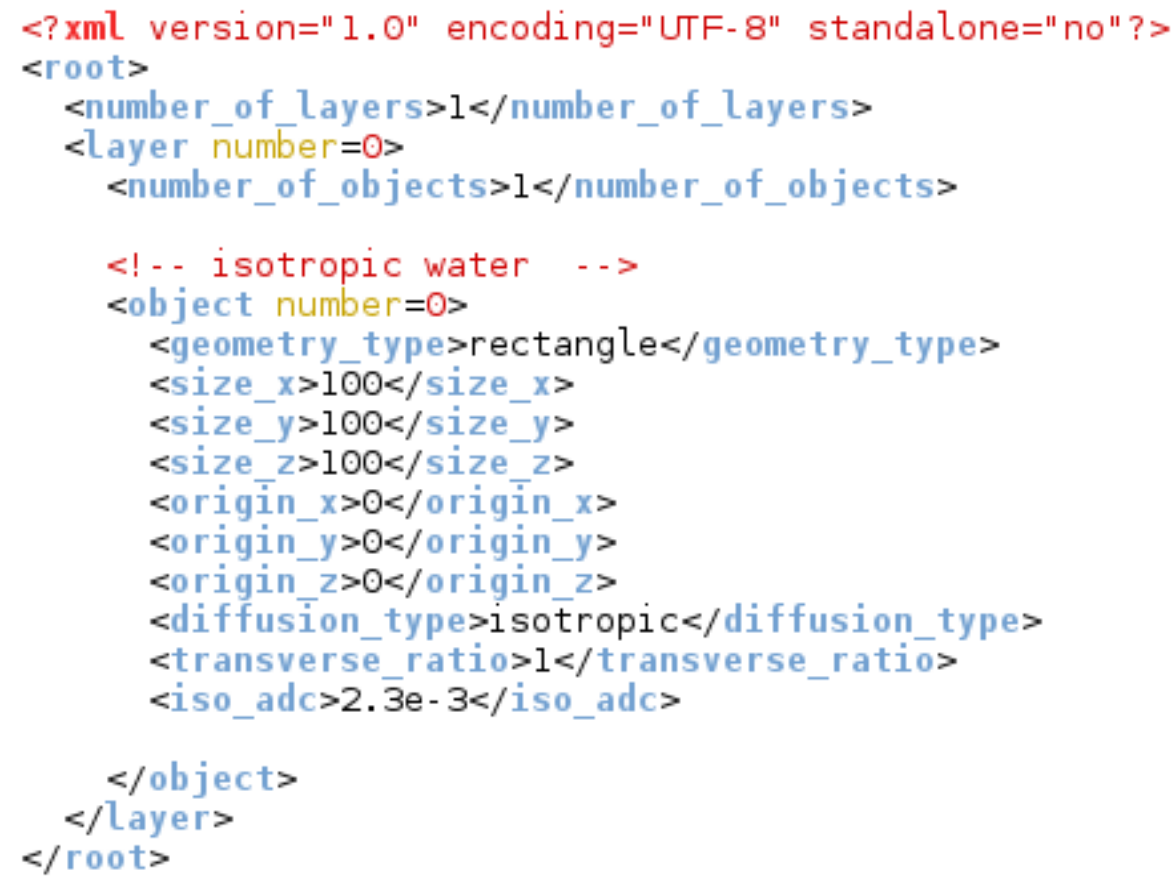

Figura 3.3: Especificação de uma máscara contendo um prisma retangular com água em difusão isotrópica.

respeito da amostra que pretende investigar.

Uma máscara de difusão, tal como desenvolvemos nesta pesquisa, corresponde a um modelo extremamente concreto de difusão. Em outras palavras, nossas máscaras de difusão especificam a direção e magnitude da difusão em cada voxel da amostra (além de conterem o sinal $T_{2}$ original).

Além de ser tedioso, escrever manualmente o arquivo de máscaras pode levar a erros, e o resultado seria de difícil compreensão. Além disso, supomos que os operadores do software terão inicialmente um modelo bastante abstrato da difusão em sua amostra, e que desejam sintetizar uma imagem de difusão a partir desse modelo abstrato, comparar os resultados com uma imagem de difusão equivalente, mas obtida por uma máquina de RM, e então aprimorar seu modelo, e reiniciar o processo. Dessa forma, nosso software é uma ferramenta para refinar modelos de difusão.

Por isso, escrevemos a ferramenta "mask_generator", que produz máscaras de difusão concretas a partir de descrições abstratas, desde que expressas no formato que iremos descrever na próxima seção. Dessa forma, se um operador define uma especificação de máscara que não preveja todos os valores concretos, nossa ferramenta poderá gerar as informações que faltam. Essa geração pode se dar de diversas maneiras. Por exemplo, cada voxel pode ter sua direção e magnitude de difusão copiada de valores padrão. A direção também pode ser sorteada aleatoriamente, ou pode ter uma direção específica, e um sorteio de quanto divergir dessa direção ${ }^{1}$.

\subsubsection{Estrutura da especificação de máscaras}

Uma especificação de máscara consiste essencialmente em coleções de sólidos geométricos. Cada coleção é denominada camada (layer) e cada sólido é denominado objeto (object). As camadas e objetos são especificados sequencialmente, e cada objeto sobreescreve os anteriores, caso exista sobreposição dos sólidos. Cada objeto pode especificar o tipo, a magnitude e a direção da difusão em seu interior.

\footnotetext{
${ }^{1}$ I.e., o operador pode especificar um "valor de divergência" (fudge factor). O padrão da ferramenta é usar o valor 0 (zero) para o fudge factor.
} 
Cada objeto pode ter sua posição e tamanho especificados. Os objetos podem ser prismas retangulares ou cilíndricos. O tipo de difusão pode ser isotrópica ou anisotrópica, e neste caso, a direção de difusão deve ser especificada.

$\mathrm{O}$ valor do ADC deve ser especificado para cada objeto. Opcionalmente, podemos especificar valores de corte (threshold) para que a máscara só seja aplicada nos voxels em que o sinal $T_{2}$ estiver dentro de certos limites.

\subsubsection{Geração da máscara a partir de sua especificação}

A geração da máscara é iniciada criando uma matriz tridimensional, aonde cada valor inicial é nulo. Em seguida, o arquivo XML é lido, e a cada objeto especificado nesse arquivo, essa matriz é atualizada ${ }^{2}$.

Todo objeto tem de ter especificada a magnitude do ADC da água no seu interior.

Quando um objeto da especificação tem difusão do tipo "anisotropic", ele deve especificar os componentes cartesianos da direção principal de difusão. O "mask_generator", ao encontrar este objeto, irá copiar esses componentes cartesianos em cada voxel da região delimitada por esse objeto, e portanto os objetos desse tipo podem ser considerados como modelos determinísticos de difusão.

Um objeto da especificação pode ter tipo de difusão "isotropic", e nesse caso o "mask_generator" irá, a cada voxel da região delimitada por esse objeto, sortear os componentes cartesianos de sua direção de difusão, por meio do algoritmo 3.1:

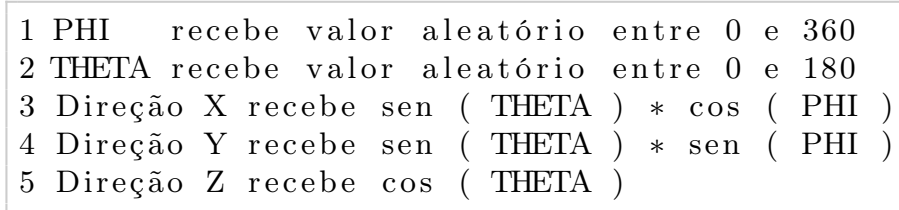

Listagem 3.1: Algoritmo que gera versores pseudoaleatórios.

\subsubsection{Visualização das projeções da máscara}

O programa gerador de máscaras produz, além do arquivo da máscara propriamente dito, que não é facilmente visualizável, três arquivos auxiliares: projeções da máscara para os eixos cartesianos X, Y e Z. Cada uma é um arquivo binário que tem apenas a magnitude da projeção da direção de difusão nessa direção em cada voxel. Esses três arquivos podem ser visualizados em softwares de visualização de imagens, como BioImage $\left[\mathrm{PJR}^{+}\right]$ou MedSquare [JMea]. Dessa forma, é possível verificar que a máscara corresponde ao desenho pretendido (cf. figuras 3.5, 3.6 e 3.7) ${ }^{3}$.

Elaboramos um exemplo didático a partir do layout ilustrado na figura ??.

Na figura 3.5, criamos uma especificação de máscara com uma única camada, e um único objeto, um prisma retangular com difusão isotrópica e $\mathrm{ADC}$ de valor 1, e que ocupa todo o volume da imagem $^{4}$. As imagens das projeções ortogonais desta máscara parecem ser apenas ruído. Isto é esperado, pois cada imagem é um corte de uma projeção ortogonal do vetor de difusão, que foi, a cada voxel, sorteado aleatoriamente. Como será mostrado adiante, regiões anisotrópicas das projeções da máscara não aparentam ser ruído, tal como esperado.

Em seguida, cf. figura 3.6, adicionamos um segundo objeto dentro dessa especificação de máscara, um prisma retangular com $\mathrm{ADC}=5$ e difusão anisotrópica. Podemos notar que as imagens agora parecem indicar duas regiões com ruído, mas uma delas (a mais interna) mais brilhante que a outra. Esse é o resultado esperado, pois o objeto mais interno tem difusão isotrópica (e portanto a projeção ortogonal de seus vetores de difusão deve parecer ruído) e tem ADC maior que o ADC da região

\footnotetext{
${ }^{2}$ Portanto, se quisermos modelar um volume de ar que contém um volume de água que contém um volume de tecido, especificamos os objetos nessa ordem, para que os objetos menores sobreescrevam parte dos objetos maiores.

${ }^{3}$ Estas figuras foram visualizadas no software MedSquare [JMea], usando os seguintes parâmetros de visualização: Window $=4.0$, Level $=1.0$, Opacity $=1.0$.

${ }^{4}$ As máscaras criadas nesta seção foram produzidas com base numa imagem com geometria 128 x 128 x 56 .
} 


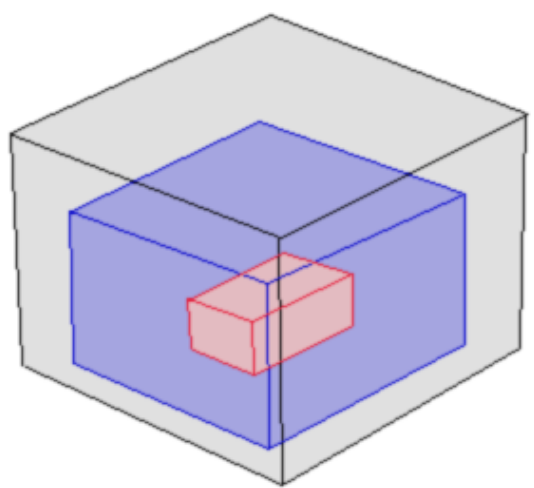

Figura 3.4: Esboço do exemplo a ser sintetizado: três prismas retangulares de diferentes tamanhos, cada um contendo os prismas que forem menores.
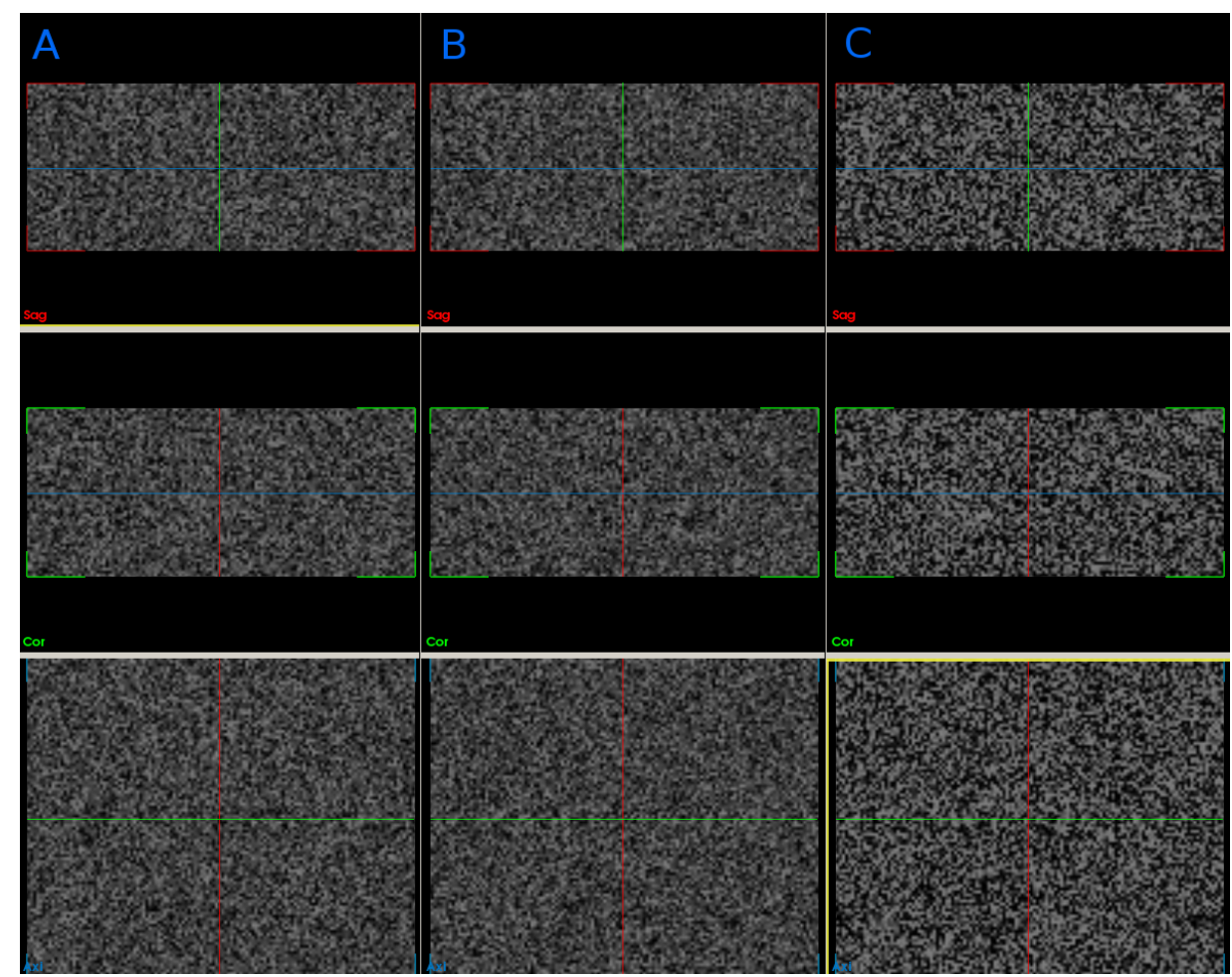

Figura 3.5: Coleção organizada em colunas de imagens das projeções ortogonais de máscara com especificação de um único objeto com $A D C=1$ e difusão isotrópica. A) Projeção da máscara no eixo X. B) Projeção da máscara no eixo $Y$. C) Projeção da máscara no eixo $Z$.

mais externa (e portanto suas projeções ortogonais devem ter, em média, magnitudes maiores que as magnitudes, em média, da região mais externa. Por isso, parece mais brilhante).

Finalmente, a figura 3.7 ilustra as projeções da máscara com especificação de máscara contendo três objetos: os mesmos dois objetos da figura anterior, e um prisma retangular com ADC $=10$ e difusão anisotrópica, com direção preferencial paralela ao eixo Z (coluna C nas imagens).

Novamente, as imagens desta figura são o resultado esperado. A região mais interna parece ter um sinal homogêneo, e isso é esperado pois as projeções de seus vetores de difusão são todas 


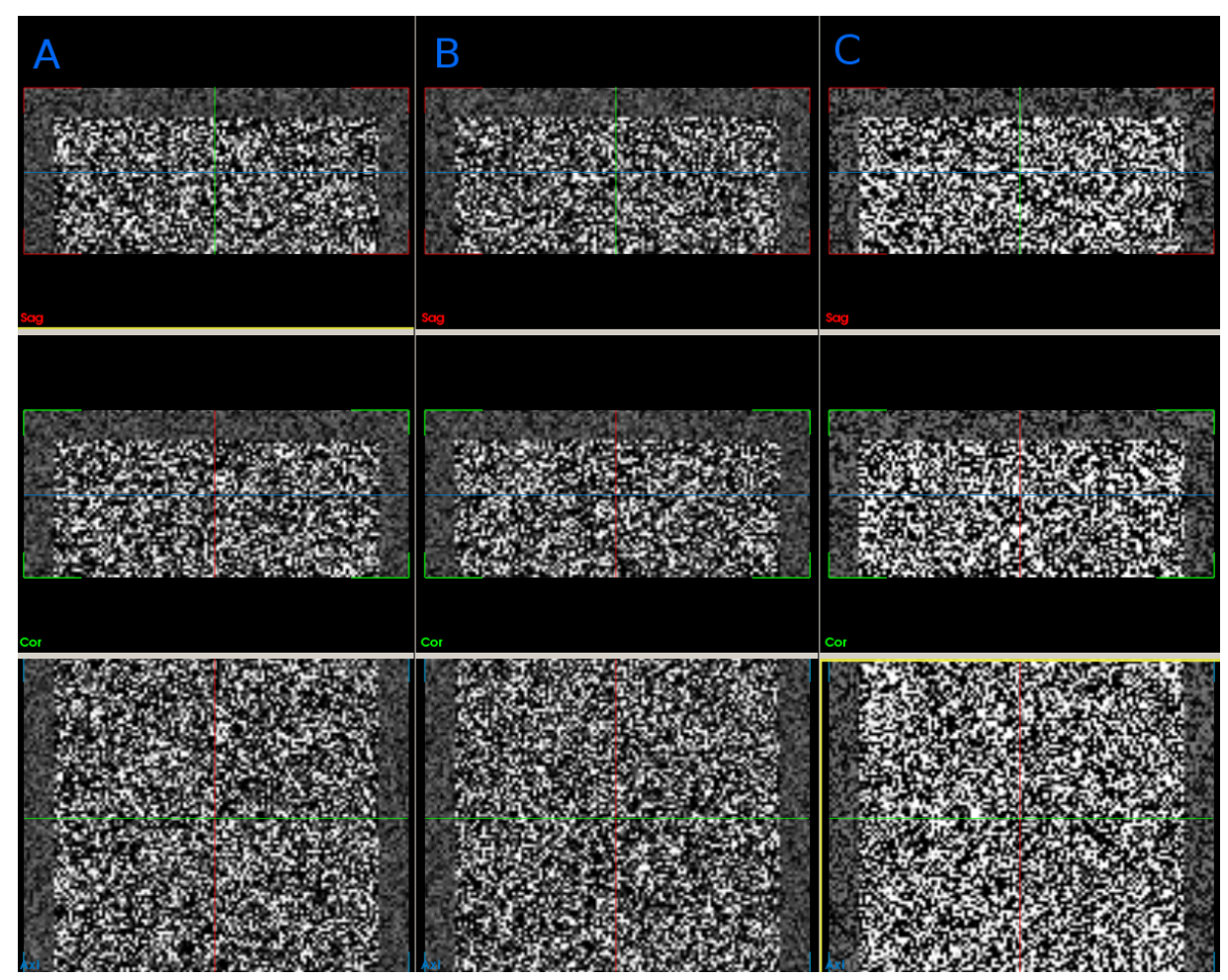

Figura 3.6: Coleção organizada em colunas de imagens das projeções ortogonais de máscara com especificação de um objeto com $A D C=1$ e difusão isotrópica, e um objeto com $A D C=5$ e difusão isotrópica, contido no anterior. A) Projeção da máscara no eixo X. B) Projeção da máscara no eixo Y. C) Projeção da máscara no eixo $Z$.

de mesma magnitude em todos os voxels, uma vez que seus vetores de difusão são todos iguais. A projeção no eixo $\mathrm{Z}$ é mais brilhante que as projeções nos eixos $\mathrm{X}$ e $\mathrm{Y}$ (que são aparentemente iguais), e isso é o resultado esperado de todos os vetores de difusão desse objeto terem magnitude muito maior no eixo $\mathrm{Z}$ do que nos eixos $\mathrm{X}$ e $\mathrm{Y}$ (que têm magnitudes iguais em todos os vetores).

Esta série de imagens mostra as projeções da máscara de direções, e sugerimos que sejam interpretadas da seguinte forma: a figura 3.5 ilustra que para um objeto da especificação de máscara aonde a difusão seja isotrópica, as máscaras são produzidas de modo a terem, em cada voxel, uma direção aleatória, com magnitude igual à do ADC especificado pelo operador. A figura 3.6 ilustra que a composição de objetos de uma especificação de máscara se dá por sobreposição, que pode ser vista pela diferença de contraste entre as duas regiões das imagens, devida à diferença dos ADCs usados pelo operador. A terceira série de imagens demonstra que um objeto da especificação de máscara que tenha difusão anisotrópica terá diferenças perceptíveis entre as imagens das projeções axiais de sua máscara. A região mais interna na coluna $\mathrm{C}$ da imagem 3.7 é mais brilhante que a mesma região nas colunas A e B (que têm intensidades equivalentes entre si) devido à direção do vetor de difusão especificado pelo usuário: $(x=0.1, y=0.1, z=0.9)$ para o objeto mais interno da especificação de máscara.

\subsubsection{Simulação computacional}

Conforme indicado nos capítulos Introdução (p. 1) e Teoria (p. 7), o que é medido através da técnica de imagens de difusão por RM é a atenuação do sinal de RM que ocorre numa certa direção, quando aplicamos um gradiente magnético, com relação ao sinal original, que é medido sem o gradiente.

A equação de Stejskal e Tanner (equação 2.1, p. 14) nos permite calcular essa diminuição do sinal, em uma direção específica.

O resultado do programa gerador de máscaras é um conjunto de dados para cada voxel da 

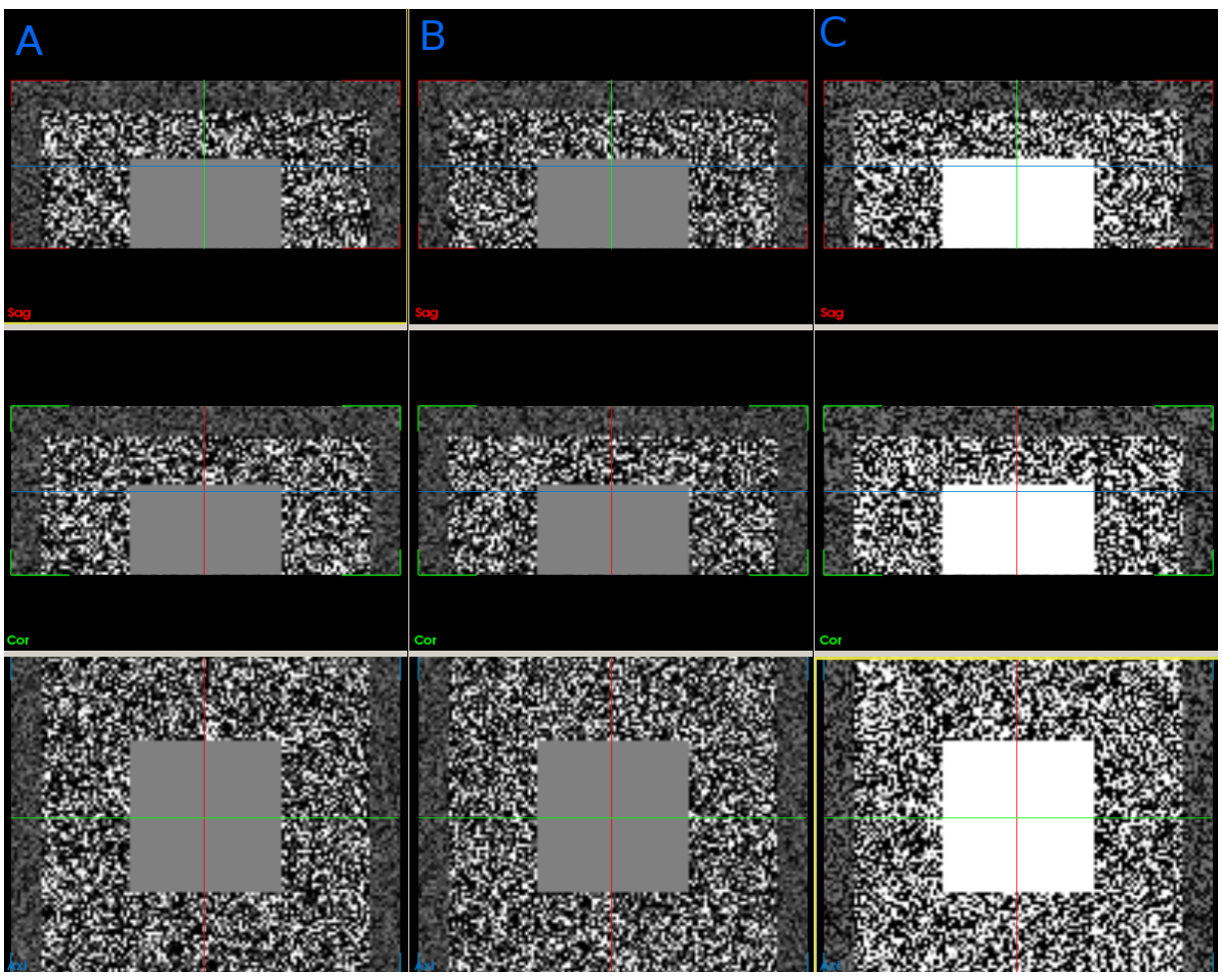

Figura 3.7: Coleção organizada em colunas de imagens das projeções ortogonais de máscara com especificação de um objeto com $A D C=1$ e difusão isotrópica, um objeto com $A D C=5$ e difusão isotrópica, contido no anterior, e um objeto com $A D C=10$, de difusão anisotrópica, contido no anterior e com direção $(x=0.1, y=0.1, z=0.9)$. A) Projeção da máscara no eixo X. B) Projeção da máscara no eixo $Y$. C) Projeção da máscara no eixo $Z$.

amostra, contendo o sinal original (medido da amostra pelo equipamento de RM), o ADC e a direção de difusão (especificados pelo usuário, a partir de seu modelo de difusão).

Para contornar problemas de correlação de número pseudoaleatórios, realizamos chamadas de sistema para criar sementes de números aleatórios a cada 100 versores aleatórios criados.

O que nos resta, portanto, é especificar as direções em que iremos aplicar os gradientes magnéticos, e então calcular a atenuação. Para que os resultados sintéticos sejam equivalentes aos resultados de uma aquisição de imagem de difusão pelo equipamento de RM, é necessário usar as mesmas direções nos dois casos. A partir de uma lista dessas direções, o software irá sintetizar a imagem atenuada em cada uma dessas direções. Para cada uma destas sínteses, a equação de Stejskal-Tanner [ST65] (equação 2.1, reproduzida abaixo) será integrada para cada voxel.

$$
\begin{aligned}
& \ln \left[\frac{A\left(\tau^{\prime}\right)}{A(0)}\right]=-\gamma^{2} D\left[\int_{0}^{\tau^{\prime}} F^{2} d t-4 f \int_{\tau}^{\tau^{\prime}} F d t+4 f^{2}\left(\tau^{\prime}-\tau\right)\right], \text { aonde } \\
& F(t)=\int_{0}^{t} G\left(t^{\prime}\right) d t^{\prime}, \mathrm{e} \\
& G(t)= \\
& \begin{array}{llrl}
g_{0} & \text { quando } & 0 & <t<t_{1} \\
g_{0}+g & \text { quando } & t_{1} & <t<t_{1}+\delta<\tau \\
g_{0} & \text { quando } & t_{1}+\delta & <t<t_{1}+\Delta>\tau \\
g_{0}+g & \text { quando } & t_{1}+\Delta & <t<t_{1}+\Delta<2 \tau \\
g_{0} & \text { quando } & t_{1}+\Delta+\delta & <t .
\end{array}
\end{aligned}
$$

O lado esquerdo da equação de Stejskal-Tanner corresponde à atenuação da amplitude máxima de um eco quando são aplicados pulsos de gradiente de campo magnético entre os pulsos de RF, o que sensibiliza a amostra à difusão. 
O algoritmo usado para realizar os cálculos pode ser escrito cf. a listagem 3.2, e recebe como entrada os parâmetros da sequência, o arquivo de entrada que contém a imagem $T_{2}$ e a especificação máscara de direções de difusão.

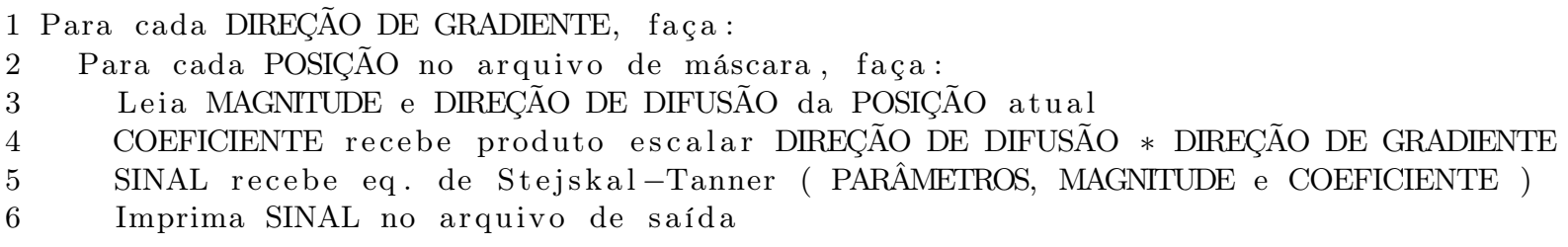

Listagem 3.2: Pseudocódigo relativo ao cálculo do sinal sintético de difusão por RM.

Essencialmente, uma função denominada "attenuation" calcula o lado direito da equação de Stejskal-Tanner, supondo que uma variável chamada "params" é global e contém os dados relativos à especificação de pulso a ser simulada. A função "attenuation" também precisa da magnitude do sinal no pixel em questão, e do valor da projeção do vetor de direção de difusão com relação ao vetor de direção do gradiente aplicado. Por isso, esse valor é calculado antes que essa função seja iniciada.

Finalmente, a integração é realizada por meio de mais uma função de indireção, para deixar o código pronto para utilizar uma biblioteca de integração de terceiros (como a GSL [Fou]). Isto será necessário para aprimorar o desempenho do simulador. Mas para que o algoritmo seja tão verificável quanto possível, escrevemos nossa própria função de integração, a mais simples possível ${ }^{5}$.

\subsubsection{Verificação do b-value}

Um problema recorrente encontrado na produção dos resultados apresentados no capítulos Resultados (p. 27) e no Apêndice E (p. 47) foi não dispormos de valores exatos para alguns parâmetros necessários para a simulação. Conforme mencionado no capítulo Teoria (p. 7), as sequências de pulso efetivamente utilizadas em equipamentos de RM são altamente complexas, pois o interesse econômico em minimizar o tempo de aquisição impulsionou o desenvolvimento de diversas variações com relação às sequências de pulso "ideais". Por isso, tivemos de estimar valores para alguns parâmetros, e validar essas estimativas por meio do cálculo do b-value.

Os cálculos realizados são exatos apenas para a sequência PGSE "ideal". Utilizamos os equipamentos de RM em sua configuração mais próxima possível dessa sequência "ideal", e validamos a estimativa dos valores desconhecidos dos parâmetros verificando que a estimativa é coerente com o cálculo do b-value (cf. equação 2.2, p. 15).

\footnotetext{
${ }^{5} \mathrm{O}$ código-fonte de todo o software desenvolvido nesta pesquisa foi disponibilizado sob licença GPL [Fou07] online [Bor]. Uma descrição da metodologia de integração numérica está no Apêndice C (p. 43).
} 


\section{Capítulo 4}

\section{Resultados}

Apresentamos neste capítulo os resultados relativos a um fantoma construído com tubos capilares, e comparamos as imagens obtidas com um equipamento de RM de $9.4 \mathrm{~T}$ com imagens sintetizadas pelo nosso software. Ao longo de nossos trabalhos, realizamos alguns experimentos preliminares, que estão documentados no Apêndice E (p. 47).

\subsection{Fantoma de tubos capilares}

As imagens obtidas para este fantoma foram coletadas no Martino's Center for Biomedical Imaging, em Boston pelos colegas Shuning Huang e Choukri Mekkaoui, num equipamento experimental de RM de 9.4 T, e a amostra consistiu num feixe de tubos capilares torcidos dentro de um recipiente cilíndrico (cf. figuras 4.1 e 4.2). Este recipiente foi colocado dentro de um invólucro contendo água (cf. figura 4.2), e esse invólucro foi envolto em algodão e fita adesiva, para mantê-lo firme no lugar dentro da abertura no centro do campo do aparelho.

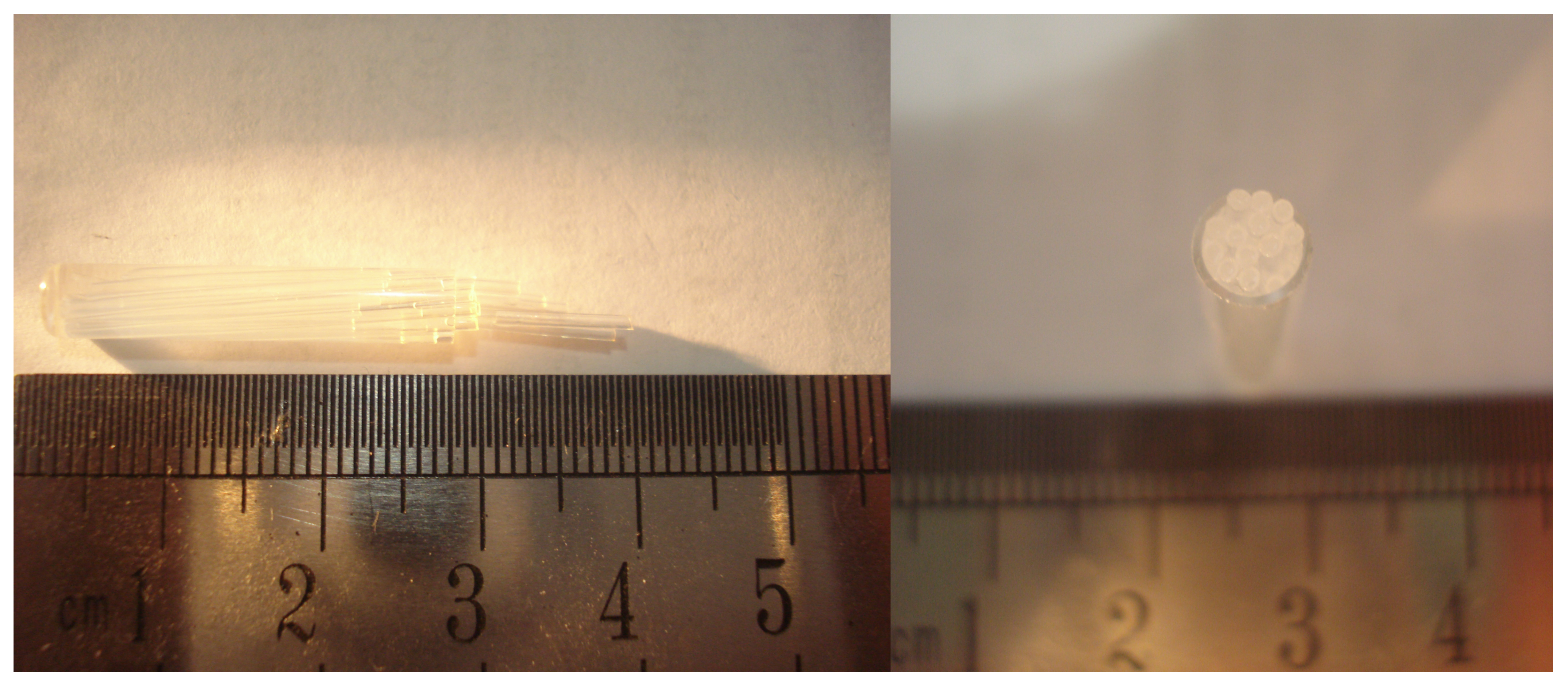

Figura 4.1: Fotos do fantoma de tubos capilares. Pode-se ver na foto à direita que ele é composto por pequenos tubos capilares. Um invólucro transparente mantém os capilares em seu lugar, como pode ser visto na foto à esquerda. Os tubos capilares foram torcidos para que coubessem no invólucro.

Foram adquiridas as imagens de difusão por RM no equipamento experimental, e essas imagens foram processadas usando os softwares MedSquare [JMea] e BioImage [PJR ${ }^{+}$] para produzir imagens de difusão, cf. pode ser visto nas figuras 4.3 e 4.4 .

Imagens de difusão para esta amostra podem ser vistas na figura 4.3. Observamos que há um sinal distinto muito claro com formato de anel - este sinal é da água do invólucro que contém os capilares, e não dos capilares eles mesmos. A região dos capilares é a região circular dentro do anel. Essa região de interesse, tal como pode ser visto na imagem da direita da figura 4.3, também é 


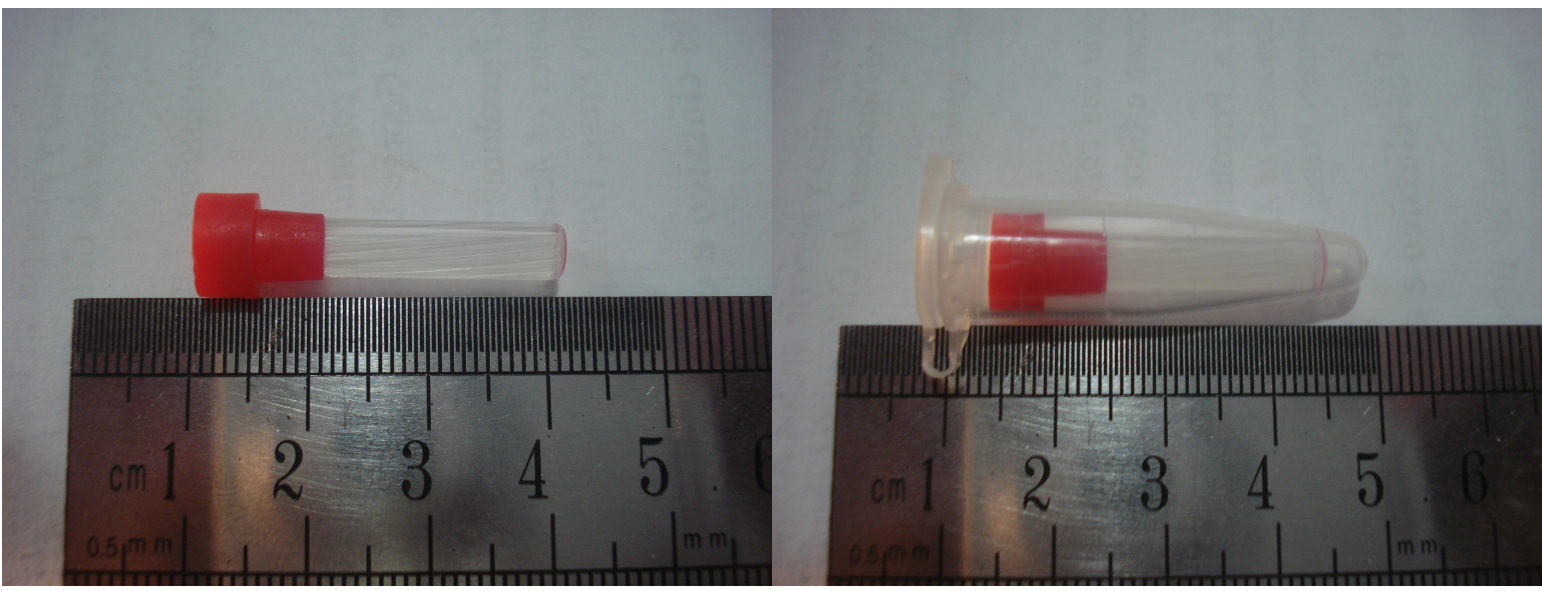

Figura 4.2: Fotos do fantoma de tubos capilares. Na foto da esquerda, o recipiente transparente contendo os capilares está fechado, e contendo água. Na foto da direita, o recipiente está colocado dentro de um invólucro com tampa, e também foi colocada água no espaço entre os dois recipientes.

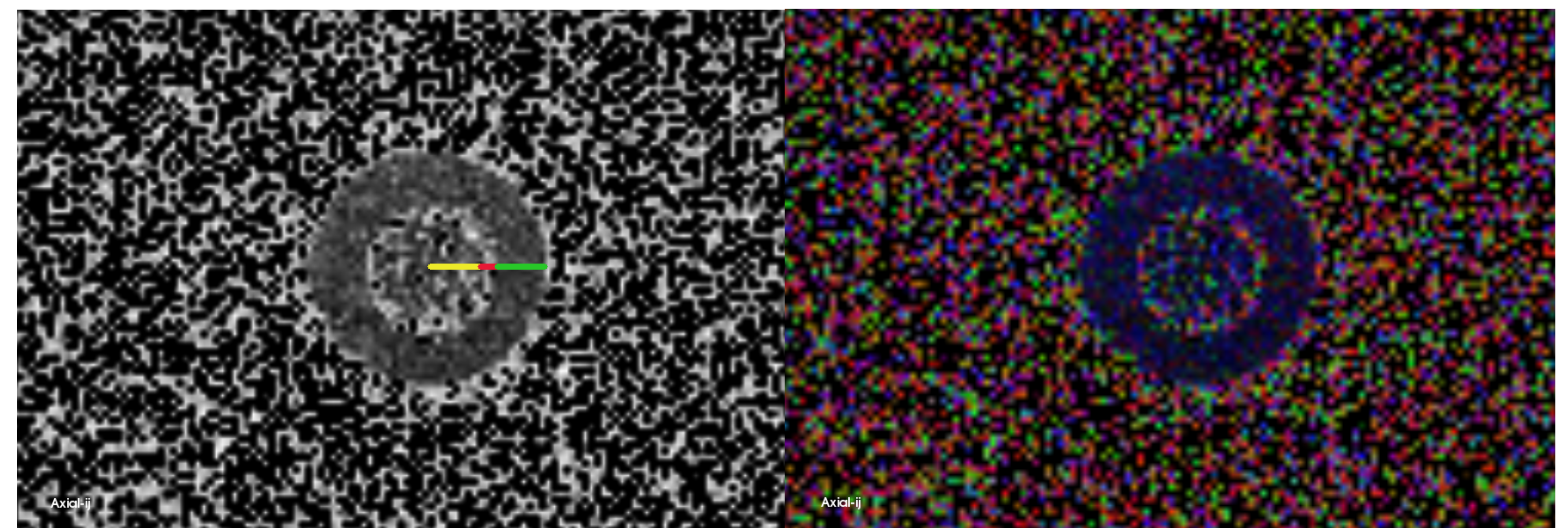

Figura 4.3: Imagens de difusão obtidas por meio de um equipamento de RM, e processada pelos softwares MedSquare [JMea] e BioImage [JMea]. A imagem esquerda mostra as magnitudes dos coeficientes de difusão. A linha amarela indica o raio aproximado da região que contém os tubos capilares. A linha vermelha indica a espessura aproximada do recipiente. A linha verde indica a espessura aproximada da região que contém água entre o recipiente e o invólucro. A imagem da direita foi colorida de acordo com a direção da difusão. É possível notar que as regiões contendo água têm predominio da cor azul, que neste caso, indica predominância da difusão na direção que atravessa o papel.

relativamente homogênea, com difusão na direção axial (cor azul na imagem) e portanto deve ter vetores principais de difusão aproximadamente alinhados com essa direção.

A figura 4.4 corresponde à nossa região de interesse, e foram incluídos elementos tridimensionais (pequenas barras) para indicar a direção principal de difusão ("Fast eigenvetors" no software Bioimage $\left.\left[\mathrm{PJR}^{+}\right]\right)$. Como previsto, a direção predominante é ortogonal ao plano da imagem.

Nossa pretensão com este fantoma era obter imagens em que a difusão fosse claramente anisotrópica na região dos tubos capilares, e significativamente mais isotrópica na região entre o recipiente e o invólucro. Entretanto, as duas regiões têm características difusão equivalentes. Por isso, não é possível distinguir a anisotropia devida aos tubos capilares e a anisotropia devida às paredes do invólucro e do recipiente.

Interpretamos esse fato como sendo o resultado do uso de um intervalo de aplicação do gradiente de difusão (o parâmetro $\delta$ da sequência de Stejskal-Tanner) grande o suficiente para detectar a diferença entre a difusão da água restrita pelo plano do anel e a difusão da água perpendicular a esse plano. Sendo esse o caso, o parâmetro $\delta$ foi superestimado, pois como o diâmetro dos capilares é muito menor que a dimensão da região anular, teria sido possível obter imagens que mostrassem a anisotropia da água dentro dos capilares com um valor menor de $\delta$. Além disso, se o parâmetro 


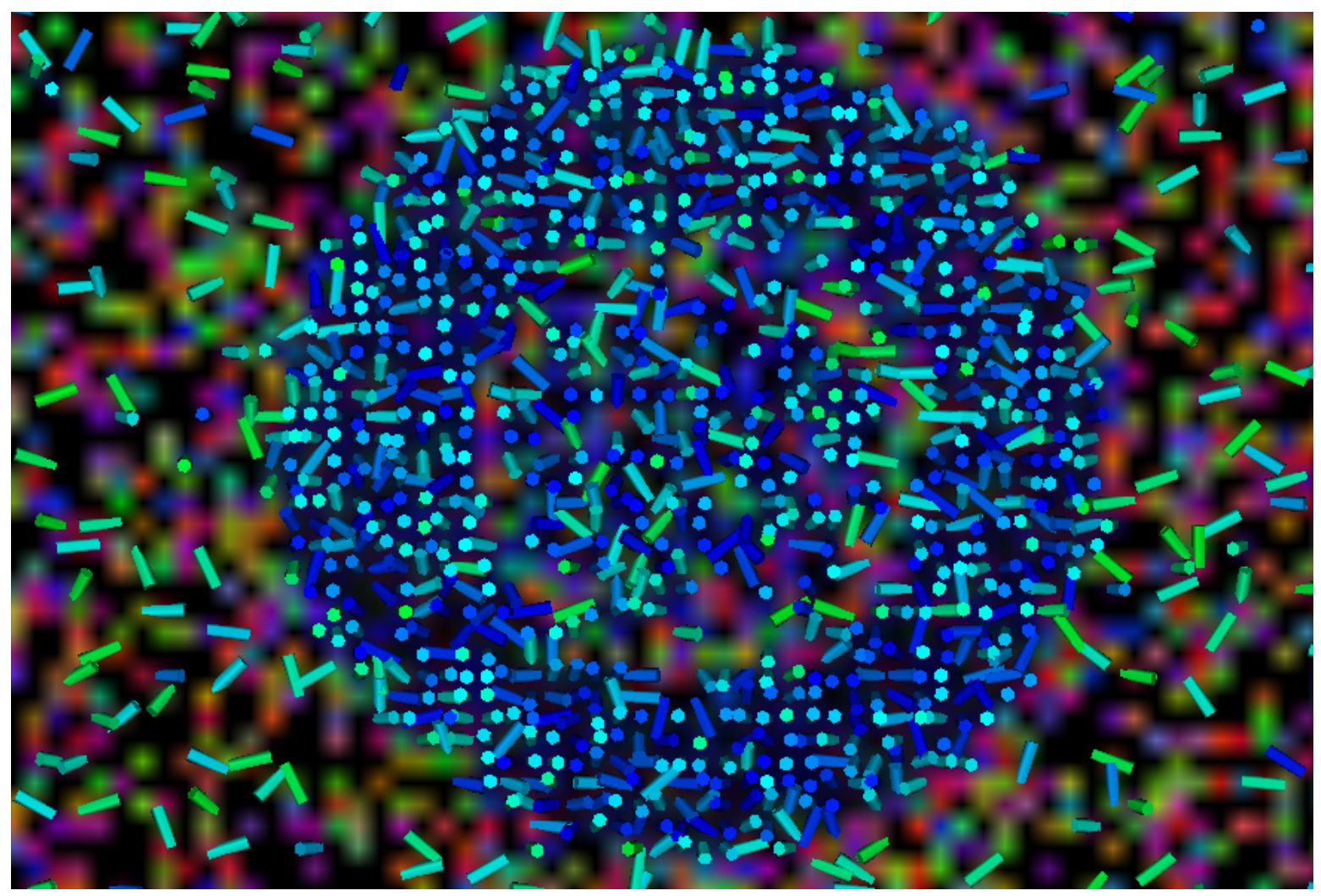

Figura 4.4: Imagem de difusão do fantoma de tubos capilares. As barras tridimensionais representam os vetores principais de difusão, filtrados para o intervalo aonde FA está entre 0.1 e 0.5 .

$\delta$ fosse pequeno o suficiente para que ele correspondesse a um deslocamento médio das moléculas de água menor do que a distância entre as paredes da região anelar, o sinal dessa região não seria atenuado preferencialmente na direção axial, e os vetores não estariam ordenados.

Em outras palavras, se $\delta$ fosse menor, a região do "anel" teria difusão isotrópica, e a difusão na região de interesse ainda seria anisotrópica. Infelizmente não pudemos realizar uma segunda sessão na máquina de RM experimental, e por isso usamos estes resultados tais como estão.

Ainda que o parâmetro $\delta$ tenha sido superestimado nesta aquisição, o efeito disto na região de interesse, o cilindro contendo os tubos capilares, é limitado ao fato de que a aquisição poderia ter sido um pouco mais rápida. Na verdade, esperamos que o resultado tal como está deve ser mais dramático do que teria sido se um valor menor de $\delta$ tivesse sido usado, pois nesse caso a diferença entre a difusão paralela e perpendicular ao eixo dos capilares teria sido menor, e portanto a FA teria sido menor nessa região.

Por outro lado, não podemos atribuir a anisotropia da difusão na região dos tubos à restrição que os tubos impõem à difusão da água. Isto pois o resultado pode ter sido obtido devido à anisotropia da água devida às paredes do invólucro.

Uma vez feita esta análise, concluímos que estas imagens são apropriadas para basearmos a comparação de nossas simulações com a imagem real. Especificamente, a região de interesse é a região circular mais interna do fantoma.

\subsubsection{Especificação da máscara relativa ao fantoma}

Para modelar a difusão do fantoma, criamos uma especificação de máscara com uma camada contendo 5 objetos. O primeiro objeto corresponde ao Campo de Visão (FOV, ou Field of View), que corresponde ao ar e algodão em torno do fantoma. O FOV é um prisma retangular com difusão isotrópica. $\mathrm{O}$ ADC da água nesta substância nos é desconhecido, e por isso atribuímos um valor arbitrário $\left(10^{-4} \mathrm{~mm}^{2} / \mathrm{s}\right)$ uma ordem de grandeza menor que o valor da literatura para o ADC da água. A razão entre difusão principal e transversal foi configurado como 1:1, pois não esperamos 
que existam restrições geométricas consistentes nessa região.

O segundo objeto corresponde à parede do recipiente, modelada como uma parede cilíndrica de difusão isotrópica e espessura 1 pixel. Novamente, nos é desconhecido o ADC nesta substância, e por isso atribuímos um valor arbitrário $\left(10^{-5} \mathrm{~mm}^{2} / \mathrm{s}\right)$ uma ordem de grandeza menor que o ADC atribuído à agua no algodão. Novamente, a razão entre difusão principal e transversal foi configurada como 1:1.

O terceiro objeto corresponde à agua entre o recipiente e o invólucro. Foi modelado como uma parede cilíndrica de difusão isotrópica e espessura 9 pixels. Atribuímos o valor do ADC da água típico para massas extensas de água (bulk water) em condições normais de temperatura e pressão [KGS78] $2.3 \times 10^{-3} \mathrm{~mm}^{2} / \mathrm{s}$. Nesta região, e na região dos capilares, sabemos que as paredes restringiram a difusão de maneira que a água teve difusão menos restrita ao longo de uma única direção. Então configuramos o valor da razão entre difusão principal e transversal como 1:0.9.

O quarto objeto corresponde à parede do invólucro, modelada como uma parede cilíndrica de difusão isotrópica e espessura 2 pixels. Atribuímos o mesmo valor de ADC que foi atribuído para a parede do recipiente $\left(10^{-5} \mathrm{~mm}^{2} / \mathrm{s}\right)$. A razão entre difusão principal e transversal foi configurada como 1:1.

O quinto objeto corresponde aos tubos capilares e à água que eles contêm. Foi modelado como um cilindro de difusão anisotrópica e raio 8 pixels. A direção de difusão foi especificada como sendo $(x=0.100, y=0.100, z=0.990)$. O ADC atribuído foi o de bulk water $\left(2.3 \times 10^{-3} \mathrm{~mm}^{2} / \mathrm{s}\right)$. Novamente, configuramos a razão entre a difusão principal e transversal como 1:0.9.

O modelo de difusão que supomos para este fantoma é que na região do FOV só há sinal devido ao vapor de água presente no ar e no algodão em torno do fantoma. O ADC desse sinal nos é desconhecido, mas supomos que seja um sinal isotrópico por toda sua extensão.

Realizamos diversas simulações antes de encontrarmos os valores indicados acima. O que nos guiou foram os resultados estatísticos obtidos para a imagem original: procuramos modificar cada parâmetro para coincidir tanto quanto possível os resultados numéricos sintéticos com os originais.

\subsubsection{Comparação entre a imagem adquirida e sintetizada}

A imagem original possui dimensões $128 \times 128$ x 8. Produzimos uma imagem para cada um dos 8 cortes ao longo do eixo $\mathrm{Z}$ tanto para a imagem original quanto para a sintética, e as colocalmos lado a lado, cf. a figura 4.5 .

Os valores estatísticos levantados pelo programa bioimage estão todos coerentes, dentro de uma ordem de grandeza, entre os valores relativos à imagem original e a imagem sintética (ver tabelas 4.1 e 4.2), com boa concordância dos valores de FA, e concordância menor dos valores relativos à Difusividade Média (Mean Diffusivity, ou MD). Pequenos refinamentos no modelo apresentado para esta amostra não tiveram efeito sobre estes valores de MD.

\begin{tabular}{c|c|c|r|c} 
& FA médio & Variância & $\begin{array}{r}\text { MD médio } \\
\left(\mathrm{mm}^{2} / \mathrm{s}^{-1}\right)\end{array}$ & Variância \\
\hline Fantoma & 0.4594 & 0.0444 & 0.0001 & $\sim 0.0001$ \\
Síntese & 0.4594 & 0.0370 & $\sim 0.0001$ & $\sim 0.0001$
\end{tabular}

Tabela 4.1: Resultados estatísticos para a região fora do "cilindro" (122560 voxels).

\begin{tabular}{c|c|c|c|c} 
& FA médio & Variância & $\begin{array}{c}\text { MD médio } \\
\left(\mathrm{mm}^{2} / \mathrm{s}^{-1}\right)\end{array}$ & Variância \\
\hline Fantoma & 0.3472 & 0.0251 & 0.0025 & $\sim 0.0001$ \\
Síntese & 0.3433 & 0.0014 & 0.0006 & $\sim 0.0001$
\end{tabular}

Tabela 4.2: Resultados estatísticos para a região do "anel" (5504 voxels).

Finalmente, comparamos visualmente apenas as duas regiões de interesse, ou seja, apenas as 

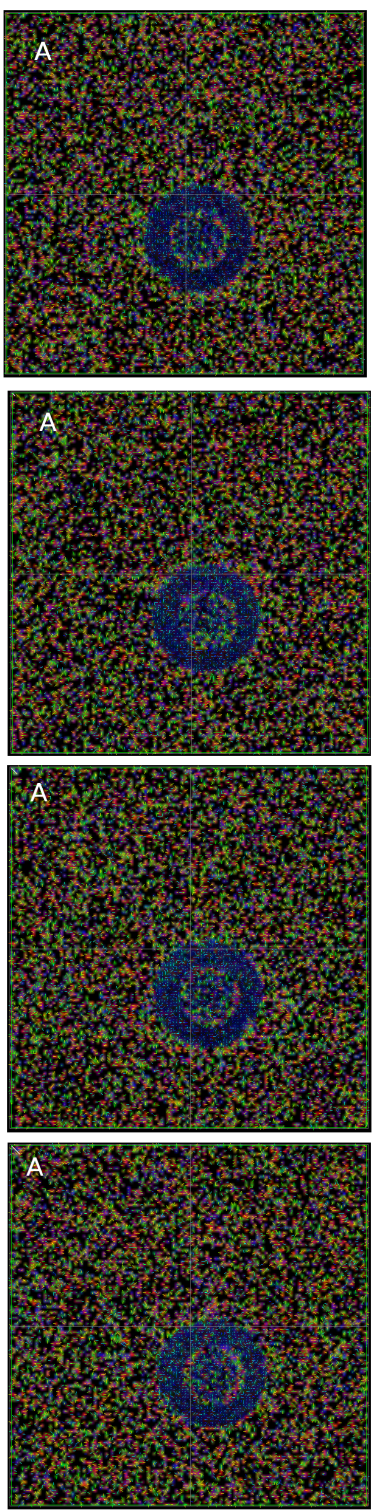
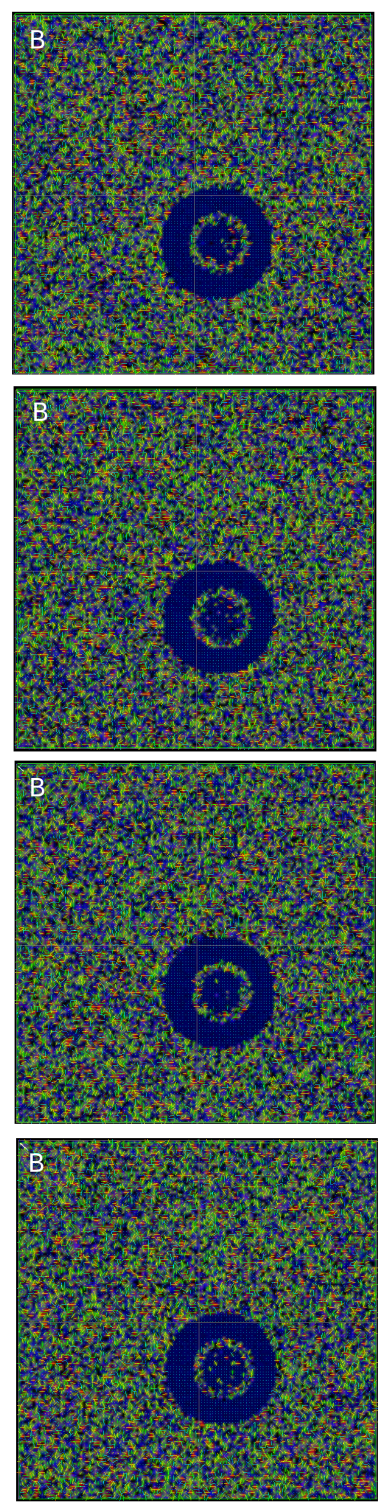
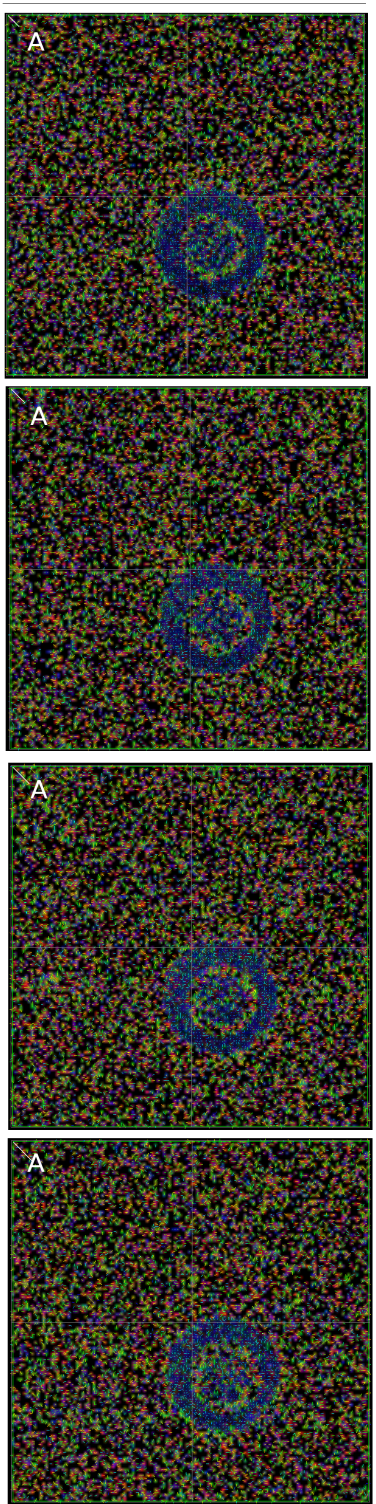
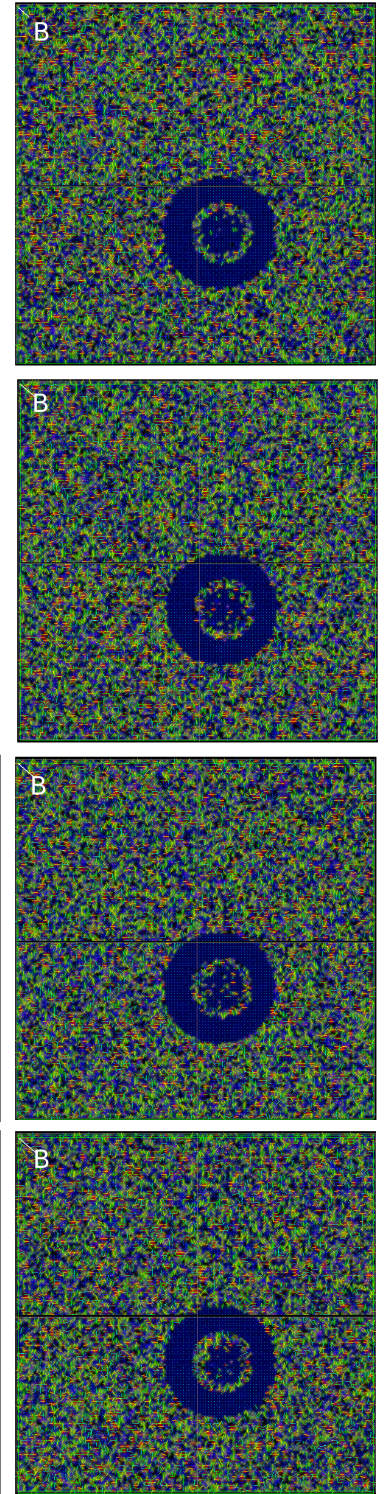

Figura 4.5: Imagens de cada um dos 8 cortes axiais das imagens original e sintética, lado a lado, em duas colunas. As imagens originais estão identificadas com a letra A, e as imagens sintéticas com a letra B. As imagens têm colorização de seu fundo de acordo com a direcionalidade (azul para direção axial, verde para direção sagital e vermelho para direção coronal). Os segmentos de reta indicam a direção dos autovetores da direção principal de difusão em cada ponto, e são coloridos usando cores frias para FA próximo de 0 e cores quentes para FA próximo de 1. Qualitativamente, as diferenças entre as duas séries de imagens se resumem a uma tonalidade mais esverdeada para a região isotrópica da imagem sintética, enquanto a imagem original tem tonalidade mais alaranjada, e a região com água é mais intensamente azul na imagem síntetica do que na original.

regiões com água na imagem original e na sintética.

O modelo que propomos para este fantoma é portanto capaz de aproximar a imagem final com fidelidade suficiente para correlacionar a difusão ao longo do eixo do fantoma com a medida de FA da imagem, e do resultado visual relativo à região com água do fantoma.

\subsection{Consumo de recursos pela simulação}

Por desenho, escolhemos implementar a integração numérica explicitamente, da maneira mais simples possível (implementação "ingênua"). Uma vez que a integração numérica é a atividade mais custosa de nossa simulação, esperamos que exista ampla oportunidade para otimização de tempo 

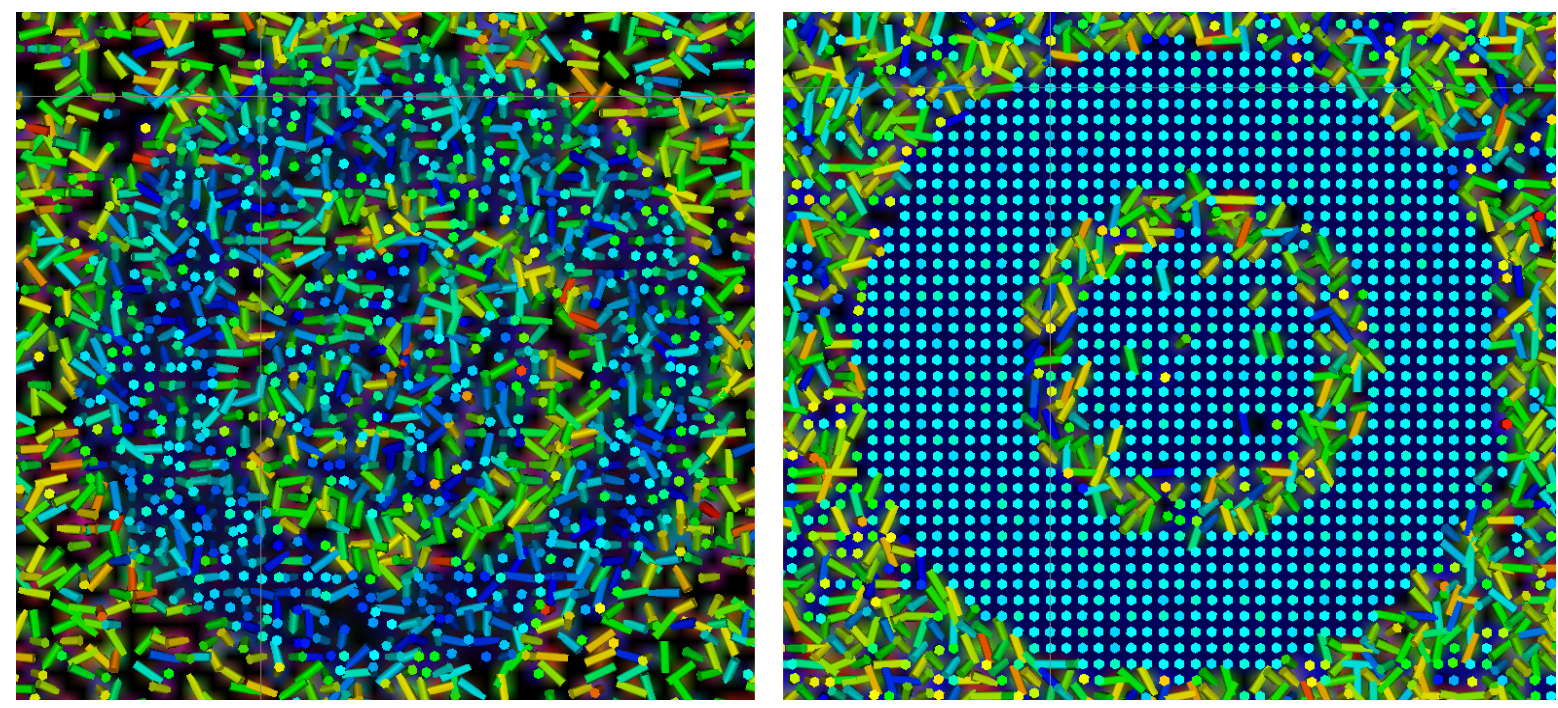

Figura 4.6: Imagens das Regiões de Interesse (ROI ou Region Of Interest) das imagens original (esquerda) e sintética (direita). É possível notar claramente que a imagem sintética tem a região com água modelada de maneira excessivamente "homogênea", se comparada à imagem original: as barras tridimensionais sugerem que no fantoma a difusão da água ocorre privilegiadamente num intervalo de direções aproximadamente axiais, enquanto que na imagem sintética, a difusão se dá quase que exclusivamente ao longo de uma única direção.

nesta simulação. É nossa expectativa integrar a simulação com o software MedSquare [JMea], e nessa ocasião pretendemos substituir as chamadas às funções ingênuas por chamadas a funções da GNU Scientific Library, uma biblioteca científica amplamente utilizada [Fou].

Em sua forma atual, para efeitos de comparação de tempo para uma aplicação em imagem muito grande (i.e., com grande resolução), utilizamos um cluster para executar nossa simulação, e sempre dividimos a carga de trabalho em 70 unidades $^{1}$. Instrumentamos o software da simulação para que um dos parâmetros a serem especificados em sua chamada seja o número de passos a serem computados em cada integração. Em outras palavras, se a integração deve ser feita para um intervalo de 0 a 1 segundos, por exemplo, o número de passos determina qual o intervalo de discretização desse intervalo total (por exemplo, para integrar de 0 a 1 segundos, em 1000 passos, teríamos intervalos discretos de $10^{-3}$ segundos).

Obtivemos a tabela 4.3 variando o número de passos ${ }^{2}$ :

Em seguida, construímos o gráfico da figura 4.7, considerando as médias dos tempos para os valores repetidos na tabela 4.3, e assumindo os intervalos de incerteza como sendo iguais à incerteza instrumental de 1 minuto.

Uma observação a ser feita é que ao longo destes testes, também variamos alguns parâmetros que têm influência no custo computacional ${ }^{3}$, como os limites de threshold. Por isso, a tabela e o gráfico acima não devem ser considerados como "finais" com relação à eficiência do sistema. Isto é ainda mais relevante considerando que ainda usamos um código de integração "ingênuo", e portanto oferecemos estes resultados como sugestivos do crescimento linear do custo temporal de acordo com o tamanho do problema, mas acreditamos que os valores absolutos dos testes estejam superestimados.

Entretanto, a simulação converge para valores de FA e MD com muito menos passos do que o

\footnotetext{
${ }^{1}$ Esse número foi escolhido pois a imagem usada para comparar o tempo de execução tem 70 cortes, e o cluster utilizado tem 192 núcleos, o suficiente para executar essas 70 unidades ao mesmo tempo.

${ }^{2}$ Como a execução foi feita num cluster, aonde o tempo total depende da orquestração de diversas máquinas, e da transmissão dos arquivos de entrada e saída pela rede, consideramos que apesar de podermos relatar o tempo de execução com precisão de milisegundos, a incerteza da medida é muito maior. Para estarmos seguros de nossas medidas, adotamos uma incerteza de 1 minuto.

${ }^{3}$ Certamente nos ocorreu a idéia de realizarmos testes múltiplos com as mesmas exatas configurações, variando exclusivamente o número de passos. Entretanto, isso não foi feito para não consumir recursos que preferimos usar para aprimorar a simulação em si, do que utilizar para medir seu custo computacional.
} 


\begin{tabular}{l|r|l}
\hline Modelo & Passos & Tempo de execução (min) \\
\hline \hline xml061 & 700 & 21 \\
xml062 & 800 & 42 \\
xml063 & 900 & 51 \\
xml065 & 1000 & 62 \\
xml071 & 600 & 23 \\
xml072 & 500 & 16 \\
xml073 & 500 & 16 \\
xml074 & 500 & 16 \\
xml075 & 500 & 16 \\
xml076 & 500 & 16 \\
\hline
\end{tabular}

Tabela 4.3: Variação do número de passos de integração, e o tempo total de execução da simulação, com 70 núcleos em paralelo.

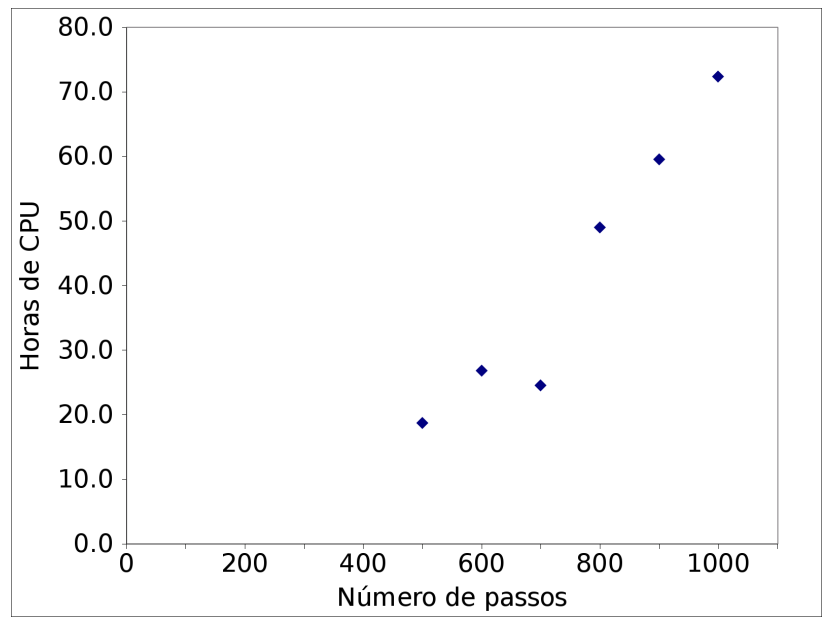

Figura 4.7: Gráfico do consumo de tempo por número de passos, para 70 núcleos em paralelo.

ilustrado acima (pois o exemplo anterior é uma estimativa de custo para imagens muito maiores do que as que utilizamos). Por exemplo, Usando um núcleo de um processador Intel i5-3570K 3.40GHz, obtivemos convergência dos valores de FA e MD com menos de 1000 passos, e mesmo os valores para simulações com apenas 10 passos já foram muito próximos dos valores finais, conforme ilustrado nas tabelas 4.4 e 4.5 .

\begin{tabular}{r|r|r|r|r|r|r} 
Passos & Tempo (s) & FA médio & Variância & $\begin{array}{r}\text { MD médio } \\
\left(\mathrm{mm}^{2} / \mathrm{s}^{-1}\right)\end{array}$ & Variância & Voxels \\
\hline 10 & $3(1)$ & 0.4594 & 0.0370 & $\sim 0.0001$ & $\sim 0.0001$ & 122560 \\
100 & $66(1)$ & 0.4594 & 0.0370 & $\sim 0.0001$ & $\sim 0.0001$ & 122560 \\
200 & $247(1)$ & 0.4594 & 0.0370 & $\sim 0.0001$ & $\sim 0.0001$ & 122560 \\
Original & & 0.4594 & 0.0444 & 0.0001 & $\sim 0.0001$ & 122560
\end{tabular}

Tabela 4.4: Resultados estatísticos para a região fora do "anel".

Portanto, o uso do sintetizador pode ser realizado num laptop com processador moderno, e os resultados serão obtidos em muito menos que uma hora, para imagens com resolução considerável (como a do nosso exemplo, $128 \times 128$ x 8, em seis direções). 


\begin{tabular}{r|r|r|r|c|c|c} 
Passos & Tempo (s) & FA médio & Variância & $\begin{array}{c}\text { MD médio } \\
\left(\mathrm{mm}^{2} / \mathrm{s}^{-1}\right)\end{array}$ & Variância & Voxels \\
\hline 10 & $3(1)$ & 0.3425 & $\sim 0.0001$ & 0.0009 & $\sim 0.0001$ & 5504 \\
100 & $66(1)$ & 0.3425 & $\sim 0.0001$ & 0.0005 & $\sim 0.0001$ & 5504 \\
200 & $247(1)$ & 0.3425 & $\sim 0.0001$ & 0.0004 & $\sim 0.0001$ & 5504 \\
Original & & 0.3472 & 0.0251 & 0.0025 & $\sim 0.0001$ & 5504
\end{tabular}

Tabela 4.5: Resultados estatísticos para a região do "anel", contendo sinal anisotrópico. 


\section{Capítulo 5}

\section{Conclusões}

\subsection{Considerações Finais}

O problema que suscitou esta pesquisa é a dificuldade de relacionar hipóteses relativas a modelos de difusão macroscópicos com as imagens de difusão por RM que podem ser produzidas para cérebros vivos. Nos propusemos o objetivo de desenvolver uma ferramenta de modelagem de difusão, acoplada a um sistema de síntese de imagens de difusão por MR. O mecanismo essencial desta ferramenta, cf. demonstrado no capítulo Resultados (p. 27), é capaz de produzir imagens que são qualitativamente equivalentes às imagens de difusão. Entretanto, o software produzido é de baixa usabilidade, pois exige que o operador edite arquivos de texto, e utilize um cluster para realizar suas simulações. De modo que o objetivo de produzir uma ferramenta nos parece ter sido alcançado, mas é uma ferramenta com uma curva de aprendizado demasiadamente íngreme.

A metodologia adotada nos permite sintetizar imagens de objetos macroscópicos e complexos, e por isso sua aplicabilidade a amostras de natureza biológica cumpre o objetivo proposto de ser uma ferramenta para investigação de correlações entre modelos abstratos de difusão e as imagens de difusão produzidas por aparelhos de RM. Por outro lado, a natureza macroscópica dos modelos simulados limita as análises quantitativas a aproximações, e portanto a aplicabilidade da simulação tende para uma análise visual e qualitativa dos modelos de difusão.

Implementamos os objetos geométricos necessários para lidar com os fantomas que foram utilizados durante a elaboração da dissertação: prismas retangulares e cilíndricos. Mas para que a ferramenta seja aplicável a objetos com geometrias mais complexas, teremos de adicionar novos objetos geométricos primitivos, e inventar maneiras de refinar esses objetos. Uma das idéias que temos para o futuro do sintetizador é obter a geometria das máscaras a partir de arquivos gerados por programas de desenho arquitetônico ou de engenharia mecânica.

Com base nas imagens $T_{2}$ de um fantoma de tubos capilares, sintetizamos imagens DWI e comparamos essas imagens com as imagens obtidas por meio de um equipamento de RM. Quantitativamente, comparamos as imagens através do levantamento estatístico feito pelo programa bioimage $\left[\mathrm{PJR}^{+}\right]$, e descobrimos que os valores de MD para as imagens sintéticas são cerca de duas ordens de grandeza menores que os valores das imagens de RM, enquanto que todos os demais valores diferem por no máximo uma ordem de grandeza, com relação aos valores das imagens não-sintéticas.

Este valor muito baixo para MD ocorreu sistematicamente ao longo das simulações; acreditamos que esteja relacionado ao mecanismo de síntese das regiões de difusão isotrópica, pois ao realizar testes usando um modelo em que o volume todo tem difusão anisotrópica, só é possível alcançar os valores de MD similares aos valores da imagem original parametrizando o ADC da água nesse volume com valores muito maiores (aproximadamente $1 \mathrm{~mm}^{2} / \mathrm{s}$ ) do que o valor adotado como padrão para o ADC da água em condições normais de pressão e temperatura $\left(2.310^{-3} \mathrm{~mm}^{2} / \mathrm{s}\right.$ [KGS78]).

Esta incorreção da síntese foi ignorada pois ela influencia pouco as regiões de interesse, aonde a difusão é anisotrópica. Para estas regiões, a medida estatística de interesse é a FA, e para essa medida a imagem sintética final tem todos os valores (FA mínima, FA máxima, FA média e variância da FA), similares dentro de uma ordem de grandeza com relação aos valores originais. 
Visualmente, o resultado da síntese representa o modelo desenhado, e as diferenças que se pode perceber entre a imagem original e a imagem sintética acreditamos que sejam devidas a complexidades que não são contempladas pelo software, como ruídos eletromagnéticos, artefatos de aquisição, e pela idealização do objeto real (um conjunto de tubos capilares imersos em água) como sendo uma região homogênea de difusão anisotrópica.

Consideramos que os objetivos propostos foram alcançados, na medida em que a ferramenta proporciona uma visualização eficaz do modelo de difusão desenhado, e dessa forma aponta tanto os aspectos em que esse modelo é aproximadamente correto quanto sugere insuficiências do modelo. Portanto, a ferramenta permite aprimorar modelos de difusão.

\subsection{Sugestões para Pesquisas Futuras}

Inicialmente, nossa inteção era sintetizar imagens a partir de modelos de tecidos neuronais, e realizar simulações que considerassem as especificidades desse tipo de tecido. A orientação dos membros da banca de qualificação foi muito preciosa por nos fazer ver que o desenvolvimento da metodologia de simulação, e sua validação por meio de fantomas, serviria como base para esse empreendimento, e que esse desenvolvimento por si mesmo já seria mais trabalhoso do que o tempo de que dispúnhamos para completar o programa de mestrado. Mas a idéia inicial persiste, e uma vez que agora dispomos de uma metodologia concreta para simular imagens de difusão a partir de suas imagens $T_{2}$, acreditamos que estender esta pesquisa para o estudo de tecidos biológicos de interesse médico é um empreendimento factível e de grande interesse. Em especial, seria interessante validar hipóteses acerca das contribuições específicas da mielina e das membranas citoplasmáticas para a FA, nos moldes do estudos empreendidos por Beaulieu[BA94] [Bea]. Para isso, procuraremos parcerias com colegas das áreas de Medicina e Biologia.

Tal como indicado anteriormente, há muita oportunidade de otimizar os algoritmos da simulação desenvolvida aqui. Como se costuma dizer, a otimização prematura é a raiz de quase todos os males da computação. Por isso, decidimos utilizar um algoritmo muito simples e explícito para a integração numérica, que é a maior consumidora de recursos desta simulação. Acreditamos que o uso de uma biblioteca científica, como a GNU Scientific Library [Fou], nos permitirá reescrever nossa simulação com muito maior eficiência, e portanto permitirá também realizar os cálculos com maior número de passos, obtendo maior precisão.

Outra extensão futura deste projeto é desenvolver uma interface gráfica para o uso da simulação, algo que pretendemos fazer integrando as simulações com o software MedSquare [JMea], para que seu uso seja disseminado. Dessa forma, ao mesmo tempo que contribuiremos um pouco para o êxito desse projeto, também teremos uma vitrine para difundir o sintetizador desenvolvido nesta dissertação.

Assim como o simulador SIMRI $\left[\mathrm{BCCB}^{+}\right]$valida sua aplicabilidade por meio da síntese de imagens de ressonância que apresentem artefatos, pretendemos estender o sintetizador para que seja capaz de gerar imagens com artefatos típicos da modalidade de difusão por RM.

Finalmente, pretendemos modificar o sintetizador atual para que represente os modelos de difusão por meio de tensores ${ }^{1}$. O tensor é uma representação matemática equivalente à matriz de covariância de uma distribuição gaussiana tridimensional da difusão. Os autovalores do tensor em cada voxel seriam as variâncias e os autovetores suas direções principais. De modo que poderíamos usar uma distribuição gaussiana tridimensional como aproximação do modelo de difusão em cada ponto, capturando todas as possibilidades de isotropia/anisotropia. O cálculo da contribuição de cada componente usaria a interseção entre a representação elipsoidal do tensor e o vetor de direção de gradiente.

Dessa forma, o modelo matemático usado para sintetizar imagens de difusão seria mais restrito,

\footnotetext{
${ }^{1}$ Em comparação, o sistema apresentado nesta dissertação usa dois vetores, mas não representa o vínculo entre eles, ficando a cargo do algoritmo gerar vetores que sejam coerentes com a difusão. O cálculo da contribuição de sinal em cada direção é feita por meio de produtos internos entre os vetores de direção do gradiente e os vetores que representam o modelo de difusão.
} 
mas esta restrição corresponde a um vínculo que corresponde mais realisticamente à natureza dos fenômenos investigados. 


\section{Capítulo 6}

\section{Apêndice A}

Para descrevermos o modelo matemático que representa uma aquisição de imagem de difusão por RM, precisamos apresentar alguns resultados teóricos anteriores.

\subsection{As equações de Bloch}

Inicialmente, a RM utilizava a técnica de ondas contínuas, na qual (resumidamente) um determinado campo magnético é aplicado à amostra, e então é aplicada radiofrequência, com frequências diferentes a cada aplicação. O objetivo disto é descobrir a frequência de ressonância, por meio da análise do espectro resultante do experimento.

As equações de Bloch [Blo46] foram escritas dentro desse contexto, e foram usadas amplamente, por seu poder descritivo do comportamento de spins sob campo magnético, radiofrequência e relaxamento. As equações podem ser escritas tal como em [Lev08]:

$$
\frac{d}{d t}\left(\begin{array}{c}
M_{x} \\
M_{y} \\
M_{z}
\end{array}\right)=\left(\begin{array}{ccc}
0 & -\Omega^{0} & \omega_{n u t} \sin \phi \\
\Omega^{0} & 0 & -\omega_{n u t} \cos \phi \\
-\omega_{n u t} \sin \phi & \omega_{n u t} \cos \phi & 0
\end{array}\right)\left(\begin{array}{c}
M_{x} \\
M_{y} \\
M_{z}
\end{array}\right)-\left(\begin{array}{c}
T_{2}^{-1} M_{x} \\
T_{2}^{-1} M_{y} \\
T_{1}^{-1}\left(M_{z}-1\right)
\end{array}\right)
$$

Aonde $\Omega^{0}$ é o offset de resonância ${ }^{1}, \omega_{n u t}$ é a frequência de nutação ${ }^{2}$ do pulso e $\phi$ é a fase do campo equivalente à radiofrequência ${ }^{3}$.

\subsection{As equações de Torrey-Bloch}

Torrey [Tor] modificou as equações de Bloch incluindo termos relativos à difusão de partículas, e desta forma derivou expressões diferenciais que consideram o efeito da translação das partículas sob o sinal de ressonância:

$$
\begin{aligned}
& \frac{\partial M_{x}}{\partial t}=\gamma(M \times H)_{x}-\frac{M_{x}}{T_{2}}+\nabla \cdot D \nabla\left(M_{x}-M_{x 0}\right) \\
& \frac{\partial M_{y}}{\partial t}=\gamma(M \times H)_{y}-\frac{M_{y}}{T_{2}}+\nabla \cdot D \nabla\left(M_{y}-M_{y 0}\right)
\end{aligned}
$$

\footnotetext{
${ }^{1}$ Levitt define como offset de resonância a diferença entre a frequência de Larmor e a frequência de referência do equipamento.

${ }^{2}$ Nutação é o movimento clássico composto pela rotação em torno de dois eixos simultaneamente. Veja a figura 6.1 .

${ }^{3}$ Aquilo que chamamos ocasionalmente de "radiofrequência" consiste em ondas eletromagnéticas, possuindo componente de campo elétrico e componente de campo magnético variáveis. Desprezando o campo elétrico, podemos modelar a radiofrequência como um campo magnético auxiliar, variando no tempo. Essa variação é indicada como sendo uma fase, em função do tempo.
} 


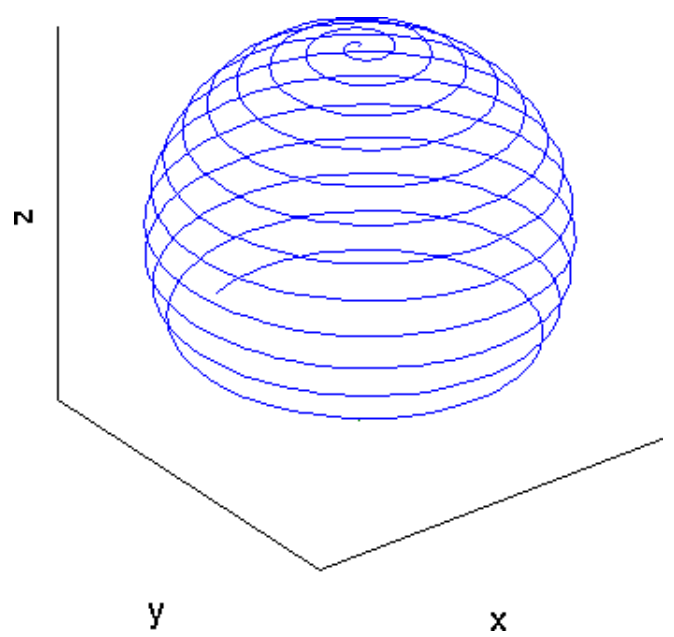

Figura 6.1: Trajeto percorrido pela ponta de um vetor em nutação em torno dos eixos $X$ e Z. Fonte: [RDR].

$$
\frac{\partial M_{z}}{\partial t}=\gamma(M \times H)_{z}+\frac{\left(M_{0}-M_{z}\right)}{T_{1}}+\nabla \cdot D \nabla\left(M_{z}-M_{z 0}\right)
$$

Aonde $M_{i 0}=\frac{n \mu^{2}}{k T} H_{i}, i=x, y, z$ são os componentes do vetor de magnetização quando a amostra está em equilíbrio.

Assim como as equações de Bloch, as equações de Torrey possuem uma certa organização: cada derivada tem um primeiro termo, que corresponde ao componente do vetor de magnetização na direção da equação, um segundo termo que corresponde aos efeitos dos relaxamentos $T_{1}$ e $T_{2}$, e um termo exclusivo das equações de Torrey, que descreve os efeitos da difusão. 


\section{Capítulo 7}

\section{Apêndice B}

\subsection{Seleção dos parâmetros da sequência de pulso simulada}

Conforme indicado no capítulo Metodologia (p. 17), as sequências de pulso efetivamente utilizadas em equipamentos de RM são em geral muito complexas, por usarem técnicas desenhadas para otimizar a aquisição do sinal. Por isso, temos de considerar a sequência usada pelo equipamento de RM como uma sequência aproximadamente equivalente à sequência PGSE.

Para achar os parâmetros da sequência PGSE equivalente, adotamos o seguinte procedimento:

No arquivo "method" da aquisição dos fantomas de terceira geração, estão especificados os valores para as durações dos pulsos dos gradientes magnéticos e do intervalo entre dois pulsos.

1 \#\# $\$$ GDIFF_LittleDelta $=3$

$2 \$ \$ @ v i s=$ PVM_RefAttMod1 PVM_RefAttStat1 Nuclei GDDIFF_NoDiffExp

$3 \#$ \#\$GDIFF_BigDelta $=8$

Infelizmente, não encontramos uma especificação de qual a unidade utilizada nestes dois parâmetros. Supomos que sejam décimos de segundo, pois valores com esta ordem de grandeza são coerentes com os demais parâmetros utilizados.

Outro parâmetro necessário é a magnitude do gradiente de difusão. Esse parâmetro não está disponível nos arquivos de saída do equipamento de RM, e portanto utilizamos um algoritmo para calcular esse parâmetro ${ }^{1}$ a partir de diferentes valores de $\delta$ e $\Delta$, considerando a relação $\frac{\Delta}{\delta}=\frac{8}{3}$. Obtivemos os seguintes valores:

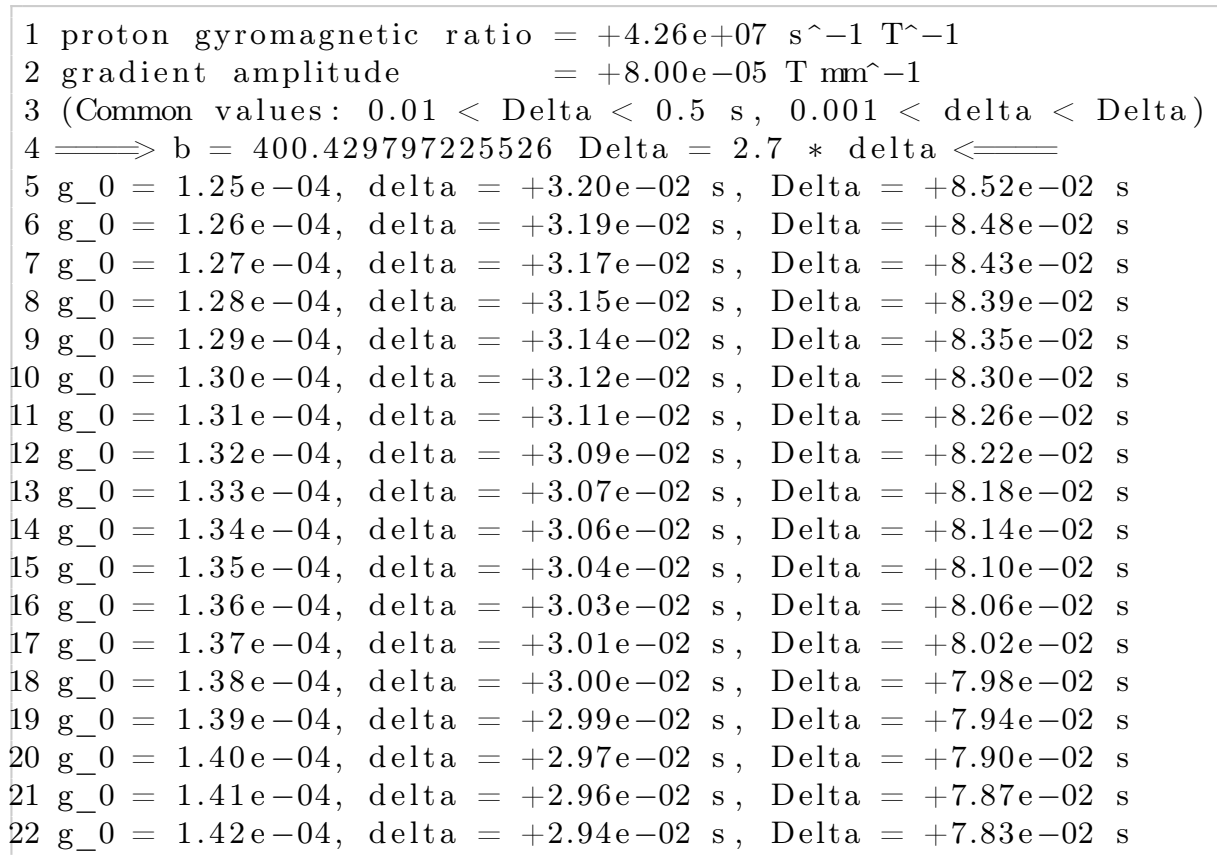

\footnotetext{
${ }^{1} \mathrm{O}$ código desse procedimento está no arquivo "b-value_calculation.cpp" da referência [Bor].
} 
$23 \mathrm{~g} \quad 0=1.43 \mathrm{e}-04$, delta $=+2.93 \mathrm{e}-02 \mathrm{~s}$, Delta $=+7.79 \mathrm{e}-02 \mathrm{~s}$

$24 \mathrm{~g} 0=1.44 \mathrm{e}-04$, delta $=+2.92 \mathrm{e}-02 \mathrm{~s}$, Delta $=+7.76 \mathrm{e}-02 \mathrm{~s}$

$25 \mathrm{~g} \_0=1.45 \mathrm{e}-04$, delta $=+2.90 \mathrm{e}-02 \mathrm{~s}$, Delta $=+7.72 \mathrm{e}-02 \mathrm{~s}$

$26 \mathrm{~g} 0=1.46 \mathrm{e}-04$, delta $=+2.89 \mathrm{e}-02 \mathrm{~s}$, Delta $=+7.69 \mathrm{e}-02 \mathrm{~s}$

27 g_0 $=1.47 \mathrm{e}-04$, delta $=+2.88 \mathrm{e}-02 \mathrm{~s}$, Delta $=+7.65 \mathrm{e}-02 \mathrm{~s}$

$28 \mathrm{~g} \_0=1.48 \mathrm{e}-04$, delta $=+2.86 \mathrm{e}-02 \mathrm{~s}$, Delta $=+7.62 \mathrm{e}-02 \mathrm{~s}$

$29 \mathrm{~g} \_0=1.49 \mathrm{e}-04$, delta $=+2.85 \mathrm{e}-02 \mathrm{~s}$, Delta $=+7.58 \mathrm{e}-02 \mathrm{~s}$

30 g_0 $=1.50 \mathrm{e}-04$, delta $=+2.84 \mathrm{e}-02 \mathrm{~s}$, Delta $=+7.55 \mathrm{e}-02 \mathrm{~s}$

31 g_0 $=1.51 \mathrm{e}-04$, delta $=+2.83 \mathrm{e}-02 \mathrm{~s}$, Delta $=+7.51 \mathrm{e}-02 \mathrm{~s}$

32 g_0 $=1.52 \mathrm{e}-04$, delta $=+2.81 \mathrm{e}-02 \mathrm{~s}$, Delta $=+7.48 \mathrm{e}-02 \mathrm{~s}$

Note que, se os valores indicados no arquivo "method" houverem sido arredondados ou truncados, o intervalo de valores possível para $g_{0}$ (a amplitude máxima do gradiente de difusão) é entre 1.25 . $10^{-4}$ e $1.52 \cdot 10^{-4} \frac{T}{m m}^{2}$.

\footnotetext{
${ }^{2} \mathrm{Um}$ fornecedor de antenas para gradiente de MRI oferece em seu site antenas de gradiente máximo $53 \mathrm{G} / \mathrm{cm}$ (http://www.dotynmr.com/mri/mri_fcgcpg.htm, consultado em 2013-03-19). Isso equivale a $5.3 \cdot 10^{-4} \frac{T}{\mathrm{~mm}}$. Portanto o intervalo calculado é coerente com os valores de um equipamento disponível no mercado.
} 


\section{Capítulo 8}

\section{Apêndice C}

\subsection{Integração numérica}

Conforme mencionado anteriormente, decidimos usar funções explícitas e simples para a integração numérica, para que o código fosse facilmente "auditável" por todos os interessados. Escrevemos uma função de integração que recebe como argumentos a função a ser integrada, suas váriaveis, e um número de intervalos de discretização (igual ao "número de passos" especificado para a simulação), tal como indicado na listagem abaixo:

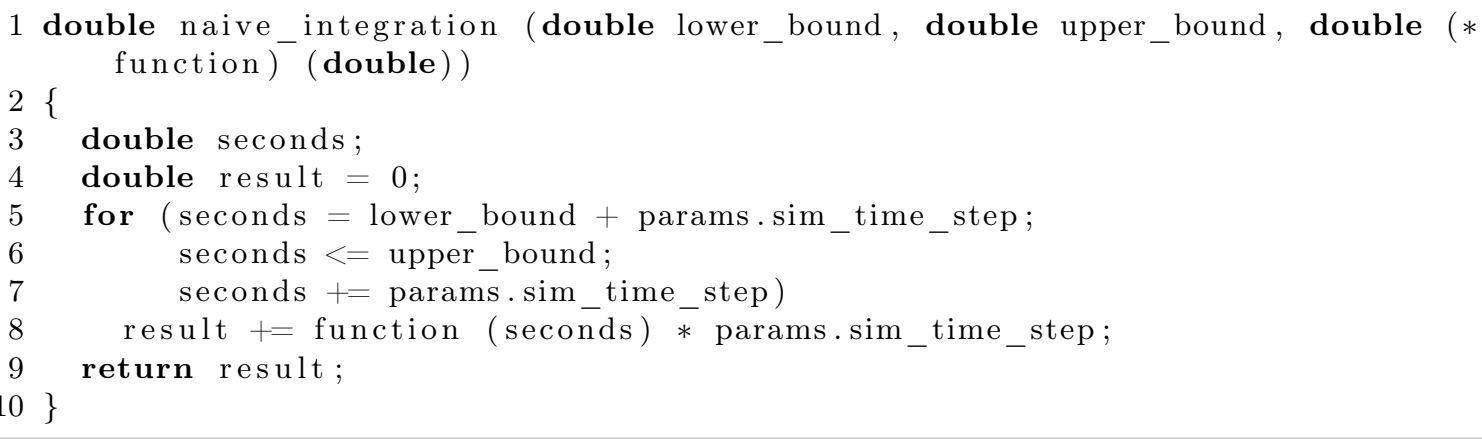

Em seguida, a função é calculada para cada ponto da série \{ limite inferior + intervalo de discretização, limite inferior $+2 *$ intervalo de discretização, ..., limite inferior $+\mathrm{X} *$ intervalo de discretização, limite superior \}, e o resultado do produto entre o valor da função no ponto multiplicado pelo intervalo de discretização é acumulado numa variável, que após exaurida a série, corresponde ao valor aproximado da integração. Este mecanismo é similar ao da soma Riemanniana [MT72], conforme ilustrado na Figura 8.1.

\subsection{Os algoritmos da simulação}

Todo o software desenvolvido nesta dissertação tem licença GPL [Fou07], e está disponível online [Bor], ou por meio de contato com o autor: rborges@ime.usp.br.

O desenho atual do software utilizado é modular, e cada etapa do processamento e da simulação é realizada por programas executáveis independentes, e, uma vez que foi utilizado um cluster para os cômputos, foi incorporada a divisão das simulações em $\mathrm{N}$ pedaços, sendo que por comodidade $\mathrm{N}$ corresponde ao número de cortes da imagem $\mathrm{b}=0$ original.

Desenvolvemos software de processamento das imagens, para conversão de formato e reordenação dos volumes. Esse software está disponível junto com o software de simulação. O fluxo de trabalho da simulação inicia-se com a especificação dos parâmetros, e de um arquivo contendo os dados brutos da imagem $\mathrm{b}=0$, e de um arquivo contendo as direções dos gradiente aplicados para a produção da imagem real. Elaborar o arquivo de configuração da máscara é parte do fluxo, que está ilustrado na Figura 8.2 


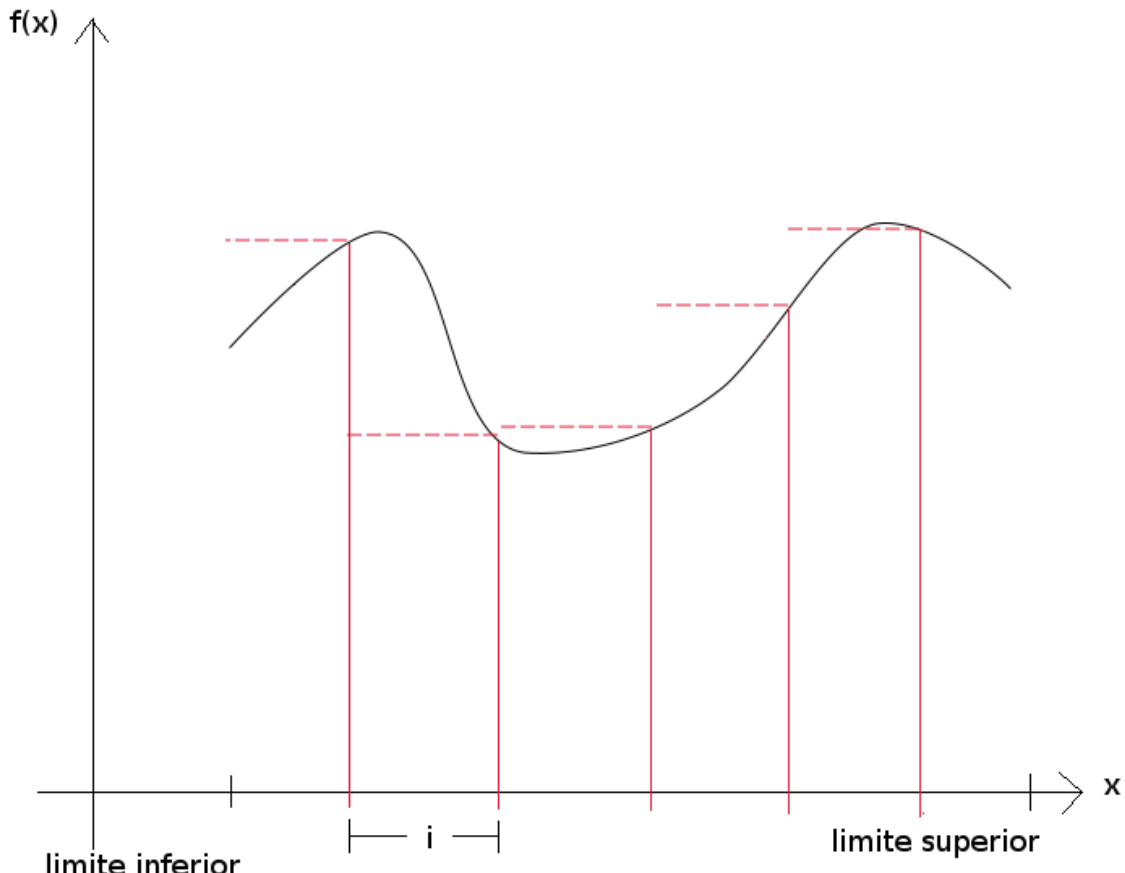

Figura 8.1: Esboço de gráfico de uma soma Riemmaniana similar à do algoritmo utilizado nesta dissertação. $i$ é o intervalo de discretização (intervalo total / número de passos), e o valor da integral é aproximado como sendo o valor da soma da série de $f(x)$ multiplicado pelo intervalo de discretização. Quanto menor o intervalo, mais o valor da soma da série se aproxima do valor da integral, e mais custoso computacionalmente o algoritmo. Figura adaptada do livro de McAloon e Trombe [MTY2].

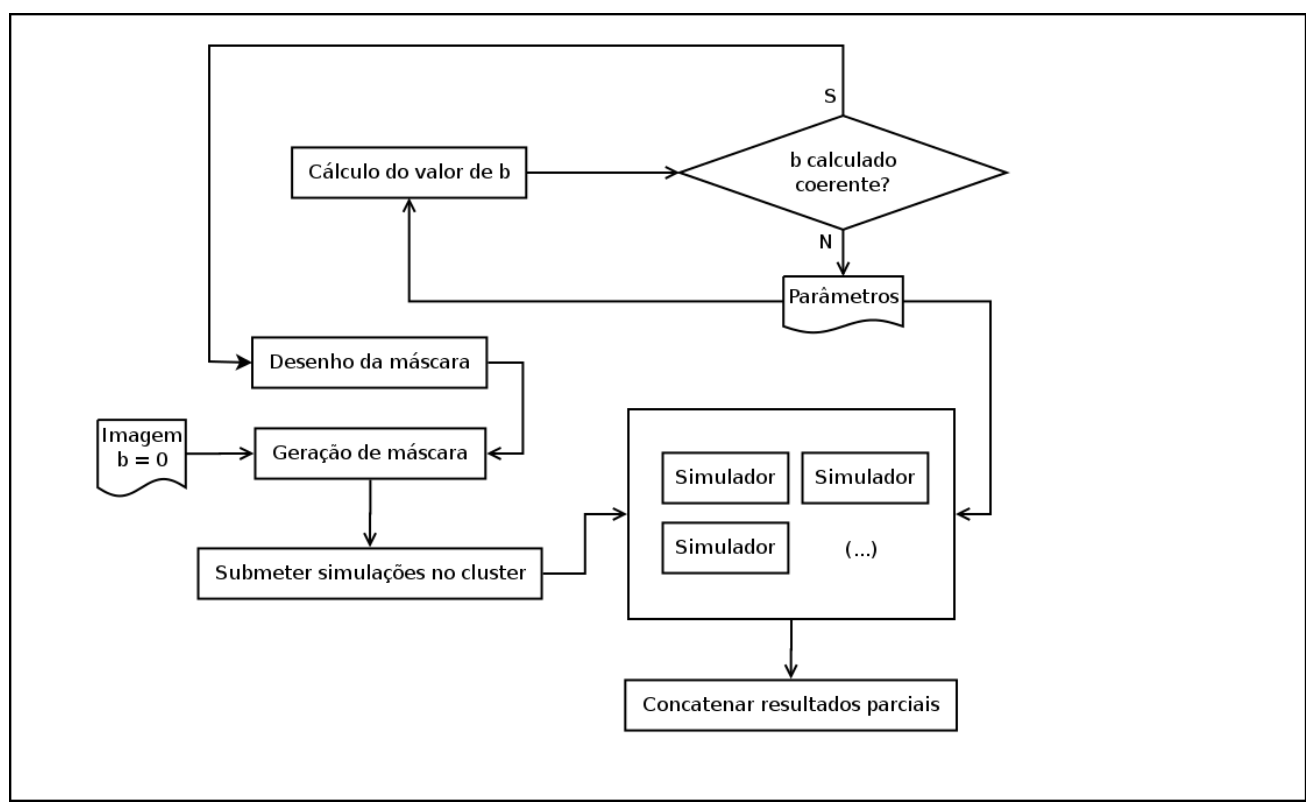

Figura 8.2: Diagrama ilustrativo do fluxo de trabalho da simulação. 


\section{Capítulo 9}

\section{Apêndice D}

\subsection{Fluxo de trabalho}

Nos parece relevante indicar uma maneira de utilizar as ferramentas produzidas nesta pesquisa para gerar autonomamente imagens de difusão por RM sintéticas. Para tanto, iremos descrever os passos utilizados para gerar resultados equivalentes aos do capítulo Resultados (p. 27).

Conforme discutido anteriormente, partimos de uma imagem $T_{2}$, fornecida por um equipamento de RM. A imagem deve ser do tipo RAW, e cada pixel deve estar codificado com um valor do tipo unsigned short. Esse arquivo deve ter o nome "b0.raw".

As dimensões da imagem devem ser conhecidas, ou seja, quantos pontos nas direções $\mathrm{X}$ e $\mathrm{Y}$ cada slice possui, e quantos slices compõem o volume.

Também é necessário escrever um arquivo de texto puro, contendo na primeira linha apenas um número inteiro que indica quantas direções do gradiente serão simuladas, e nas linhas seguintes, os valores cartesianos da direção desses gradientes, sendo cada componente separado por um espaço em branco. O arquivo deve ter como nome "directions.dat".

O software disponibilizado pelo autor [Bor] deve estar disponível num computador rodando sistema operacional GNU/Linux, e os programas executáveis devem ter sido compilados usando o padrão do arquivo "compile.cmd".

Um modelo da difusão esperada deve ser criado pelo operador, e este modelo deve ser expresso em linguagem XML num arquivo cujo nome será usado como parâmetro ao executar o programa da simulação.

Juntamente com o software, disponibilizamos todos os dados do capítulo Resultados (p. 27), e portanto os operadores poderão consultar esses exemplos para criar suas máscaras.

Em alguns segundos, os arquivos intermediários necessários para a simulação terão sido criados. Caso o operador queira verificar as máscaras, ele poderá visualizar os arquivos que codificam o ADC em cada direção cartesiana. (Assim que esses arquivos não forem mais necessários, eles serão automaticamente apagados).

Os arquivos intermediários podem ser usados de maneira distribuída, executando a simulação num cluster, ou podem ser usados serialmente, num único computador.

Finalmente, o resultado da síntese consistirá em tantos arquivos de saída quanto máquinas do cluster forem utilizadas para executar a simulação. Esses resultados preliminares são concatenados automaticamente entre si e com o arquivo b0.raw de entrada, resultando num arquivo com o mesmo nome do arquivo XML da máscara, mas com a extensão .raw.

\subsubsection{Conversão de arquivos}

Em nossa experiência, esse arquivo final é equivalente aos arquivos produzidos pelas máquinas de RM, porém estas máquinas em geral produzem arquivos codificados com formatos que contêm metadados, e portanto não são idênticos aos arquivos RAW, que contêm exclusivamente os valores dos pixels. 
Portanto, é necessário converter os arquivos de saída para um formato que o software de análise a ser empregado compreenda. No caso do BioImage $\left[\mathrm{PJR}^{+}\right]$, utilizamos o formato "Analyze" para construir mapas de difusão, e portanto precisamos converter arquivos RAW para Analyze. Para isso, usamos o MedSquare [JMea].

Analogamente, os arquivos de entrada da simulação, que precisam estar em formato RAW, podem ser obtidos convertendo os arquivos de saída dos equipamentos de RM por meio de alguma ferramenta. No caso das imagens que utilizamos, de formato REC/PAR e Bruker 2dseq, esses dados estão disponíveis em arquivos de mesmo conteúdo que um arquivo RAW equivalente, porém com a ordem dos volumes e imagens determinada arbitrariamente pelo fabricante do equipamento. Desenvolvemos ferramentas para separar os volumes e reordená-los de maneira que nosso simulador possa interpretá-los corretamente, e este software está também disponível [Bor]. Entretanto, dada a variedade de fabricantes, especificações, padrões e exceções a padrões de formato de arquivos de imagens médicas, não poderia ser nossa pretensão desenvolver ferramentas genéricas. Portanto, supomos que o usuário da ferramenta poderá converter a imagem para um formato adequado, e ordenar os volumes da mesma maneira que nossa ferramenta supõe que os volumes estejam ordenados. Nos dispomos a auxiliar nesse processo, para usuários que tenham dúvidas sobre como realizar essa etapa.

\subsubsection{Mapas de difusão}

Uma vez de posse do resultado final da simulação, queremos criar os mapas de difusão da imagem sintética, e comparar com os resultados originais. Para isso, precisamos primeiro converter a imagem sintética do formato RAW para um formato que o BioImage $\left[\mathrm{PJR}^{+}\right]$compreenda, especificamente, para o formato Analyze.

Finalmente, usando a ferramenta BioImage $\left[\mathrm{PJR}^{+}\right]$, carregamos as imagens sintéticas, e elaboramos mapas de difusão especificando o mesmo arquivo de direções que foi usado para a síntese de imagens, o mesmo b-value utilizado como parâmetro da simulação, e desativando o threshold automático (para termos um resultado tão completo quanto possível). A imagem gerada deverá ser equivalente à imagem gerada a partir da imgem de difusão por RM obtida diretamente da máquina de RM, exceto nas regiões em que o modelo de difusão especificado pelo operador não coincida com a difusão real da amostra. 


\section{Capítulo 10}

\section{Apêndice E}

\subsection{Resultados preliminares}

O primeiro exercício empreendido foi tentar reproduzir a figura 6 do artigo de Roberts [Rob91] (ver a figura 10.1).

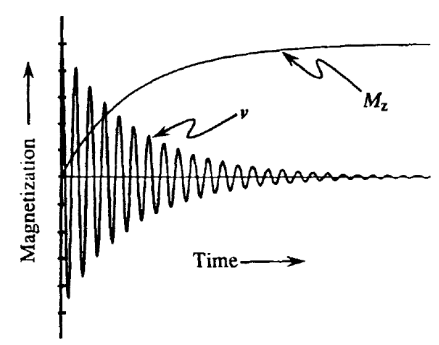

Figura 10.1: No artigo de Roberts, esta é a figura número 6. Corresponde ao FID obtido pelo autor para o algoritmo que ele propõe.

Em seu artigo, Roberts especifica o algoritmo e os valores iniciais para produzir essa figura. Entretanto, nossa implementação resultou em uma imagem diferente: o módulo do vetor de magnetização $M_{z}$ pouco diminui, e haviam menos picos na curva FID da função v, ao contrário da imagem apresentada por esse autor.

Modificamos os valores iniciais, e assim conseguimos obter um resultado visualmente compatível com o resultado apresentado pelo autor (ver figura 10.2). Entretanto, como o gráfico original não indica as unidades e os valores em seus eixos, a comparação fica limitada ao contraste visual.

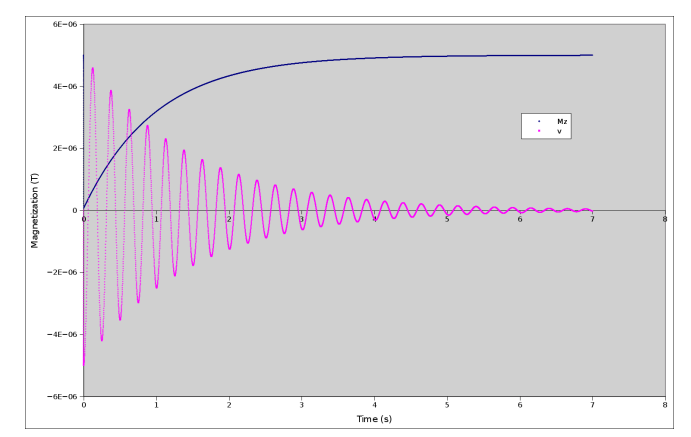

Figura 10.2: Nossa tentativa de reproduzir os resultados da figura 6 do artigo de Roberts.

Segundo Hoa [Hoa], os valores para T1 e T2 da água são ambos 3000 ms. Usando estes valores para os parâmetros do algoritmo, aumentando o tempo de observação para 15 segundos e modificando o parâmetro $\left(\omega_{0}-\omega\right)$ para $10 \mathrm{~Hz}$, obtivemos um gráfico equivalente ao anterior, mas para a água (ver figura 10.3). 


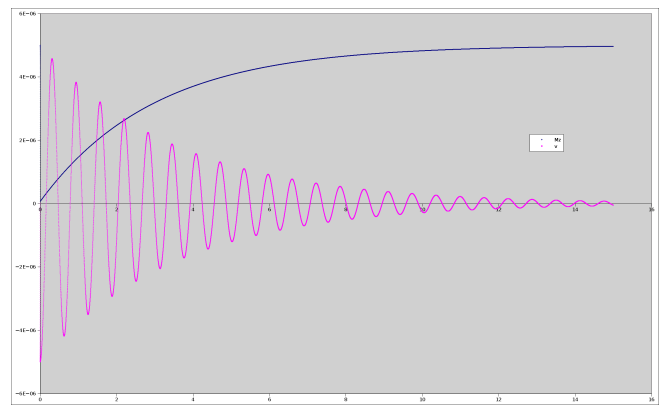

Figura 10.3: FID para os parâmetros $T 1=T 2=3000 \mathrm{~ms}$, usando o algoritmo adaptado de Roberts. As unidades dos eixos são as mesmas da figura 10.2.

As funcções $\mathrm{u}(\mathrm{t})$ e $\mathrm{v}(\mathrm{t})$, tal como definidos por Roberts, são as magnitudes dos componentes paralelo e perpendicular de $\mathrm{M}_{x y}$ em relação ao vetor $\mathrm{B}_{1}$. Dessa maneira, podemos calcular $\mathrm{M}_{x y}(\mathrm{t})$.

O segundo exercício empreendido consistiu em produzir um arquivo com os dados do k-space a partir do sinal obtido anteriormente. Essa imagem foi então carregada no programa BioImage Suite (Jackowski et al $\left[\mathrm{PJR}^{+}\right]$) e a iFFT (Transformada Inversa de Fourier Rápida - inverse Fast Fourier Transform) aplicada, com o resultado de uma imagem cinza homogênea, condizente com o modelo adotado anteriormente.

\subsubsection{Fantomas de primeira geração}

O primeiro conjunto de imagens de fantomas físicos que obtivemos foi descartado, pois por equívoco no arquivo final não foram salvas as direções dos gradientes de difusão usadas pelo equipamento de RM. Por isso, estas imagens não puderam ser aproveitadas. Mas alguns problemas na confecção dos fantomas foram observados e corrigidos para uma segunda versão.

\subsubsection{Fantomas de segunda geração}

Foram adquiridas imagens de difusão por RM por intermédio da Profa. Dra. Maria Concepción García Otaduy, no Hospital das Clínicas da Faculdade de Medicina da Universidade de São Paulo, escaneados em 2012-07-10.

A segunda versão dos fantomas sofreu com um erro estratégico na sequência de pulsos escolhida: foram adquiridas 32 direções de gradiente, mas sem repetições. Por isso, a SNR é pequena. Outro problema é devido à tensão exagerada do fio de nylon em torno de seu suporte: praticamente não há sinal de difusão entre as fibras, possivelmente devido à água não ter penetrado nessa região.

Por motivos práticos, a escritura e o desenvolvimento dos métodos de simulação foram empreendidos em grande parte utilizando este segundo conjunto de imagens, em especial as do salsão, apesar de não serem imagens de boa qualidade.

Os fantomas de "primeira geração" (vide figura 10.4) consistiram de potes plástico transparente, com tampa emborrachada para melhor evitar vazamentos. No centro de duas faces opostas do pote, foi afixado um suporte redondo, no formato de uma rosca, de plástico. Foi construída uma haste de plástico flexível removendo partes de uma colher plástica para cozinha.

Nessa haste foram presos, usando braçadeiras plásticas, os talos de salsão fresco, ou o rolo de fio de nylon. A haste então foi colocada dentro do pote, apoiada nas roscas. A flexibilidade das paredes do pote permitiu usar uma haste suficientemente longa para que existisse uma tensão das paredes sobre a haste, de modo a mantê-la firme no lugar.

No dia anterior ao experimento, foram adquirido o salsão fresco, montados os talos na haste e fixada a haste no pote. Dois potes foram então preenchidos com água, sendo que em um deles foi adicionado açúcar refinado. Um terceiro pote foi montado com o rolo de fio de nylon.

No dia seguinte, os fantomas foram transportados para o equipamento de ressonância, e as imagens foram adquiridas. Infelizmente, as imagens não foram salvas junto com as informações de direção de aquisição do gradiente, e por isso não puderam ser utilizadas. 


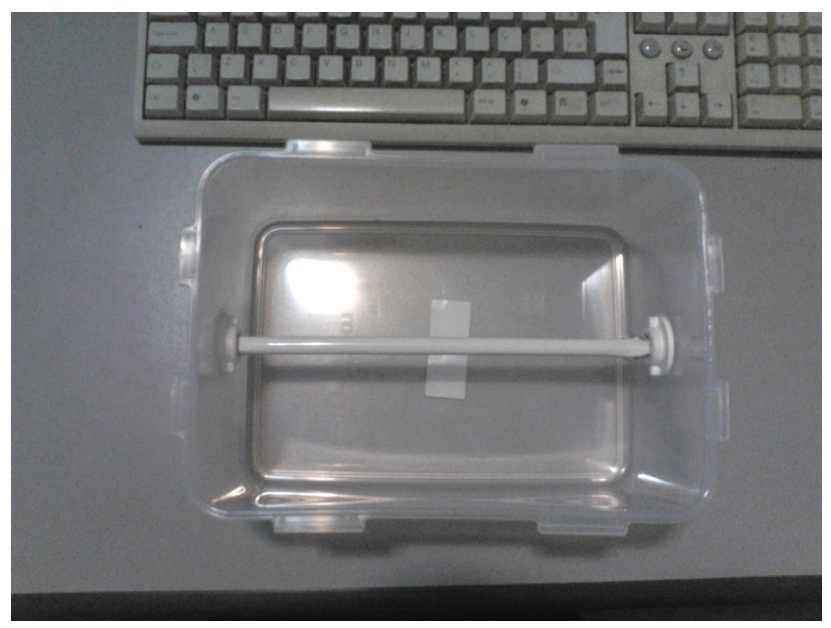

Figura 10.4: Suporte dos fantomas de primeira geração.

Os fantomas de "segunda geração" foram montados em potes semelhantes aos anteriores. Os talos de salsão desta vez foram fixados por meio de dois anéis de PVC, um em cada extremidade do fantoma. Dessa forma, não utilizamos a haste plástica ao longo da amostra, algo que complicava desnecessariamente o fantoma de primeira geração.

Os anéis deste novo fantoma tinham pés, de modo que os talos de salsão preenchiam uma região aproximadamente cilíndrica do fantoma, sem encostar em nenhuma parede do pote. O fantoma de nylon consistiu de dois rolos de $500 \mathrm{~m}$ de fio de nylon, mas devido à falta de sinal obtido com este fantoma, ele não foi aproveitado para a produção de resultados (vide figura 10.5). O sinal de difusão só aparece com direcionalidade coerente na região limítrofe das fibras com a água, e por isso não é possível determinar se este sinal é devido à difusão da água numa camada superficial das fibras, ou se é devido a um efeito de as moléculas de água baterem na superfície do rolo como se fosse uma "parede", sem penetrar entre as fibras. O que esperávamos era obter um resultado em que o sinal fosse coerente no interior da região das fibras, o que não aconteceu.

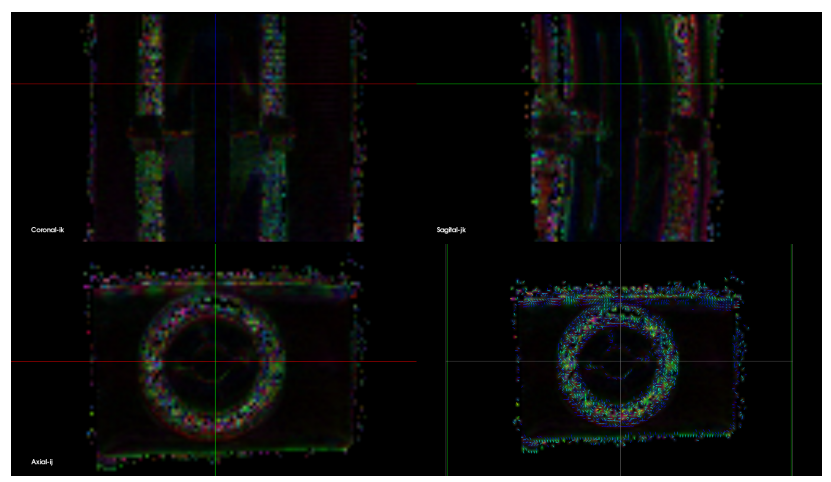

Figura 10.5: Imagens de difusão do fantoma de nylon. Produzidas com os software MedSquare [JMea] e Bioimage $\left[P J R^{+}\right]$.

Uma possível explicação para a falta de sinal de difusão coerente é que em 24 horas a água não penetrou profundamente entre as fibras de nylon, devido à tensão excessiva do rolo (que foi usado tal como adquirido, ou seja, com a tensão própria de sua produção industrial). Isto causou uma falta de sinal de hidrogênios da água, que pode ser notada já na imagem com $b=0$ (vide figura 10.6).

Uma vez que não havia sinal suficiente na região das fibras, a SNR dessa região é muito pequena, e por isso a difusão é incoerente nessa região: o algoritmo de cálculo dos tensores tinha poucos dados para calcular a direção principal de difusão em cada ponto.

Um outro detalhe que pode ser notado na imagem com $\mathrm{b}=0$ é a distorção que se pode observar no corte coronal da imagem. É provável que tal distorção seja efeito de bolhas de ar que permanece- 


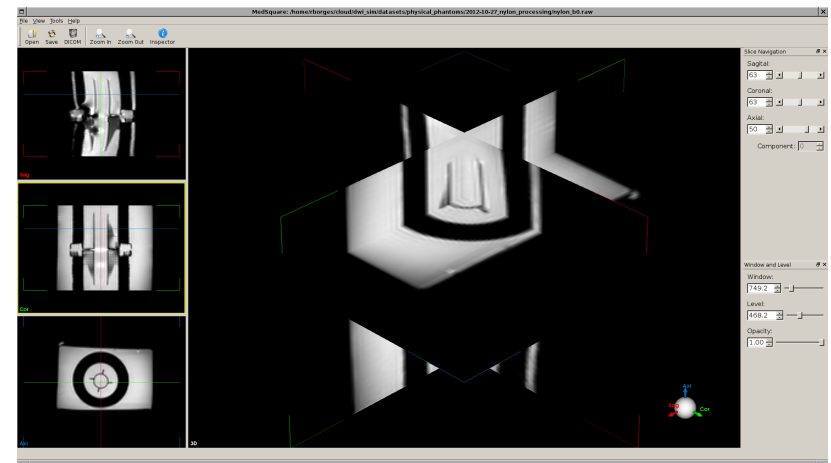

Figura 10.6: Imagem do fantoma de nylon. $b=0$. Produzido com o software MedSquare [JMea].

ram no fantoma. Isto indica a necessidade de se preparar cada fantoma com o máximo de cuidado para que esteja tão livre de bolhas quanto possível.

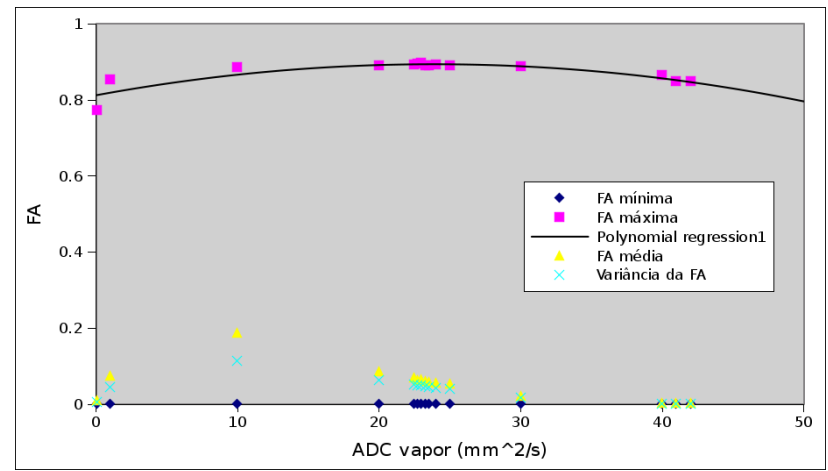

Figura 10.7: Gráfico da variação do parâmetro "ADC do vapor d'água". A curva contínua indica uma interpolação polinomial de grau 2, e sugere que há um máximo local para a simulação, com estas condições, para $A D C$ do vapor próximo de $23 \mathrm{~s} / \mathrm{mm}^{2}$.

As simulações exigem, além da imagem T2 real, uma máscara de direções para o cálculo da difusividade. Essa máscara é gerada a partir de uma especificação textual. No caso do exemplo indicado nesta seção, a especificação (cf. Figura 10.8) indica um valor muito baixo para o ADC do vapor d'água (componente "FOV" da especificação). Este parâmetro, e outros, foram modificados, de modo a convergir a estatística da simulação para valores próximos aos da estatística da imagem real.

\subsubsection{Fantoma de nylon}

Foi construído um fantoma de nylon (figura 10.9), composto por 7 rolos de fio de nylon, adquiridos comercialmente. Cada rolo possui fios de espessura diferente: $0.16,0.20,0.28,0.30,0.35,0.40$ e $0.50 \mathrm{~mm}$.

Esse fantoma foi escaneado num aparelho Philips Achieva 3.0T, com o eixo ao longo do qual os rolos estavam dispostos paralelo ao eixo principal do campo magnético B0.

Foram adquiridos 4 conjuntos de imagens DWI, com b-values 250, 500, 750 e $1000 \mathrm{~s} / \mathrm{mm}^{2}$. Cada um destes conjuntos foi escaneado em 32 direções diferentes.

\subsubsection{Fantoma de salsão}

Foi construído um fantoma de salsão (figura 10.10), composto por 8 segmentos de talos de salsão, que foram medidos conforme indicado nas figuras 10.11 e 10.12: o diâmetro externo e a espessura máxima do talo de salsão, respectivamente. Essas medidas foram feitas próximas (a menos de $1 \mathrm{~cm}$ ) de cada extremidade do talo. 4 dos segmentos de salsão deste fantoma foram ignorados, por terem sido fatiados ao longo de seu comprimento, um erro na preparação do fantoma (cf. tabela 10.1). 


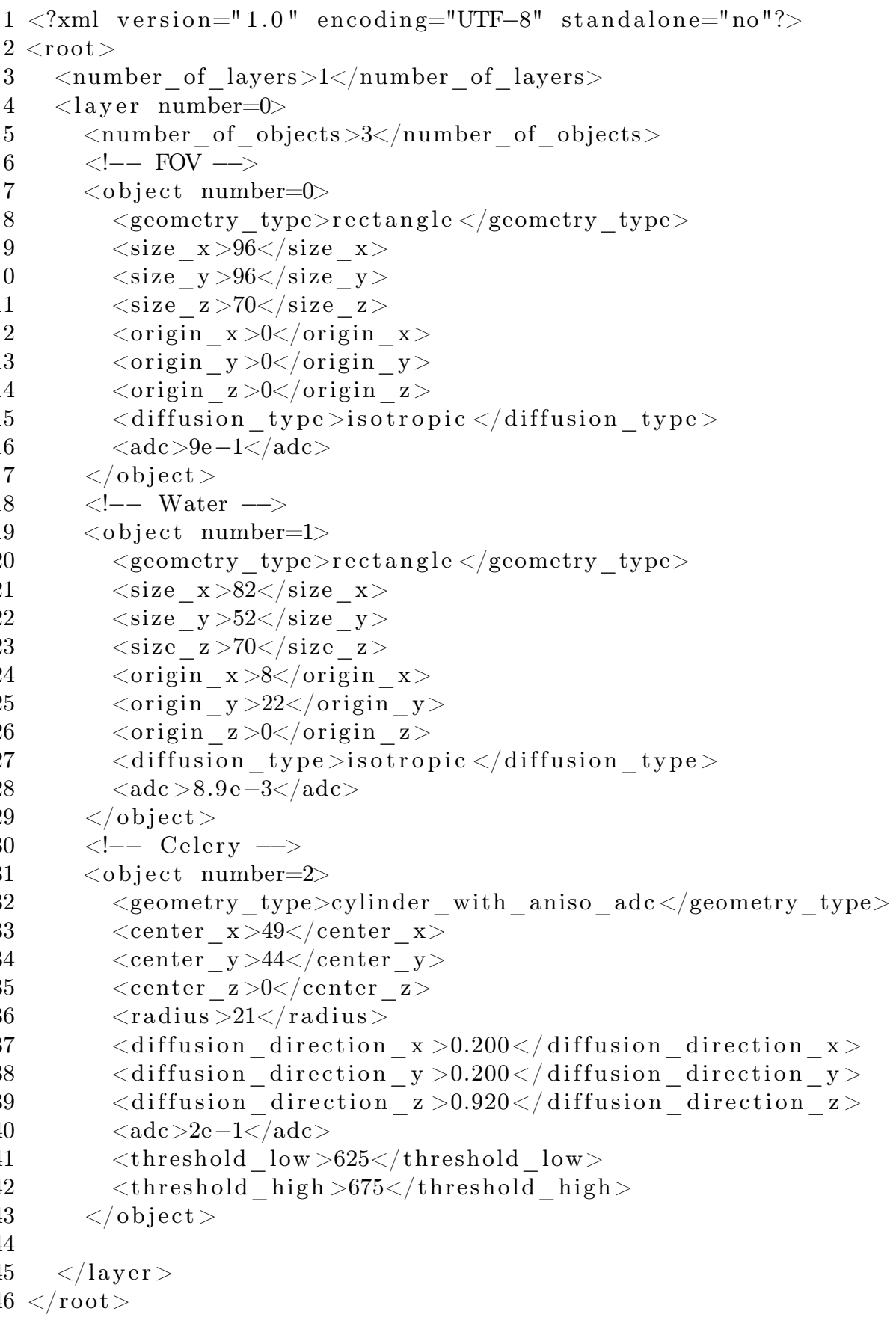

Figura 10.8: Especificação da máscara para a simulação 50.

Também foi medido o diâmetro do fantoma montado, aproximadamente no centro de cada região entre as braçadeiras plásticas que seguravam o conjunto no lugar (cf. tabela 10.2).

Esse fantoma foi escaneado num aparelho Philips Achieva 3.0T, com os talos dispostos paralelos ao eixo principal do campo magnético B0.

Foram adquiridos 4 conjuntos de imagens DWI, com b-values 250, 500, 750 e $1000 \mathrm{~s} / \mathrm{mm}^{2}$. Cada um destes conjuntos foi escaneado em 32 direções diferentes.

\subsubsection{Fantoma de salsão com sal}

Foi construído um fantoma de salsão (figura 10.13), equivalente ao fantoma de salsão indicado anteriormente, mas imerso em solução de água com sal. Este fantoma foi construído com 7 segmentos 


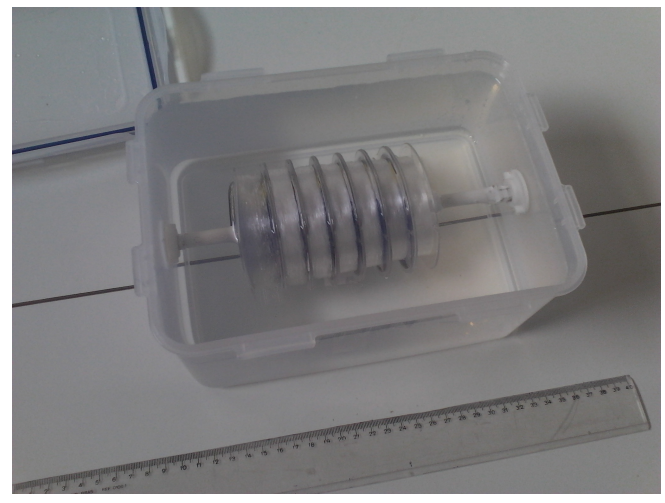

Figura 10.9: Fantoma de nylon, aberto.

\begin{tabular}{lc} 
Medida & Diâmetro $(\mathrm{mm})$ \\
\hline 1 & 47.25 \\
2 & 47.20 \\
3 & 47.40 \\
4 & 46.65 \\
5 & 47.40
\end{tabular}

Tabela 10.1: Diâmetros do fantoma de salsão.

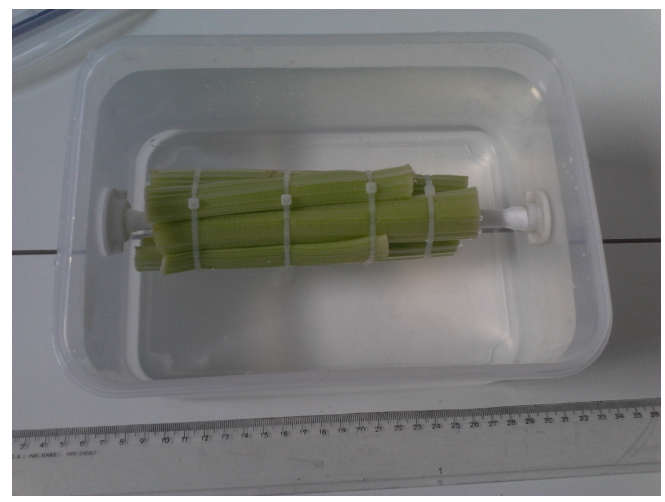

Figura 10.10: Fantoma de salsão, aberto.

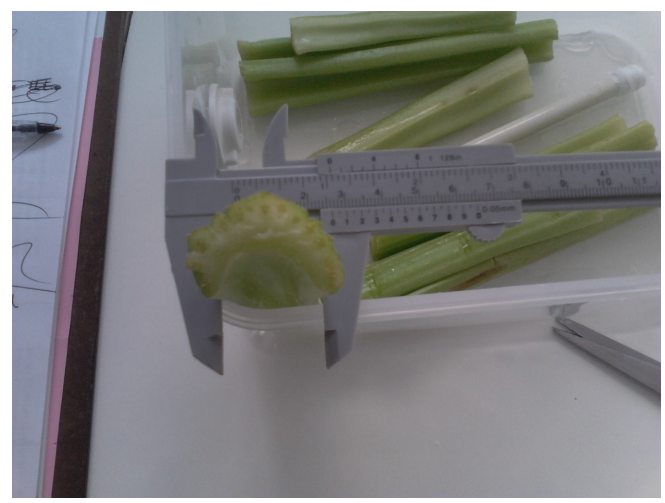

Figura 10.11: Medição do diâmetro externo do talo de salsão.

de talos de salsão.

Foi medido o diâmetro do conjunto, tal como no fantoma anterior (cf. tabela 10.3).

Esse fantoma foi escaneado num aparelho Philips Achieva 3.0T, com o eixo ao longo do qual os rolos estavam dispostos paralelo ao eixo principal do campo magnético B0.

Foram adquiridos 4 conjuntos de imagens DWI, com b-values 250, 500, 750 e $1000 \mathrm{~s} / \mathrm{mm}^{2}$. Cada 


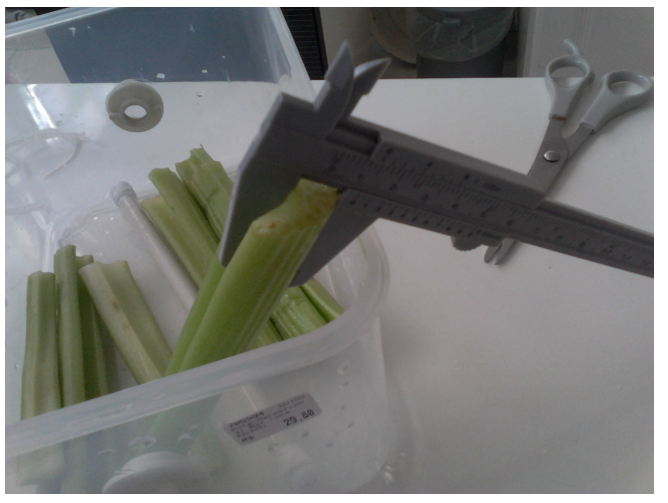

Figura 10.12: Medição da espessura máxima do talo de salsão.

\begin{tabular}{lcl} 
Talo & Diâmetro $(\mathrm{mm})$ & Espessura $(\mathrm{mm})$ \\
\hline $1 \mathrm{a}$ & 29.80 & 11.65 \\
$\mathrm{~b}$ & 21.15 & 11.95 \\
$\mathrm{2a}$ & 24.35 & 10.20 \\
$2 \mathrm{~b}$ & 18.80 & 11.80 \\
$3 \mathrm{a}$ & 24.55 & 8.65 \\
$3 \mathrm{~b}$ & 18.60 & 8.55 \\
$4 \mathrm{a}$ & 21.50 & 10.50 \\
$4 \mathrm{~b}$ & 19.70 & 10.85
\end{tabular}

Tabela 10.2: Diâmetros e espessuras dos talos usados no fantoma de salsão.

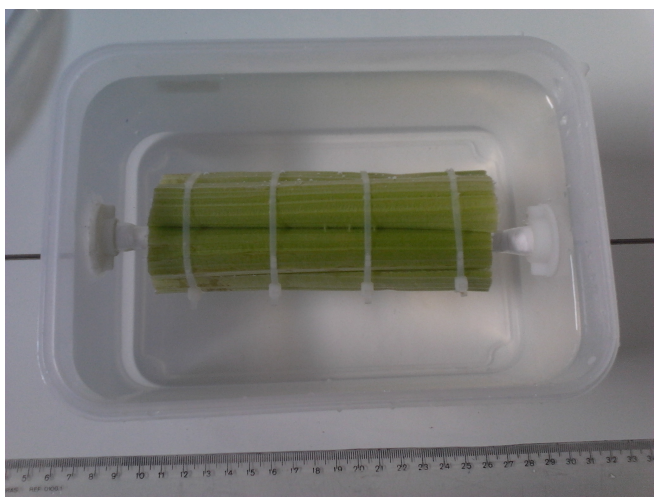

Figura 10.13: Fantoma de salsão com sal, aberto.

um destes conjuntos foi escaneado em 32 direções diferentes.

As medidas de diâmetro e espessura foram feitas tais como para o fantoma do salsão, e foram descartadas as medidas de 2 talos, pois correspondiam a talos cortados ao longo de seu comprimento, algo que demonstrou ser um erro na preparação do fantoma (cf. tabela 10.4).

\begin{tabular}{lc} 
Medida & Diâmetro $(\mathrm{mm})$ \\
\hline 1 & 49.35 \\
2 & 46.40 \\
3 & 47.65 \\
4 & 47.20 \\
5 & 46.45
\end{tabular}

Tabela 10.3: Diâmetros do fantoma de salsão. 


\begin{tabular}{lcl} 
Talo & Diâmetro $(\mathrm{mm})$ & Espessura $(\mathrm{mm})$ \\
\hline 1a & 25.25 & 18.20 \\
1b & 18.75 & 8.20 \\
2a & 21.65 & 8.45 \\
2b & 11.50 & 7.65 \\
3a & 21.80 & 11.75 \\
3b & 20.10 & 10.40 \\
$4 \mathrm{a}$ & 20.50 & 10.85 \\
$4 \mathrm{~b}$ & 16.90 & 9.85 \\
$5 \mathrm{a}$ & 22.25 & 10.15 \\
$5 \mathrm{a}$ & 17.20 & 9.60
\end{tabular}

Tabela 10.4: Diâmetros e espessuras dos talos usados no fantoma de salsão com sal.

\subsubsection{Processamento das imagens adquiridas}

As imagens foram salvas em formato REC/PAR, sendo que os dados para cada b-value estavam intercalados, isto é, foi criado um único arquivo .REC para cada fantoma, e esse arquivo continha 132 componentes, que correspondiam a 33 componentes para cada b-value, sendo 32 os componentes com gradiente de difusão em direções diferentes, e 1 componente sem gradiente de difusão.

Foi escrito um software para abrir cada um desses arquivos, e extrair os componentes, em ordem, para cada b-value. O componente que corresponde à ausência de gradiente foi deslocado do fim para o início do arquivo. Os dados foram salvos com o formato RAW.

O software para processar as imagens REC/PAR de saída do equiapmento Philips foi sistematizado para que com um único comando, especificando todos os parâmetros a serem utilizados, o processamento seja feito:

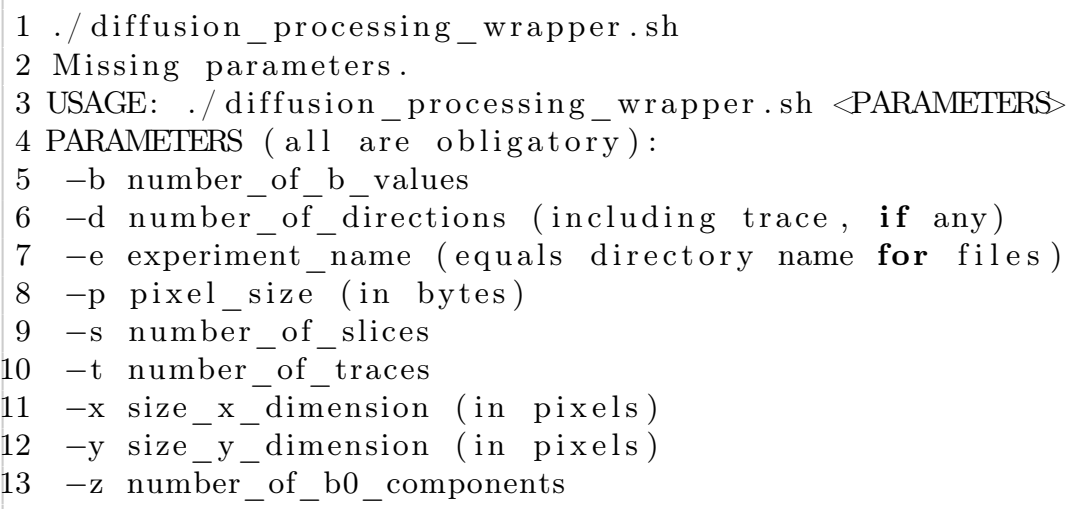

A saída final desse script consiste num arquivo RAW que tem a imagem $T_{2}$ e os componentes da imagem, um para cada direção, nessa ordem, e um arquivo com as direções dos gradientes de difusão, na mesma ordem do arquivo RAW.

Usando o software MedSquare [JMea], transformamos os arquivos individuais do formato RAW para o formato Analyze, que é então usado para gerar os arquivos com o tensores de difusão e as imagens finais, com o software bioimage $\left[\mathrm{PJR}^{+}\right]$.

\subsubsection{Convergência da simulação com a imagem real}

Após realizarmos diversas simulações exploratórias, para compreender qualitativamente a influência de cada parâmetro no resultado final, realizamos séries de simulações variando apenas um dos parâmetros, escolhendo valores para convergir algum dos resultados estatísticos para o valor do resultado real. Apresentaremos apenas uma parte dos dados aqui. O conjunto completo dos dados pode ser obtido online [Bor].

No capítulo sobre motivação, mostramos (cf. Tabela 10.6 e Figura 10.7) o conjunto de simulações feitas para convergir o valor de FA máximo da simulação com o valor real. Analogamente, realizamos 
uma série de simulações para convergir o valor da FA média (cf. Tabela 10.5 e Figura 10.14), desta vez variando o valor do $\mathrm{ADC}$ da região com água líquida na simulação.

\begin{tabular}{l|r|l|l|l|l}
\hline Modelo & ADC água $\left(\mathrm{mm}^{2} / \mathrm{s}\right)$ & FA mínima & FA máxima & FA média & Variância da FA \\
\hline \hline Real & - & 0.0023 & 0.9633 & 0.1152 & 0.0122 \\
xml091 & $1 \mathrm{E}-02$ & 0.0004 & 0.8906 & 0.1522 & 0.0660 \\
xml092 & $5 \mathrm{E}-03$ & 0.0004 & 0.8906 & 0.0615 & 0.0463 \\
xml093 & $7.5 \mathrm{E}-03$ & 0.0004 & 0.8906 & 0.0628 & 0.0465 \\
xml094 & $8.5 \mathrm{E}-03$ & 0.0004 & 0.8906 & 0.0862 & 0.0510 \\
xml095 & $9 \mathrm{E}-03$ & 0.0004 & 0.8906 & 0.1063 & 0.0557 \\
xml096 & $9.5 \mathrm{E}-03$ & 0.0004 & 0.8906 & 0.1285 & 0.0610 \\
xml097 & $9.25 \mathrm{E}-03$ & 0.0004 & 0.8906 & 0.1172 & 0.0583 \\
\hline
\end{tabular}

Tabela 10.5: Variação do parâmetro "ADC da água líquida" modifica o valor da FA média das simulações; tentamos convergir para o valor real, que está indicado para $A D C$ da água $=0$ no gráfico.

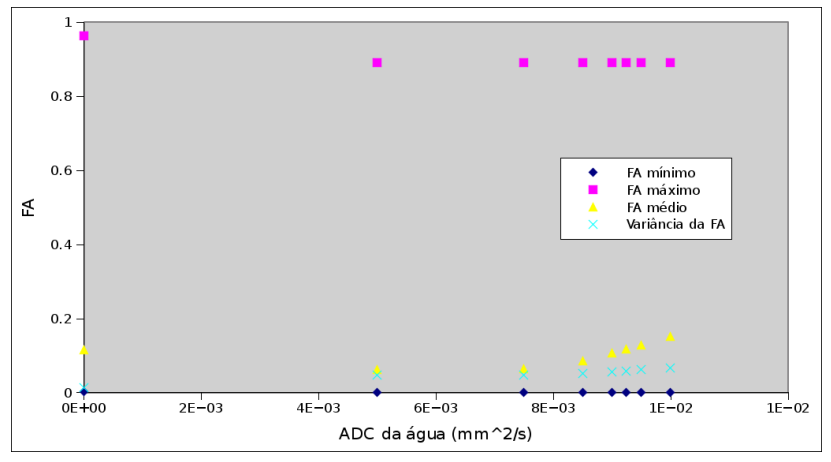

Figura 10.14: Gráfico da variação do parâmetro "ADC da água líquida".

Este resultado para a média da FA foi apenas um exercício para verificar se os resultados da simulação são próximos do resultado conhecido na literatura, de que o o coeficiente de difusão da água na temperatura típica de um corpo humano (37 C) é $3 \cdot 10^{-3} \mathrm{~mm}^{2} \mathrm{~s}^{-1}$ [JBB09]. Uma vez que obtivemos um valor na mesma ordem de grandeza, e sabendo que a amostra se refere a um tecido vegetal, à temperatura ambiente (cerca de $20 \mathrm{C}$ ), consideramos que o exercício indica a validade do simulador. Ainda assim, esse valor é apenas uma primeira aproximação, pois o próximo passo foi incluir a região dos talos de salsão e isto modificou o valor da FA média. Note que os valores para FA máxima e mínima não variaram para os diferentes valores de $\mathrm{ADC}$ da água. Isto se dá pois o valor mínimo para FA é na região que contém apenas ar no fantoma, e o valor máximo se dá na região da amostra propriamente dita, aonde a geometria das fibras induz uma maior anisotropia da difusão.

\subsubsection{Estudo de variação do parâmetro "ADC do vapor d'água"}

Um dos usos pretendidos para o sintetizador é que auxilie no estudo sistemático dos efeitos da variação de um parâmetro que influencie a difusão sobre as imagens de difusão por RM.

A maneira como isto pode se dar é usando a simulação para obter imagens de difusão de uma amostra fixa, variando ao menos um parâmetro da simulação da aquisição e então construindo, por exemplo, uma tabela (cf. Tabela 10.6) ou um gráfico (cf. Figura 10.7) que relaciona o parâmetro investigado com a intensidade de sinal na região de interesse na imagem ${ }^{1}$. Dessa forma, é possível

\footnotetext{
${ }^{1}$ No exemplo, foi estudado o efeito de modificar o valor do ADC do vapor de água, que corresponde às regiões com intensidade mínima do sinal, mas uma vez que há pouco sinal no ar, essas regiões são as de máximo valor de FA. Nestes experimentos, a região da máscara anisotrópica foi mantida mínima, e a região que contém água na amostra do fantoma foi mascarada com um valor de ADC constante. O único parâmetro variado foi o ADC do vapor, e dessa forma tentamos alcançar um valor equivalente para a FA máxima, com relação ao valor medido na amostra
} 
prever, por exemplo, qual o valor ideal para o parâmetro investigado, para se obter uma imagem com intensidade máxima na região de interesse. Ao investigar sistematicamente os parâmetros que podem ser variados na simulação, um pesquisador poderá determinar aproximadamente os parâmetros de aquisição de imagens de difusão por RM que melhor expõem o objeto que ele pretende discernir através da aquisição de uma imagem no equipamento de RM. Esta técnica também permite prever como mudanças quantitativas do ADC irão influenciar a imagem de difusão final.

\begin{tabular}{l|l|l|l|l|l}
\hline Modelo & ADC vapor $\left(\mathrm{mm}^{2} / \mathrm{s}\right)$ & FA mínima & FA máxima & FA média & Variância da FA \\
\hline \hline fantoma & - & 0.0023 & 0.9633 & 0.1152 & 0.0122 \\
71 & 0.100 & 0.0004 & 0.7733 & 0.0104 & 0.0049 \\
72 & 1.000 & 0.0004 & 0.8533 & 0.0747 & 0.0443 \\
73 & 10.000 & 0.0004 & 0.8843 & 0.1876 & 0.1137 \\
76 & 40.000 & 0.0004 & 0.8653 & 0.0015 & 0.0003 \\
80 & 41.000 & 0.0004 & 0.8484 & 0.0013 & 0.0002 \\
81 & 42.000 & 0.0004 & 0.8474 & 0.0013 & 0.0001 \\
82 & 20.000 & 0.0004 & 0.891 & 0.0851 & 0.0622 \\
83 & 30.000 & 0.0004 & 0.8874 & 0.0217 & 0.0166 \\
84 & 25.000 & 0.0004 & 0.8889 & 0.0524 & 0.0399 \\
85 & 22.500 & 0.0004 & 0.8916 & 0.0687 & 0.0514 \\
86 & 23.000 & 0.0004 & 0.8973 & 0.0657 & 0.0492 \\
87 & 24.000 & 0.0004 & 0.8918 & 0.0544 & 0.0413 \\
88 & 23.500 & 0.0004 & 0.8895 & 0.0579 & 0.0438 \\
89 & 22.750 & 0.0004 & 0.8939 & 0.063 & 0.0474 \\
90 & 23.250 & 0.0004 & 0.8893 & 0.0597 & 0.0451 \\
\hline
\end{tabular}

Tabela 10.6: Variação do parâmetro "ADC do vapor d'água" modifica a estatística das simulações. Os valores relativos à imagem DW MRI do fantoma também são tabelados. 


\section{Referências Bibliográficas}

[Abr61] A. Abragam. The Principles of Nuclear Magnetism. Oxford University Press, 1961. 13, 14

[BA94] Christian Beaulieu e Peter S. Allen. Water diffusion in the giant axon of the squid: Implications for the diffusion-weighted mri of the nervous system. Magnetic Resonance in Medicine, 32:579-583, 1994. iii, v, 3, 5, 36

[BAJA12] Shani Ben-Amitay, Derek K. Jones e Yaniv Assaf. Motion correction and registration of high b-value diffusion weighted images. Magnetic Resonance in Medicine, 67:1694-1702, 2012. 15

$\left[\mathrm{BCCB}^{+}\right]$H. Benoit-Cattin, G. Collewet, B. Belaroussi, H. Saint-Jalmes e C. Odet. The simri project : A versatile and interactive mri simulator. Journal of Magnetic Resonance. Accepted in September 2004. xiii, 4, 5, 6, 36

[BCGT05] G. P. Berman, B. M. Chernobrod, V. N. Gorshkov e V. I. Tsifrinovich. Spin diffusion and relaxation in a nonuniform magnetic field. Physical Review B, 71, 2005. 3, 4

[Bea] Christian Beaulieu. The biological basis of diffusion anisotropy. apud [JBB09]. 2, 4, 13, 36

[BF08] Gregory T. Balls e Lawrence Frank. A realistic dti simulation environment. Proceedings of the International Society for Magnetic Resonance in Medicine, 16:1794, 2008. iii, v, $3,4,6$

[BF13] Gregory T. Baxter e Lawrence R. Frank. A computational model for diffusion weighted imaging of myelinated white matter. NeuroImage, 75:212-220, 2013. iii, v, 3, 4, 6

[Blo46] F. Bloch. Nuclear induction. Physical Review, 70(7 and 8), 1946. 13, 39

[BM62] C. O. Bennet e J. E. Myers. Momentum, Heat, and Mass Transfer. McGraw-Hill, 1962. 7,8

[BO] Peter J. Basser e Evren Ozarslan. Introduction to diffusion mr. apud [JBB09]. xiv, 7, $8,9,14$

[Bor] Renato Callado Borges. Dwi simulation for my 2013 master thesis: software and data. Pode ser obtido em http://www.ime.usp.br/ rborges/dissertation_masters_2013/. iii, $\mathrm{v}, 4,25,41,43,45,46,54$

[CIF99] M. Cercignani, G. Iannucci e M. Filippi. Diffusion-weighted imaging in multiple sclerosis. The Italian Journal of Neurological Sciences, 20:S246-S249, 1999. 3

[Cus97] E. L. Cussler. Diffusion: Mass Transfer in Fluid Systems. Cambridge University Press, second edition edição, 1997. 4, 7, 8 
[DMS01] Andrej Duh, Ales Mohoric e Janez Stepisnik. Computer simulation of the spin-echo spatial distribution in the case of restricted self-diffusion. Journal of Magnetic Resonance, 148:257-266, 2001. 4, 5

[Fou] Free Software Foundation. Gnu scientific library. Obtida em https://www.gnu.org/ software/gsl/. Consultado in 2013-01-28. 25, 32, 36

[Fou07] Free Software Foundation. Gnu general public license. 2007. GPL version 3, de 29 de Junho de 2007. Obtida em https://www.gnu.org/licenses/gpl.html. Consultado em 2013-03-04. iii, v, 25, 43

[FR81] Eiichi Fukushima e Stephen B. W. Roeder. Experimental pulse NMR: A nuts and bolts approach. Westview Press, 1981. 12

[HJNS03] Hakan Hagslatt, Bengt Jonsson, Magnus Nyden e Olle Soderman. Predictions of pulsed field gradient nmr echo-decays for molecules diffusing in various restrictive geometries. simulations of diffusion propagators based on a finite element method. Journal of Magnetic Resonance, 161:138-147, 2003. 3, 4, 5

[Hoa] Denis Hoa. Signal weighting (t1, t2, pd) and sequences parameters : Tr, te. Publicado em 2009-02-15. Obtido em http://www.imaios.com/en/e-Courses/e-MRI/ MRI-signal-contrat/Signal-weighting. Consultado in 2012-02-21. 47

[JBB09] Heidi Johansen-Berg e Timothy E. J. Behrens. Diffusion MRI: From Quantitative Measurement to In vivo Neuroanatomy. Elsevier, 2009. 3, 4, 6, 9, 12, 15, 55, 57

[JMea] M. P. Jackowski, C. Mekkaoui e et al. Medsquare. Obtido em: http://ccsl.ime.usp.br/ medsquare/. xv, xvi, 21, 27, 28, 32, 36, 46, 49, 50, 54

[KGS78] Kazimierz Krynicki, Christopher D. Green e David W. Sawyer. Pressure and temperature dependence of self-diffusion in water. Discussion of the Chemical Society, 1978. 30, 35

[KLD96] Philip W. Kuchel, Alison J. Lennon e Christopher Durrant. Analytical solutions and simulations for spin-echo measurements of diffusion of spins in a sphere with surface and bulk relaxation. Journal of Magnetic Resonance, Series B, 112:1-17, 1996. 3, 4, 5

[Laz04] Robert A. Lazzarini. Myelin Biology and Disorders. Elsevier, 2004. 3

[LBS03] Paul-Jean Letourneau, Robert Boyko e Brian D. Sykes. Pjnmr: a platform-independent graphical simulation tool for nmr spectroscopy. Journal of Magnetic Resonance, 161:154167, 2003. xiii, 3,5

[Lev08] Malcolm H. Levitt. Spin Dynamics. Wiley, 2008. 10, 11, 12, 39

$\left[\right.$ LFS $^{+}$10] Bennet A. Landman, Jonathan A. D. Farrell, Seth A. Smith, Daniel S. Reich, Peter A. Calabresi e Peter C. M. van Zijl. Complex geometric models of diffusion and relaxation in healthy and damaged white matter. NMR In Biomedicine, 23:152-162, 2010. iii, v, $3,4,6$

[Mat13] MathWorks. Matlab. 2013. Obtido em http://www.mathworks.com/products/matlab/. 5,6

[MT72] Kenneth McAloon e Anthony Trombe. Calculus, volume 1BCD. Harcourt Brace Jovanovich, Inc., 1972. xv, 43, 44

[Per13] Fabricio Pereira. Comunicado pessoal. 2013. xiii, 2 
[PJR $\left.{ }^{+}\right]$X. Papademetris, M. Jackowski, N. Rajeevan, H. Okuda, R. T. Constable e L. H. Staib. Bioimage suite: An integrated medical image analysis suite, section of bioimaging sciences, dept. of diagnostic radiology, yale school of medicine. Obtido em: http://www.bioimagesuite.org/. Consultado em 2012-03-06. xvi, 21, 27, 28, 35, 46, 48, 49,54

[PL06] Jerry L. Prince e Jonathan M. Links. Medical Imaging Signals and Systems. Pearson, 2006. $1,9,12$

[RDR] RDR. Classicalnutation. Obtido em http://www.fis.unipr.it/ derenzi/dispense/pmwiki. php?n=NMR.ClassicalNutation. Consultado em 2013-06-30. xv, 40

[Rob91] John D. Roberts. The bloch equations. how to have fun calculating what happens in nmr experiments with a personal computer. Concepts in Magnetic Resonance, 3:27-47, 1991. 5,47

[SJ95] Olle Soderman e Bengt Jonsson. Restricted diffusion in cylindrical geometry. Journal of Magnetic Resonance B, 117 (1):94-97, 1995. 3

[Sli10] Charles P. Slichter. Principles of Magnetic Resonance. Springer, terceira edição, 2010. $4,8,9,11$

[ST65] E. O. Stejskal e J. E. Tanner. Spin diffusion measurements: Spin echoes in the presence of a time dependent field. Journal of Chemical Physics, 42:288, 1965. iii, v, 4, 7, 13, 14, 24

[TdO01] Tania Tome e Mario Jose de Oliveira. Dinamica estocastica e irreversibilidade. 2001. 4, 5,6

[TK12] Taro Takahara e Thomas C. Kwee. Low b-value diffusion-weighted imaging: Emerging applications in the body. Journal of Magnetic Resonance Imaging, 35:1266-1273, 2012. 15

[Tor] H. C. Torrey. Bloch equations with diffusion terms. Physical Review, 104:563-565. 13, 39

[TS68] J. E. Tanner e E. O. Stejskal. Restricted self-diffusion of protons in colloidal systems by the pulsed-gradient, spin-echo method. Journal of Chemical Physics, 49:1768-1777, 1968. doi: 10.1063/1.1670306. 13

[W3C] W3C. Extensible markup language (xml) 1.0 (fifth edition). Available in http://www. w3.org/TR/REC-xml/. Consulted in 2013-06-03. 18

[Wika] Wikimedia. Larmor precession. Available in https://en.wikipedia.org/wiki/Larmor precession. Consulted in 2012-12-18. 9

[Wikb] Wikimedia. Mr knee. Available in https://en.wikipedia.org/wiki/File:MR_Knee.jpg. Consulted in 2012-05-02. xiii, 1 